\title{
DYNAMIC ANALYSIS OF \\ VERTICAL STORMWATER STORAGE SYSTEMS
}

\author{
by \\ Kay Taegyeong Kang \\ B.Eng., Ryerson University, Toronto, 2012
}

\author{
A thesis \\ presented to Ryerson University \\ in partial fulfillment of the \\ requirements for the degree of \\ Master of Applied Science \\ in the Program of \\ Civil Engineering
}

Toronto, Ontario, Canada, 2015

(C) Kay Taegyeong Kang 2015 


\section{AUTHOR'S DECLARATION FOR ELECTRONIC SUBMISSION OF A THESIS}

I hereby declare that I am the sole author of this thesis. This is a true copy of the thesis, including any required final revisions, as accepted by my examiners.

I authorize Ryerson University to lend this thesis to other institutions or individuals for the purpose of scholarly research.

I further authorize Ryerson University to reproduce this thesis by photocopying or by other means, in total or in part, at the request of other institutions or individuals for the purpose of scholarly research.

I understand that my thesis may be made electronically available to the public. 


\title{
Dynamic Analysis of Vertical Stormwater Storage Systems
}

\author{
Master of Applied Science 2015 \\ Kay Taegyeong Kang \\ Civil Engineering \\ Ryerson University
}

\begin{abstract}
A below-grade vertical stormwater storage system is one of the solutions to reduce the volume of sewer overflows released into the environment. The system is submerged most of the time during filling, which can result in hydraulic problems. This research intent to provide some insight on potential hydraulic problems that can occur in a vertical storage system during intense rain events. An experimental study was conducted using a physical scale model that consists of two vertical storage shafts, a horizontal tunnel and an inflow drop shaft. The results showed that both entrapped air in the system and mass flow oscillation in the system can cause a rapid rise of water level, or a geyser, at the drop shaft. The predictions of a modified version of HAMMER compared well with the experimental result while the InfoWorks CS model was unable to simulate vertical momentum in the drop shaft.
\end{abstract}




\section{Acknowledgements}

I would like to express my sincere gratitude to my supervisor, Dr. James Li, for making this research possible and for his continuous support both academically and financially in the development of this research.

I would like to thank Dr. Alan Fok for providing his time, support and expertise throughout the course of this research. This thesis would never have been completed without his guidance and encouragement.

I am thankful to Shelley Kuan for her support in the development of the physical model. I would like to extend my thanks to Dr. Sheldon Zemell and Celia Fan for their time in simulating the numerical models. My sincere thanks goes to Mr. Jean-Luc Daviau for proofreading the thesis and for providing many helpful comments. I would also like to thank Dr. Darko Joksimovic and Dr. Arnold Yuan for serving as examining committee members.

I am beyond grateful to Robin Luong, a civil engineering technician in Ryerson University, who helped me in constructing the model and provided his supports throughout this research. I would also like to acknowledge two research assistants who did all the hard works in the lab: Olumuyiwa Bello and Anton Suprun. Thank you all for helping this weak and muscle-less graduate student.

Lastly, and most importantly, I wish to thank my parents who have always supported me and loved me. This thesis is dedicated to them. 


\section{Table of Contents}

Declaration ................................................................ ii

Abstract ............................................................... ii

Acknowledgements .................................................. iv

Table of Contents ........................................................

List of Tables................................................................ viii

List of Figures............................................................ ix

List of Appendices .................................................... xi

Chapter 1. Introduction .............................................. 1

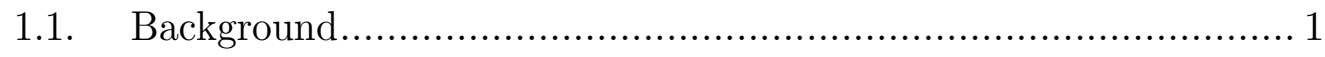

1.2. Hydraulic Issues in Underground Tunnels ......................... 5

1.2.1. Air Entrainment at Drop Shaft............................... 5

1.2.2. Air Entrainment and Oscillations in Tunnels ................ 6

1.3. Research Motivation ............................................. 10

1.4. Research Objectives................................................ 12

Chapter 2. $\quad$ Literature Review ..................................... 14

2.1. Scale Model Approach to Model Stormwater Systems............. 14

2.1.1. Previous Studies on Air Entrapment ....................... 14

2.1.2. Previous Studies on Flow Oscillation ........................ 21

2.2. Numerical Approach to Model Stormwater Systems............... 24

2.2.1. Type of Numerical Models ................................... 24

2.2.2. Numerical Simulation Methods ............................... 28 
2.3. Summary of Literature Review .................................... 32

Chapter 3. Physical Scale Model................................... 34

3.1. Vertical Storage System ......................................... 35

3.1.1. Shafts and Tunnel Design .................................. 35

3.1.2. Design Inflows and Conditions ............................. 38

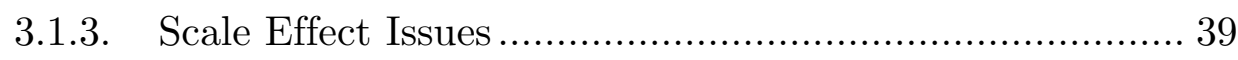

3.2. Scale Model Construction ......................................... 41

3.2.1. Model Layout................................................ 41

3.2.2. Support System for Model .................................. 45

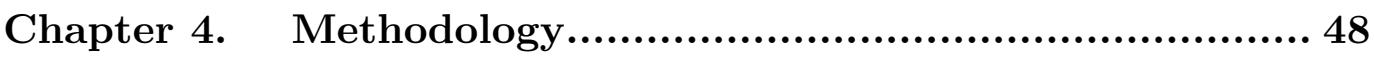

4.1. General Description of the Experiments ......................... 48

4.2. $\quad$ Procedure for Entrapped Air Study ............................... 50

4.3. Procedure for Oscillation Study ..................................... 52

4.3.1. Change of Inflow Conditions ................................. 53

4.3.2. Tunnel Gate Valve Operation................................ 55

4.4. Experimental Data Analysis ...................................... 57

4.5. Comparison with Numerical Models ............................... 58

Chapter 5. Experiment Results and Discussion ................. 59

5.1. Effects of Entrapped Air ......................................... 59

5.1.1. Air in Drop Shaft in Model................................... 60

5.1.2. Air in Drop Shaft and Tunnel in Model.................... 67

5.1.3. Air Ventilation Shaft in Prototype ........................... 70

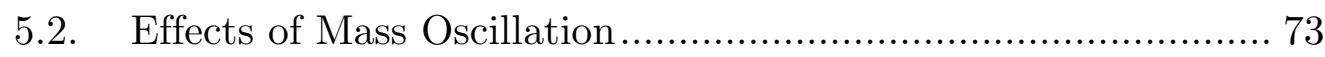


5.2.1. Rapid Start and Stoppage of Inflow........................ 74

5.2.2. Tunnel Gate Valve Operation................................. 82

Chapter 6. Numerical Simulations ............................. 83

6.1. Air in Drop Shaft............................................... 83

6.2. Effects of Mass Oscillation............................................ 84

6.2.1. InfoWorks CS Simulation ................................... 85

6.2.2. HAMMER Simulation....................................... 87

Chapter 7. Conclusion and Recommendation .................... 90

7.1. Conclusions ........................................................... 90

7.2. Recommendations ................................................ 91

Appendices............................................................... 95

Appendix A Additional Experimental Results ............................ 96

Appendix B Additional Figures ............................................... 104

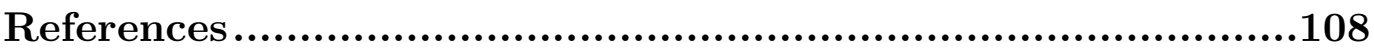




\section{List of Tables}

Table 3-1. Design Setup for Prototype and Physical Scale Model............ 37

Table 3-2. Design flows for Physical Scale Model and Prototype............ 39

Table 4-1. Experimental Variables for Entrapped Air Study ................. 51

Table 4-2. Experimental Variables for Flow Oscillation Study with Inflow

Conditions .................................................................... 55

Table 4-3. Experimental Variables for Flow Oscillation Study with Control

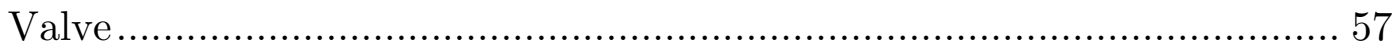

Table 5-1. Geyser Height With and Without Air Release Valves ............ 69 


\section{List of Figures}

Figure 1-1. Conventional Storm Sewer System ................................. 1

Figure 1-2. Horizontal Storage System ........................................ 3

Figure 1-3. Vertical Storage System .......................................... 4

Figure 1-4. Case Study Related to Deep Tunnel (Fok 2015) ................... 9

Figure 1-5. Potential Hydraulic Impact in Vertical Storage System (HydraTek Associates 1999) ...................................................... 11

Figure 3-1. Scale Model Design of Simplified Vertical Storage System ..... 35

Figure 3-2. Prototype Design of Simplified Vertical Storage System........ 38

Figure 3-3. Drop Shaft Inlet Hydraulic (Modified from Fok 2015) ........... 40

Figure 3-4. Physical Scale Model Design ...................................... 42

Figure 3-5. Physical Scale Model at Ryerson University ...................... 42

Figure 4-1. Sketch of Model Used in Entrapped Air Study .................... 50

Figure 4-2. Sketch of Model for Flow Oscillation Study with Change in Inflow Conditions .................................................................. 55

Figure 4-3. Sketch of Model for Flow Oscillation Study with Control Valve Operations ................................................................... 56

Figure 5-1. Experiment from Entrapped Air Study ......................... 60

Figure 5-2. Experimental Result with Entrapped in Drop Shaft (Opened

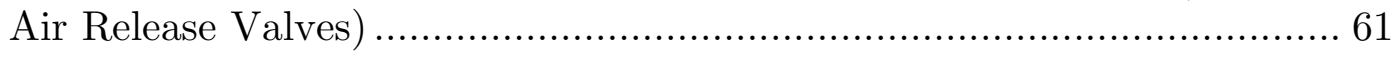

Figure 5-3. Air Entrainment in the Drop Shaft Due to a Free-falling Inflow 62

Figure 5-4. Schematic of Air Flow (Qair) in Drop Shaft during Filling..... 63

Figure 5-5. Geyser at the Drop Shaft .......................................... 64

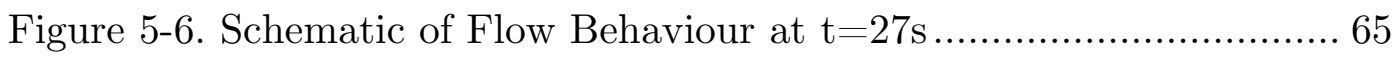


Figure 5-7. Experimental Result with Entrapped Air in Drop Shaft and Tunnel (Closed Air Release Valves) ............................................... 68

Figure 5-8. Air Pocket in Drop Shaft and Tunnel without Air Release Valves ................................................................................... 68

Figure 5-9. Schematic of Air Flow in a Shaft and an Air Ventilation Shaft (Modified from Fok 2015)

Figure 5-10. Experimental Result with Air Pockets Travelling Towards Drop Shaft 72

Figure 5-11. Experiment with Rapid Start and Stoppage of Drop Shaft Inflow 74

Figure 5-12. Water Level Over Time for Flow Oscillation Study 75

Figure 5-13. Schematic of Flows in Stage (a) .................................. 76

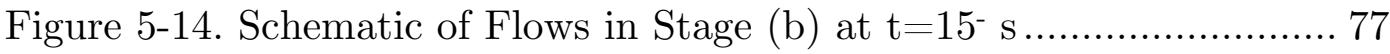

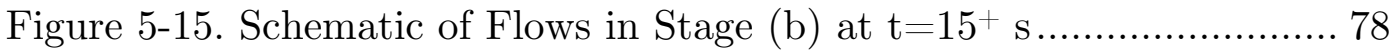

Figure 5-16. Schematic of Flows in Stage (c) .................................. 79

Figure 5-17. Schematic of Flows in Stage (d) at t=37 s..................... 79

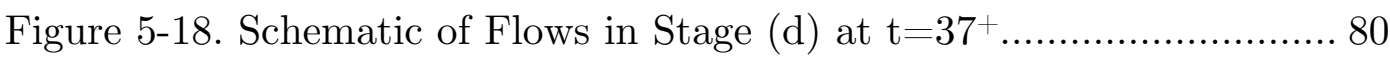

Figure 5-19. Schematic of Flow in Stage (e)................................ 81

Figure 6-1. Comparison of Experimental and InfoWorks CS Simulation Results .............................................................................. 86

Figure 6-2. Experimental Result with No Inflow Dynamic At Drop Shaft 86 Figure 6-3. Schematic of Modified Numerical Model Using HAMMER.... 88 Figure 6-4. Comparison of Experimental and Modified HAMMER Simulation Results 89 


\section{List of Appendices}

Appendix A- 1. Experimental Results for Entrapped Air Study .............. 97

Appendix A- 2. Experimental Results for Flow Oscillation Study ...........100

Appendix B- 1. An Example of Localized Rain Events in Toronto..........105

Appendix B- 2. Schematic of Storage Tunnel Filling (Fok 2015) ...........106

Appendix B- 3. Examples of Extended Physical Scale Model .................107 


\section{Chapter 1 .}

\section{Introduction}

\subsection{Background}

An underground tunnel system is one of the preferred stormwater management measures in highly urbanized areas because stormwater detention ponds or constructed wetlands may not be feasible due to limited space, level of runoff pollution, and volume of runoff. Surface runoff is collected by ditches, storm drains, and catch basins, then transported by storm sewer systems to water bodies or stormwater management facilities, such as treatment plants as shown in Figure 1-1.

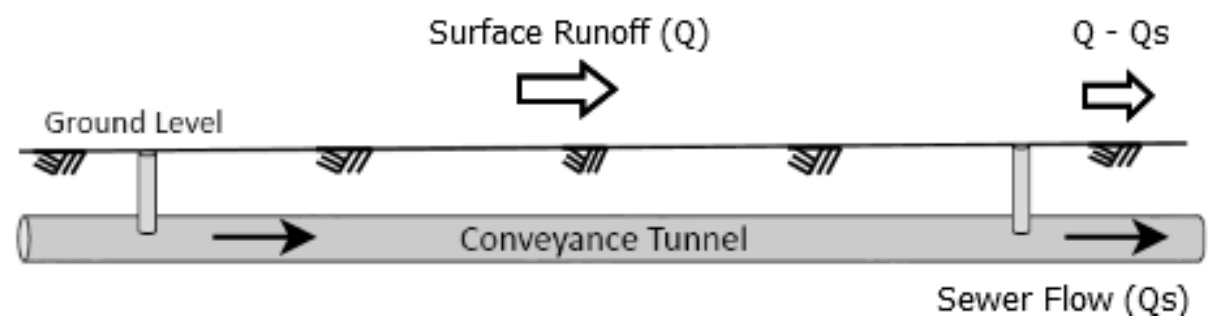

Figure 1-1. Conventional Storm Sewer System 
Many existing sewer systems are designed to operate without surcharge, but the capacity of the sewer and treatment systems are frequently exceeded during heavy storms due to increasing storm intensity and runoff volume resulting from continuous urbanization, causing overflows to be released directly to the environment without appropriate treatment.

For example, a severe storm that hit the city of Toronto in July 2013 resulted in an estimated amount of a billion litres of untreated sewage and storm runoff being dumped into Lake Ontario. This led to the closure of most of the city's beaches because a high level of E.coli was detected in the area (Vitullo 2013). Large volumes of untreated urban runoff can substantially degrade water quality in the receiving water bodies, posing serious risks to public health and the environment. Therefore, many cities around the world are calling for stricter environmental regulations and standards.

An underground stormwater storage system can reduce the number and volume of release of untreated urban runoff to the environment. Stormwater storage systems are typically constructed deep underground, often for the existing major sewer and minor systems. Sewer systems are generally designed to operate in an open channel hydraulic condition within the design 
flow capacity, beyond which overflow will occur from this upper sewer system into the stormwater storage system deep underground. The overflow volume is temporarily stored until the capacity of conveyance tunnels or treatment facilities become available.

The storage systems can be divided into two types: 1) horizontal and 2) vertical. Figure 1-2 illustrates the concept of a horizontal storage system where the overflows from upper sewer systems are transported by drop shafts to an oversized horizontal tunnel for storage until it is pumped out after the storm event.

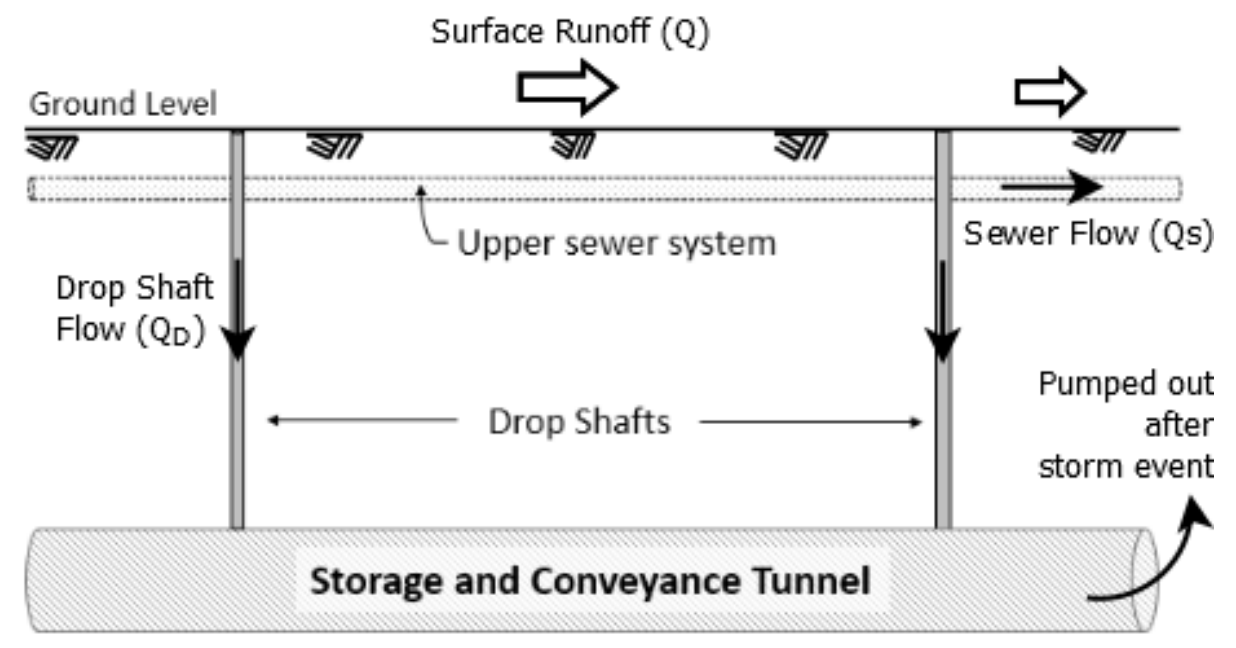

Figure 1-2. Horizontal Storage System

The tunnels operate with low flow velocity since the diameter of the horizontal storage tunnel is significantly larger than that of conventional 
conveyance tunnels. A horizontal storage tunnel operates without significant surcharge provided the storm runoff volume is within the designed storage capacity. Most of the runoff volume in the horizontal storage system is in the tunnel at the lowest system elevation.

Vertical stormwater storage systems use the horizontal tunnel as conveyance tunnel and use a number of large vertical storage shafts to store the overflows as shown in Figure 1-3. Since the diameter of horizontal conveyance tunnel is similar to that of conventional storm sewers, the velocity of the tunnel flow is relatively high. Most of the runoff volume in the vertical storage system is in the storage shafts at the highest system elevation. Therefore, it typically operates under significant surcharge.

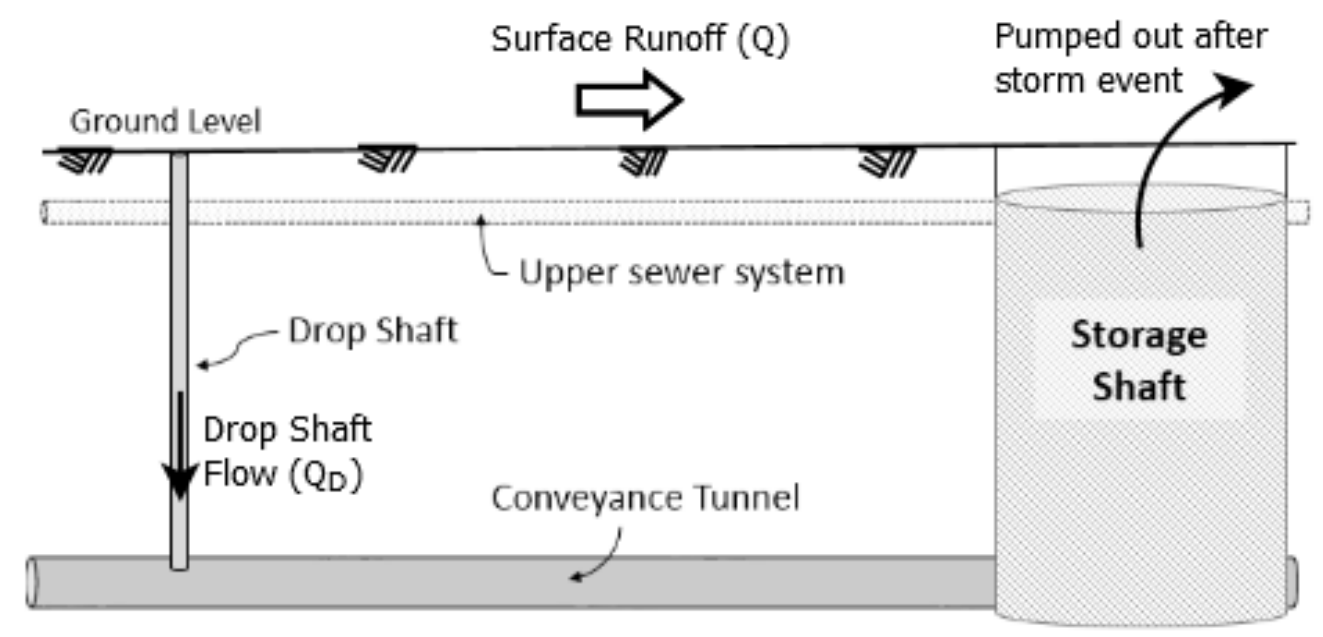

Figure 1-3. Vertical Storage System 


\subsection{Hydraulic Issues in Underground Tunnels}

\subsection{1. $\quad$ Air Entrainment at Drop Shaft}

The hydraulic conditions in drop shaft are governed by its inlet design and affected by its outlet conditions. The primary role of a drop shaft is to direct flows from a higher elevation, such as the upper sewer system, to deep tunnels by gravity. Plunge-inlet and vortex-inlet drop shafts are two common types of drop structures used in stormwater collection systems. Plunge-inlet structures simply redirect water from the upper sewer system to fall down the shaft. Vortex-inlet structures guide water into a specially designed path that allows water to spiral down and cling to the wall of the drop shaft until it separates from the wall and falls vertically if the drop height is such that tangential velocity is decayed by friction.

Vortex-inlet structures are considered to be more stable under various inflow conditions and more efficient in dissipating energy from the falling flow (Jain 1984). Although a physical model study conducted by Williamson (2001) showed better hydraulic performance for a vortex inlet compared to a plunge inlet drop shaft, Zhao et al. (2006) conducted an experimental study using a drop shaft of $3.15 \mathrm{~m}$ high and $0.223 \mathrm{~m}$ in diameter, and found that the air entrainment is primarily controlled by the velocity of a falling jet, 
CHAPTER 1. INTRODUCTION

not by the type of the inlet in a drop shaft. The author stated that a larger diameter and drop height will be an important factor and that it should be further studied due to scaling effects with air entrainment mechanisms. It is suggested that air entrainment in both vortex and plunge inlets should be considered in the design.

Zhao et al. (2006) showed that a large drop of high speed water jet into a water pool can result in significant air entrainment for both plunge and vortex-inlet shaft structures. Since drop shafts in vertical storage systems generally have a large length to diameter $(\mathrm{L} / \mathrm{D})$ ratio compared to conventional surface sewer systems, flow dynamics in the vertical drop shafts should be considered during the design process to mitigate potential hydraulic issues due to air entrainment in the shaft.

\subsubsection{Air Entrainment and Oscillations in Tunnels}

For a horizontal storage system, the hydraulic behaviour of the drop shaft and tunnel can be considered separately. Conventional conveyance tunnels are generally designed with a slope of $0.1 \%$ to $0.25 \%$ to operate on free surface or gravity flow, and to accommodate the maximum design capacity. The hydraulic issues due to air entrainment may be resolved by drop shaft inlet design, de-aeration chamber at the tunnel entrance, and an air ventilation 
or recirculation structures.

The vertical storage system design should consider further hydraulic analysis due to complex nature of fluid flows under surcharge condition. Tunnel in vertical storage systems mostly operate with full pipe flow, and vertical storage shafts and drop shaft outlets are frequently submerged during filling. Thus, horizontal tunnel and vertical shafts should be considered as one water body in terms of hydraulics.

Air entrapment can occur in the tunnel during filling when an empty tunnel is being filled or when air entrained in vertical drop shaft enters the tunnel. Entrapment occurs when air buoyancy forces are balanced or exceeded by drag force by the liquid and the air bubbles in liquid flow moves downwards along the tunnel as it fills. Air reduces the maximum flow capacity of the surcharged conveyance tunnel, and it can abruptly change the flow condition from gravity flow to pressurized flow. Studies describe that the possible outcome of this flow regime transition is a phenomenon called "geyser", which is an air-water mixture that spews out of an open manhole from a vertical drop shaft connected to the stormwater collection system. (Vasconcelos and Wright 2005; Wright et al. 2008; Zhou, Hicks and Steffler 2002). 
CHAPTER 1. INTRODUCTION

Moreover, hydraulic issues can occur with mass oscillation of flow in the system under surcharge condition due to operational problems such as pump start-up, pump stoppage, blockage of tunnel, rapid gate closures, and localized storm events (Guo and Song 1991; Hamam and McCorquodale 1982; Yen 1986).

A significant number of localized rainfall events have occurred in urbanized areas, suggesting that inflows may not be uniformly distributed into different drop shafts in an area. The figures in Appendix B is an example of localized rainfall events that occurred in July $8^{\text {th }}, 2013$ in Toronto. Non-uniform rainfall distributions may result in pressurization and/or flow oscillation in the system, and it may result in a geyser if the flow oscillation is large enough. These behaviours in the system can cause further complications, such as floating or blowing off of the manhole cover, flooding, and damaging of the tunnel structures.

Figure 1-4 illustrates a scenario that occurred in the city of Edmonton in July 4, 1995 when a localized storm event caused a pressurized surge and flow reversal to entrap air, resulting in structural damage to the manhole at the upstream end of a trunk sewer and deep tunnel system. A heavy rainfall in a localized area caused the tunnel to surcharge, and the pressure head of 
the flow in the tunnel exceeded the ground level at the upstream end of the system. During the peak inflow, the flow travelled in the reverse direction, slamming as a surge front against internal sewer structure. The subsequent release of entrapped air at the upstream end of the tunnel exerted a pressure substantial enough to blow off the manhole (Fok, 2015). Scale model experiments by Zhou, Hicks and Steffler (2002) confirmed that rapid filling, flow reversal, and air expulsion mechanisms and its magnitude are capable of causing infrastructure damages.

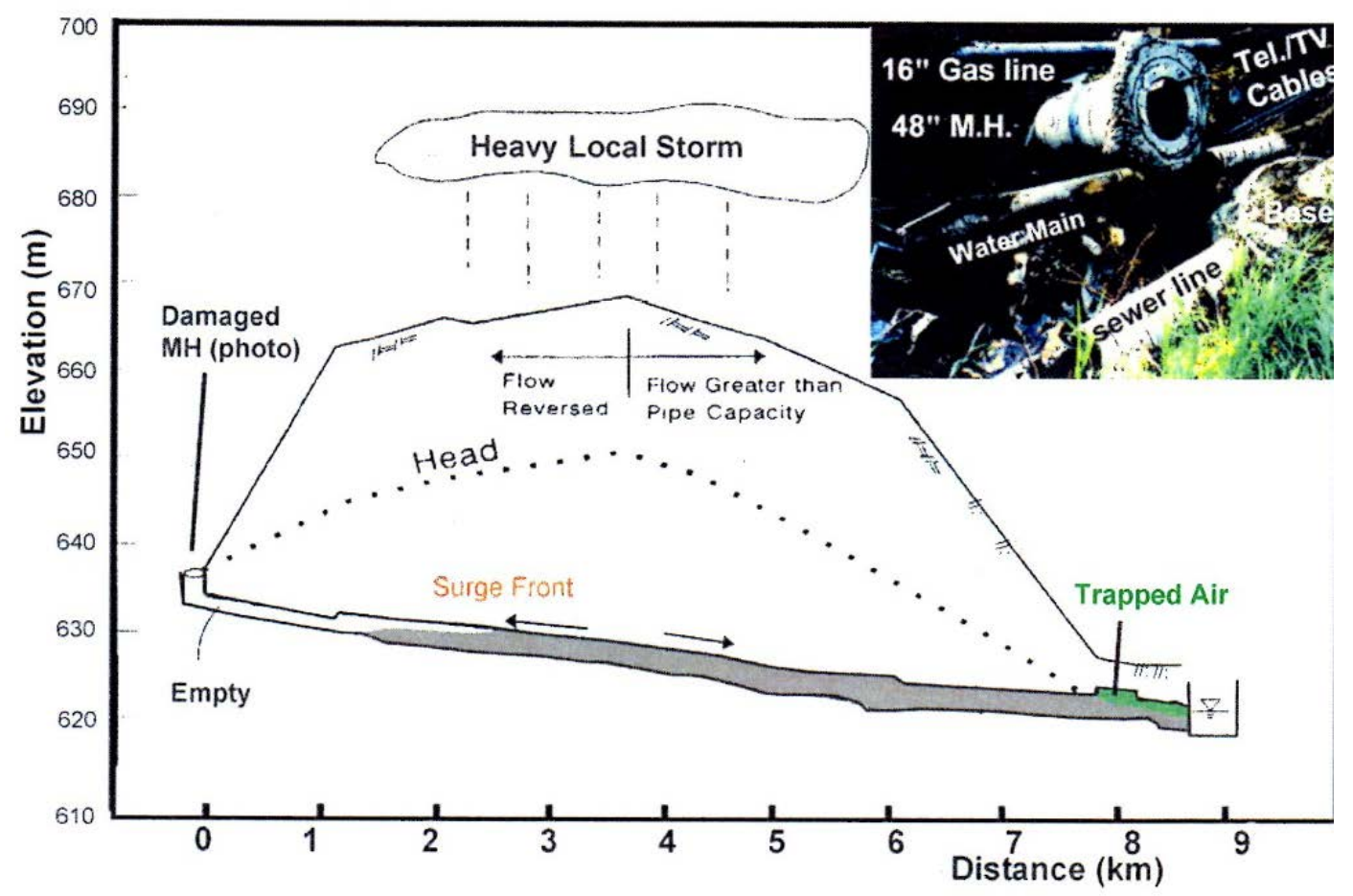

Figure 1-4. Case Study Related to Deep Tunnel (Fok 2015) 
Similar problems were also reported in deep tunnel or sewer systems, including the Chicago Tunnel and Reservoir Plan (TARP) system (Song, et al. 1988), and sewer systems in other Canadian cities including Hamilton and Amherstburg (Hamam and McCorquodale 1982, Vasconcelos and Wright 2007).

\subsection{Research Motivation}

The Western Beaches Storage Tunnel is a local example of a vertical storage system. The city of Toronto built the system in an effort to reduce a portion of 2.9 million $\mathrm{m}^{3}$ of untreated water being dumped into the western beaches of Lake Ontario each year (American Society of Civil Engineers (ASCE) 2000). Three large vertical storage shafts with a diameter of $25.7 \mathrm{~m}$ account for about $75 \%$ of the tunnel's $85,000 \mathrm{~m}^{3}$ capacity. Six smaller drop shafts with diameters of $0.71 \mathrm{~m}$ to $1.51 \mathrm{~m}$ link the surface sewer system to the tunnels constructed about 40 to $50 \mathrm{~m}$ below ground level. In total, nine vertical shafts are connected by a horizontal conveyance tunnel with a length of $4 \mathrm{~km}$ and a diameter of $3 \mathrm{~m}$.

According to a hydraulic transient analysis done by HydraTek Associates (1999), one scenario showed that the maximum tunnel hydraulic

grade line (HGL) during filling could exceed the ground surface elevation 
line (GSEL) and lake water surface elevation line (Lake WSEL) by up to approximately $23 \mathrm{~m}$ as shown in Figure 1-5.

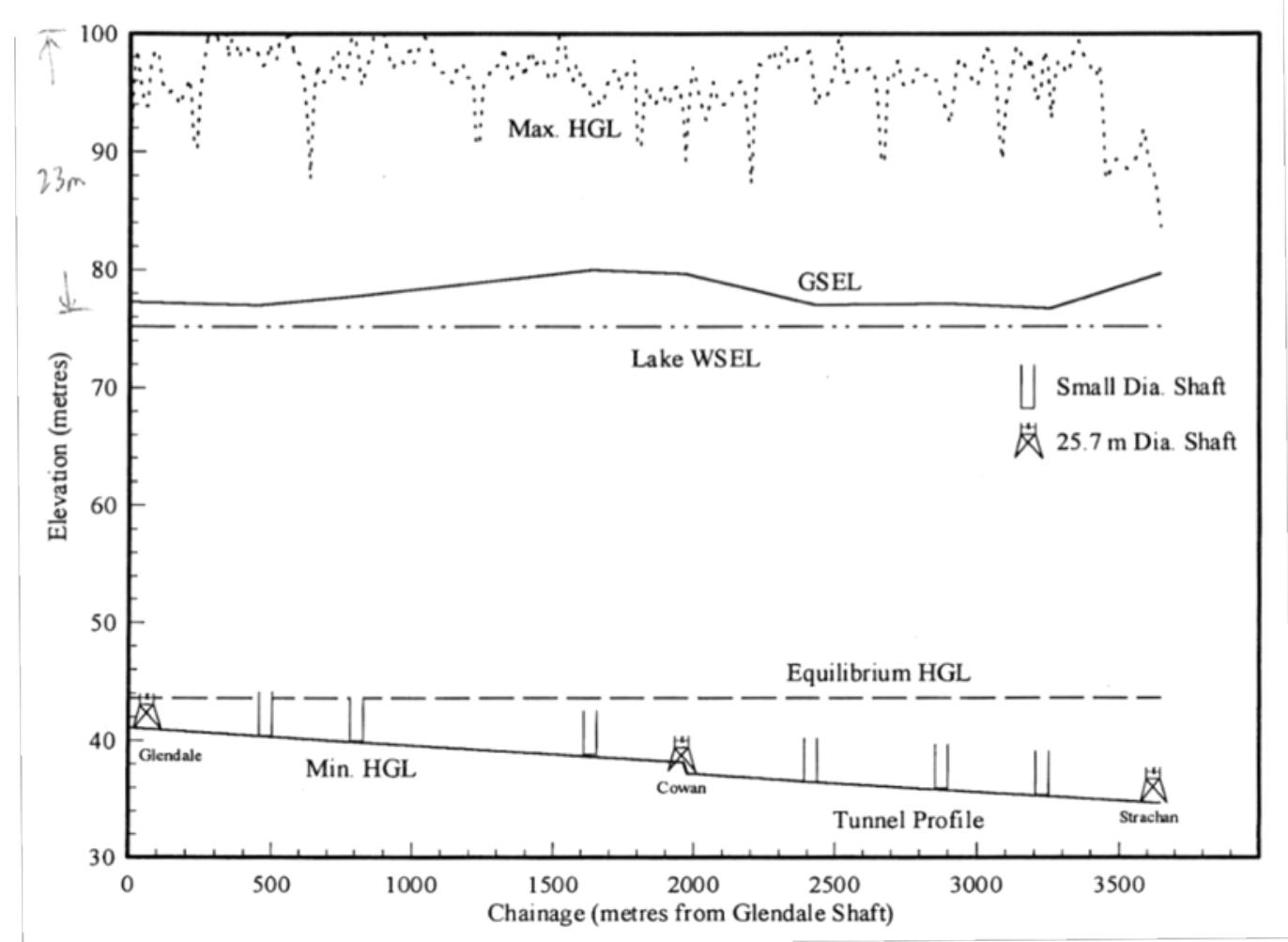

Figure 1-5. Potential Hydraulic Impact in Vertical Storage System (HydraTek Associates 1999)

As the tunnel was initially filled during a 5-year storm event, a $630 \mathrm{~m}^{3}$ air cavity was simulated in each tunnel section between the vertical storage shafts. The hydraulic responses to this entrapped air was more severe near small drop shafts than near the large vertical storage shafts. This result 
suggests that air entrapped in a tunnel under surcharge condition during filling from large storm events may potentially cause hydraulic issues in the system, especially in the vicinity of the small drop shafts.

Given the complexity of the potential dynamic flow conditions and the hydraulic problems observed in existing stormwater sewer systems, it may be useful to carry out further studies to investigate potential hydraulic problems at inflow drop shaft in a vertical storage system during filling from large storm events. This work can inform future construction of complex systems with more inflow drop shafts, vertical storage shafts and longer conveyance tunnels than the Western Beaches Tunnel.

\subsection{Research Objectives}

Numerous experimental and numerical studies have contributed to the understanding flow dynamics and hydraulic issues, such as the effects of entrapped air pockets and the mass oscillation of flow, in partially filled conventional conveyance tunnel systems. However, only a limited number of studies have been conducted on below-grade vertical stormwater storage systems that are submerged for most of the filling process during heavy storm

events. These previous studies considered the drop shaft as being independent from the tunnel in terms of hydraulics; they did not consider 
the effects of air entrapment and release that often occurs in a drop shaft with a heavily submerged outlet.

In this research, an experimental study was conducted using a simple physical scale model to gain insight into some of the potential hydraulic issues that can occur in an inflow drop shaft of a vertical storage system. Experimental data obtained from this comparative study will be a valuable resource in understanding the behaviour of flows in stormwater systems, contributing in designing and solving hydraulic issues before it occurs. The predictions of the most commonly used hydraulic modelling software: InfoWorks CS and HAMMER were compare with the experimental results to examine their performance in analyzing vertical stormwater storage systems.

The objectives of this research are:

1. To contribute to the understanding of flow dynamics in below-grade vertical stormwater storage systems during intense rain events.

2. To investigate the air behaviour and mass oscillation in an integrated drop shaft and tunnel system of a vertical stormwater storage system under various conditions during filling. 


\section{Chapter 2 .}

\section{Literature Review}

Operational problems in stormwater systems have been actively investigated to identify their cause and to prevent such unfavourable behaviours from occurring. Previous experimental studies of air pocket entrapment and flow oscillation in stormwater systems during filling are presented in Section 2.1. Section 2.2 summarizes numerical approaches and some of the commerciallyavailable hydraulic modelling software commonly used to simulate complex flows in stormwater systems during filling.

2.1. Scale Model Approach to Model Stormwater Systems

2.1.1. Previous Studies on Air Entrapment 
The work by Zhou, Hicks, and Steffler (2002) confirmed that air pocket entrapments can occur during the rapid filling process of an empty stormwater tunnel. Another cause of air entrapment is the oscillation of free surface flow due to interaction between the air and water phase in the storage system (Hamam and McCorquodale 1982).

Inflow drop shafts connected to a conveyance tunnel also have potential for air entrainment. Flow falling down an inflow drop shaft entrains and mixes with air and contributes energy when it plunges into water at the bottom of the shaft, which can result in hydraulic and structural design problems. An experimental study conducted by Williamson (2001) showed that air entrainment in a vortex inlet is less than that of a plunge inlet.

However, Zhao et al. (2006) conducted an experimental study on a drop shaft with smaller diameter (D) and longer length (L), and showed that the type of drop shaft is not a dominant factor in the amount of air entrainment generated at the bottom of the shaft. In this study, a jet-like inflow was introduced into a drop shaft with $\mathrm{L} / \mathrm{D}$ ratio of 14 . A direct relationship between the amount of air entrainment and the L/D ratio was confirmed by experimental data obtained in this study, in agreement with a study by Jain (1988). 
The velocity of jet flow $\left(\mathrm{V}_{\mathrm{j}}\right)$ at the plunge point was also found to be a factor that dominates the amount of air entrainment. Ervine (1998) expressed this relationship as:

$$
Q_{a}=\lambda \mathrm{W}\left[0.00002\left(V_{j}-1\right)^{3}+0.0003\left(V_{j}-1\right)^{2}+0.0074\left(V_{j}-1\right)-0.0058\right]
$$

where $\mathrm{Q}_{\mathrm{a}}=$ air entrainment rate $\left(\mathrm{m}^{3} / \mathrm{s}\right) ; \mathrm{W}=$ jet width $(\mathrm{m}) ; \lambda=$ coefficient for the loss of air returning back to the upstream conduit; and $\mathrm{V}_{\mathrm{j}}=$ velocity of jet flow $(\mathrm{m} / \mathrm{s})$. The equation is applicable when $\mathrm{W}>20-30 \mathrm{~mm}$ and $\mathrm{V}_{\mathrm{j}}<$ $15 \mathrm{~m} / \mathrm{s}$. According to this equation, air entrainment will be initiated if $\mathrm{V}_{\mathrm{j}}$ is $1 \mathrm{~m} / \mathrm{s}$ or higher.

Earlier studies suggested that the pressurization of air entrapped in a tunnel and drop shaft cannot create a geyser that is strong enough to blow off a manhole cover; and that it was mostly caused by the impact force of rising water (Guo and Song 1988, 1991). However, these researchers focused on investigating the interaction of air and water phase in closed conduits, and revealed the effects of air pocket entrapment in the system.

On the contrary to the assumption made in earlier studies that the geyser occurs when the hydraulic grade line is above the ground level, recent field observations and experimental studies showed that geysers can occur 
even when the hydraulic grade line is below grade (Wright, Lewis and Vasconcelos 2011, Vasconcelos and Wright 2011).

Vasconcelos and Wright (2005) showed that the release of air pockets entrapped in the tunnel plays a role in triggering large peak pressure and in creating geyser, and indicated that the geyser is not only a water jet but a mixture of air and water released by the vertical drop shaft. The authors conducted an experimental study with a 1:50 scale physical model for the design of a combined sewer overflow storage tunnel for the city of Dearborn, Michigan. The interactions of the air and water phases during a rapid filling process were observed and the phenomena were classified into 5 categories: i) no interaction, ii) prebore motion, iii) air counter flow, iv) undulatory front, and v) air intrusion in undulatory front. While no instability of free surface flow was observed when there is no interaction between the air and water phase, a significant change in the behaviour of the flow occurred with the interaction of air and water.

The study demonstrated that the problem becomes more complex if an adequate ventilation structure is not available to release the air pockets immediately before further compression. With the presence of an adequate pressure relief mechanism, the magnitude of the surges triggered by air 
pocket compression are reduced and a negative sub-atmospheric pressure did not occur in the system (Vasconcelos and Leite 2012). Furthermore, an experimental study conducted by Li and McCorquodale (1999) revealed that the release of trapped air bubbles resulted in high frequency pressure transient after a rapid gate closure; and that it also resulted in a low frequency pressure transient after a rapid flow stoppage.

In some cases, the presence of an air pocket in the tunnel can have a positive effect on the system that it helps to reduce the magnitude of the peak transient pressure in the system. An experimental study conducted by Zhou, Hicks, and Steffler (2002) found that air can act as "shock absorber" if the size of the orifice at the end of a rapidly filling horizontal pipe is very small and the release of air is not sudden. The maximum pressure observed during filling was 1.5 to 3 times the input head at the upstream supply tank. This phenomenon is categorized as Type 1 behaviour: Negligible Water Hammer Effect. A similar behaviour is later demonstrated and described by Vasconcelos and Wright (2005) as "air-cushioning" effect.

The second type of behaviour is called Type 2: Mitigated Water Hammer Effect. When the ratio of orifice diameter to the pipe diameter is greater than 0.086 , the pressure oscillation occurs for a period of time until 
a substantial volume of air is released, then the water slams into the pipe end and the orifice to fill the void after the air is completely released. Lingireddy, Wood, and Zloczower (2004) described this water hammer effect due to the release of entrapped air pockets as "air slam". This water hammer impact caused both higher and lower extreme pressures than the peak pressures measured during the oscillation period prior to the occurrence of water hammer. The inconsistency of the pressure generated by this water hammer effect is due to the sensitivity of the peak pressure to the compressed air pockets in the water. The maximum pressure observed during this experiment was about three times of the upstream pressure head.

For Type 3: Water Hammer Dominated behaviour, a large water hammer pressure can be observed if the orifice size ratio is greater than the critical range of 0.171 to 0.257 . The size of the orifice is large enough to release a substantial volume of air rapidly and the water slams into the pipe end quickly, without any preceding pressure oscillation period, resulting in a greater water hammer pressure magnitude. The maximum pressure head observed was 14 times of the upstream head.

In another experimental study that was carried out by Vasconcelos and Wright (2011), the release of entrapped air pockets occurred through a water- 
filled vertical ventilation shaft instead of an orifice at the tunnel end. Pressurized air was introduced into the water-filled tunnel near the ventilation shaft and it formed an air pocket inside the tunnel. The author suggests that two-phase transient flow problem was observed when the air pocket reached the ventilation shaft and rose up, moving the water column inside the shafts upward due to buoyancy and then flowing downward around the perimeter of the air pockets. This thin layer or water flowing downward reduced the volume of the water column pushed upward above the air pocket, thus the pressure in the shaft continues to decrease until it reaches the atmospheric pressure in the shaft or at the top of the shaft. Some scenarios resulted in the water column above the air pocket reaching the top of the shaft and spilling, suggesting that a geyser episode is a possible outcome.

The results also showed that that a ventilation shaft with smaller diameter increased the chance of geyser occurrence due to its geometry: the thin layer of flow moving downward around the outside perimeter of the air pocket is relatively reduced. In addition, a higher initial water level at the ventilation shaft did not have adverse effects on the air-phase pressure in the shaft, but it showed that it is more likely to reach the spillage point as the 
distance required for the water column to travel when the air pocket rises is relatively shorter.

\subsubsection{Previous Studies on Flow Oscillation}

Some conditions during tunnel filling can also result in flow pressurization due to oscillating flow, in addition to the effects of air pockets entrapped in the system. Sudden changes in the boundary conditions of the tunnel systems, such as a blockage due to clogging, a pump failure or gate closure, or the introduction of large volume of inflows can trigger oscillations large enough to cause instability and pressurize the flow.

An experimental study conducted by Hamam and McCorquodale (1982) showed that pipe pressurization can occur during rapid filling when the relative water depth in a circular pipe reaches about 0.8 . With a relative depth higher than 0.8 , the air travelling in front of the surge resulted in tunnel blockage and transient pressures because of the difference between water velocity and the velocity of the travelling air; resulting in large oscillations of the water surface. This phenomenon is related to geometry of the circular pipe as the same experiment using a rectangular tunnel with constant cross section area in all depths showed relatively less flow instability. As the system becomes a closed conduit, the flow oscillation will 
eventually lead to air pocket entrapment, which was discussed in the previous section. The instantaneous pressure head was found to exceed the hydraulic grade line by several times the pipe diameter. The authors predicted that a typical circular sewer can experience pressure rises of 6 to $40 \mathrm{~m}$.

Vasconcelos and Wright (2005) also demonstrated this phenomenon where the pipe flow was maintained at a relative water depth of 0.78 during the filling of an empty circular pipe, then rapid air pressurization occurred immediately followed by surface water oscillation. This wave due to air pressurization in the tunnel is described as pipe filling bore (Vasconcelos and Wright 2005, Yen 1986).

While a pipe filling bore can lead to pressurization, the water can move in the same direction ahead of the bore and slow down the velocity of the bore before impact. This phenomenon, referred to as prebore motion, changes the condition of the free surface flow region in front of the bore and adds complication to the pressurized flow condition in the tunnel (Vasconcelos and Wright 2005). Yen (1986) also described that flow oscillation can also occur when the tunnel is not equipped or provided with adequate ventilation. When negative pressure is created in the system, the 
flow oscillation can lead to pipe pressurization.

In contrast with many studies focusing on flow instability due to oscillation of flow in open channel during filling of the pipe, few researchers examined the hydrodynamics of a system with full pipe flow. Guo and Song (1991) derived general equations to study the hydrodynamics of a drop shaft in response to rapid inflow at the shaft and the introduction of a surge in the main tunnel, respectively.

Numerical analysis using the derived equations revealed that the introduction of rapid inflow at the drop shaft results in sinusoidal flow oscillation that grows in magnitude with time and eventually reaches the ground level in a manner that is similar to a geyser. A surge in main tunnel was also found to have similar effect on the water level at the drop shaft, although the initial response to the introduction of main tunnel surge was stable. One of the equations derived by Guo and Song (1991) predicted the maximum amplitude of oscillation at the drop shaft, $\mathrm{H}_{\max }(\mathrm{ft}$ or $\mathrm{m}$ ),

$$
H_{\max }=\frac{U_{m} T}{\pi}
$$

where $\mathrm{U}_{\mathrm{m}}=$ the rise speed of the main tunnel head $(\mathrm{ft} / \mathrm{s}$ or $\mathrm{m} / \mathrm{s})$; and $\mathrm{T}=$ period of oscillation (s), suggests that the water level during the flow 
oscillation at the drop shaft has the potential to reach the ground level if the main tunnel surge is large enough.

Several studies (Guo and Song, Dropshaft Hydrodynamics Under Transient Conditions 1991, Li and McCorquodale 1999, Wright, et al. 2008, Wright, Lewis and Vasconcelos 2011) described the effect of water hammer due to a sudden change of the boundary condition in closed conduit systems, such as pump failure or rapid gate closure. A significant pressure surge created due to water hammer oscillates along the tunnel and releases its pressure at a manhole or ventilation shaft, causing a geyser. A rapid gate closure caused a high initial pressure transient whereas the rapid stoppage of flow caused a low initial pressure transient (Li and McCorquodale 1999). Overall, the magnitude of pressure transient is found to be greater as the tunnel flow increases.

\subsection{Numerical Approach to Model Stormwater Systems}

\subsubsection{Type of Numerical Models}

Numerical models for mixed flows in stormwater systems can be classified into two different groups: single phase flow models and two phase flow 
models. A single phase flow models such as Preissmann slot model by Cunge and Wenger (1964) and two-component pressure approach (TPA) models by Vasconcelos and Wright (2007) are shock-capturing models that are generally a simple approach to model free-surface and pressurized flows using a simplified form of the St. Venant equation. The simplified partial differential equation employs continuity and momentum equations with many assumptions and simplifications regarding pressure distribution, velocity distribution, pipe slope, friction, viscosity effect, tension surface, and force due to internal stress, such that the equation cannot be used if these parameters becomes relevant (Bousso, Daynou and Fuamba 2013, Yen 1978). Due to these limitations, entrapped air, negative pressure, lack of ventilation, and sub-atmospheric full pipe flows cannot be simulated properly (Vasconcelos and Wright 2007).

Vasconcelos and Wright (2007) modified the St. Venant equation used in the Preissmann slot model and proposed an improved approach called the TPA model. In this approach, pressure is expressed in two components: hydrostatic pressure due to the presence of water in the cross section of the pipe, and overpressure due to pressurized flow where it is positive in full section and negative in depressurized flow. By separating the two pressure 
forces, the flows with extremely low pressure can be simulated. The limitation of the TPA model is that at high values of pressure wave speed for oscillating flows, such as high frequency water hammer, may result in instabilities (Bousso, Daynou and Fuamba 2013, Vasconcelos and Wright 2007).

More dynamic and complex flow regimes can be simulated using a two phase model, also called a two-equation model. While the two phase model requires complex and lengthy numerical calculations, it can overcome some of the limitations of single phase models, such as instabilities due to the air pressurization effect, high acoustic wave speed during oscillating flows, and full pipe flow with sub-atmospheric pressure. The two phase model includes an interface tracking model, a rigid column-based model, and a finite-volume strategy.

The interface tracking model treats free surface flow and pressurized flow separately, and it uses different methods to model each flow component. Politano, Odgaard, and Klecan (2007) proposed using the interface tracking models to simulate pressurization due to a pipe-filling bore and a gradual flow regime transition. While the equation to solve free surface flow is the same as the equation used in the Preissmann slot model, pressurized flow is 
solved using mass and momentum equations derived from the St. Venant equations (Bousso, Daynou and Fuamba 2013). The first type of interface tracking model proposed by Wiggert (1972), also known as shock-fitting model, solved the pressurized flow zone using a rigid column approach and the free surface flow zone using the Method of Characteristics (MOC).

The MOC solves partial differential equations with integrations, and it is one of the methods commonly used in fully dynamic models to analyze transient flows in pipes due to its efficiency (Vasconcelos and Wright 2007). Other types of interface tracking models are fully dynamic models that implement two different MOC to solve free surface flow and pressurized flow; and models that use the rigid column approach to solve both flow regimes. Sub-atmospheric full pipe flow can be simulated with a fully dynamic model but it cannot handle the calculation if the pipe is initially empty. There is also a limitation that the model cannot be used to simulate slow filling pipe with low head and low inflows. The model using a rigid column approach is not feasible when flow pressurization does not occur with the pipe-filling bore, but somewhere else in the pipe, because it assumes the pressurization of flow will always occur with the pipe-filling bore (Vasconcelos and Wright 2007). In addition, the limitations due to assumptions and simplifications 
used in St. Venant equations still exist (Bousso, Daynou and Fuamba 2013).

The rigid column models proposed by Hamam and McCorquodale (1982) assume a hypothetical stationary air pocket being compressed and expanded between two rigid columns. The pressure of the entrapped air pocket is determined using Helmboltz theory. Li and McCorquodale (1999) further developed the rigid column model to better simulate a pressure transient with an entrapped air pocket moving towards the upstream end of the pipe. The main limitations of the rigid column model is that it only applies to single air pocket, and it has difficulty with modelling a large air pocket.

A new finite-volume strategy can solve mass and momentum equations without mathematical artifices and model transient flows with discontinuous and complex characteristics. The Illinois transient model (ITM) is one of the examples of the finite-volume strategy. This strategy overcomes many of the limitations and instabilities shown in the previous numerical models but it can be difficult to execute the mathematical calculations due to its complexity (Bousso, Daynou and Fuamba 2013).

\subsubsection{Numerical Simulation Methods}


Various hydraulic modelling software utilizes various types of numerical approaches to model flows in stormwater systems. Some of the commercial hydraulic modelling software such as Mouse, HydroWorks, and Stormwater Management Model (SWMM) use a single-phase approach that neglects the presence of air pockets in the system. Bousso, Daynou, and Fuamba (2013) noted that a link-node model lacks spatial discretization which limits its ability to simulate the complex dynamics of mixed flow in rapidly filling stormwater systems.

InfoWorks ICM (Integrated Catchment Model) is a dynamic modelling software that integrates one-dimensional (1D) and two-dimensional (2D) hydrodynamic simulation techniques (Innovyze 2015). The SE (Sewer Edition) version of InfoWorks can model complex sewer systems and obtain fast results (Innovyze 2015). The previous version of InfoWorks ICM SE is InfoWorks CS, and it was developed in the year of 1998. The software utilizes some of the numerical approaches previously, including finite volume, conservation of mass and momentum, Runge-Kutta, and shock capturing approaches. Similar to SWMM and Mouse, this tool does not consider entrapped air in the system or the hydrodynamics of inflow drop shaft. Also, it cannot properly represent the pressurized wave fronts and the resulting 
surges.

Ridgway and Kumpula (2007) developed the Transient Analysis Program (TAP), which solves continutiy and momentum equations using finite volume strategy. A rapidly varying flow under open channel and closed conduit condition can be simulated with this tool.

HAMMER is a hydraulic transient analysis and water hammer modelling tool that uses the MOC (Bentley Systems Inc. 2015). It is able to simulate a transient phenomenon using both rigid column theory for areas experiencing mass oscillation and elastic theory everywhere else during hydraulic transient events.

Three-dimensional (3D) computational fluid dynamics (CFD) software such as Fluent, ANSYS CFX, and STAR-CCM+ can overcome most of the limitations and instabilities of 1D and 2D hydraulic modelling software. The 3D models can simulate the drop shaft and the entire tunnel as an empty system is filled to surcharge conditions to identify the effects of entrapped air pockets and mass oscillation in horizontal or vertical stormwater storage systems. While CFD software allows detailed and complex modelling of stormwater systems, it is technically demanding and time consuming to set 
up and analyze such that it typically take days to compute a single drop shaft and tunnel section, or much longer depending on the size of the model.

A dynamic tunnel model was developed by Zemell and Fok (2014) using a rigid-column theory to analyze the flows in a vertical stormwater storage system that consists of a horizontal tunnel, two large vertical storage shafts, and two or more drop shafts. It is recommended to limit the number of drop shaft to 9 . For the $\mathrm{k}^{\text {th }}$ drop shaft $(\mathrm{k}=1,2, \ldots, \mathrm{N})$, the conservation of momentum principle is expressed as:

$$
\left(\frac{\mathrm{L}_{k}}{g A_{k}}\right) \frac{d Q_{k}}{d t}=L_{k}-H_{k}-\left(\frac{f_{k} L_{k}}{2 g D_{k} A_{k}^{2}}\right) Q_{k}\left|Q_{k}\right|
$$

where $\mathrm{L}_{\mathrm{k}}=$ length of the water column in shaft $(\mathrm{m}) ; \mathrm{A}_{\mathrm{k}}=$ circular crosssectional area of the shaft $\left(\mathrm{m}^{2}\right) ; \mathrm{Q}_{\mathrm{k}}=$ flow rate in the shaft $\left(\mathrm{m}^{3} / \mathrm{s}\right) ; \mathrm{H}_{\mathrm{k}}=$ head at the junction of the shaft and tunnel $(\mathrm{m}) ; \mathrm{f}_{\mathrm{k}}=$ Darcy-Weisbach friction coefficient in the shaft; and $\mathrm{D}_{\mathrm{k}}=$ diameter of the shaft $(\mathrm{m})$.

For a tunnel segment at $\mathrm{k}^{\text {th }}$ drop shaft, the conservation of momentum principle is expressed as:

$$
\left(\frac{\mathrm{L}_{k, k+1}}{g A}\right) \frac{d T_{k}}{d t}=H_{k}-H_{k+1}-\left(\frac{f L_{k, k+1}}{2 g D A^{2}}\right) T_{k}\left|T_{k}\right|
$$


where $\mathrm{L}_{\mathrm{k}, \mathrm{k}+1}=$ distance between adjacent drop shafts $(\mathrm{m}) ; \mathrm{A}=$ cross-sectional area of the tunnel segment $\left(\mathrm{m}^{2}\right) ; \mathrm{T}_{\mathrm{k}}=$ flow rate in the tunnel segment $\left(\mathrm{m}^{3} / \mathrm{s}\right)$; $\mathrm{f}=$ Darcy-Weisbach friction coefficient in the tunnel segment; and $\mathrm{D}=$ diameter of the tunnel segment $(\mathrm{m})$.

\subsection{Summary of Literature Review}

Previous experimental and numerical studies dating back more than 40 years have enhanced the understanding of flow dynamics and revealed some of the instabilities of a mixed flow regime that can result from entrapped air and flow oscillation in the tunnel during filling. Most of these studies focused on investigating flow regime during the filling of an empty stormwater conveyance tunnel. Only few studies investigated mixed flow regime under surcharge condition in vertical stormwater storage systems during filling.

Hydraulic modelling software are unable to sufficiently simulate the exact behaviour of flows in stormwater systems during filling and up to the transition to surcharge condition because certain boundary conditions and flow regimes have to be simplified due to the complex nature of flow dynamics.

Further studies seem to be necessary to understand flow dynamics in 
vertical stormwater storage tunnel systems and to identify potential hydraulic problems that can occur in inflow drop shafts under surcharge conditions. 


\section{Chapter 3.}

\section{Physical Scale Model}

It is assumed that hydraulic instabilities in the system can be mitigated when it reaches over-sized vertical storage shafts but they may still exist in parts of the system between large vertical storage shafts. In this research, the hydraulic issues in one tunnel segment between two over-sized vertical storage shafts were investigated.

Due to financial and time constraints, it was not feasible to construct a scale model of one tunnel segment with long horizontal tunnel and multiple inflow drop shafts. It was decided to construct a physical scale model with a horizontally distorted tunnel considering the available space in the lab and the materials that were available for construction. However, a small scale model can be sufficient to conduct comparative investigations to gain some 
insight on potential hydraulic issues that can occur even in a simplified vertical storage system.

\subsection{Vertical Storage System}

\subsubsection{Shafts and Tunnel Design}

The simplified vertical storage system illustrated in Figure 3-1 was designed to reproduce a limited number of features in vertical storage systems, including a horizontal conveyance tunnel, an inflow drop shaft, and two vertical storage shafts.

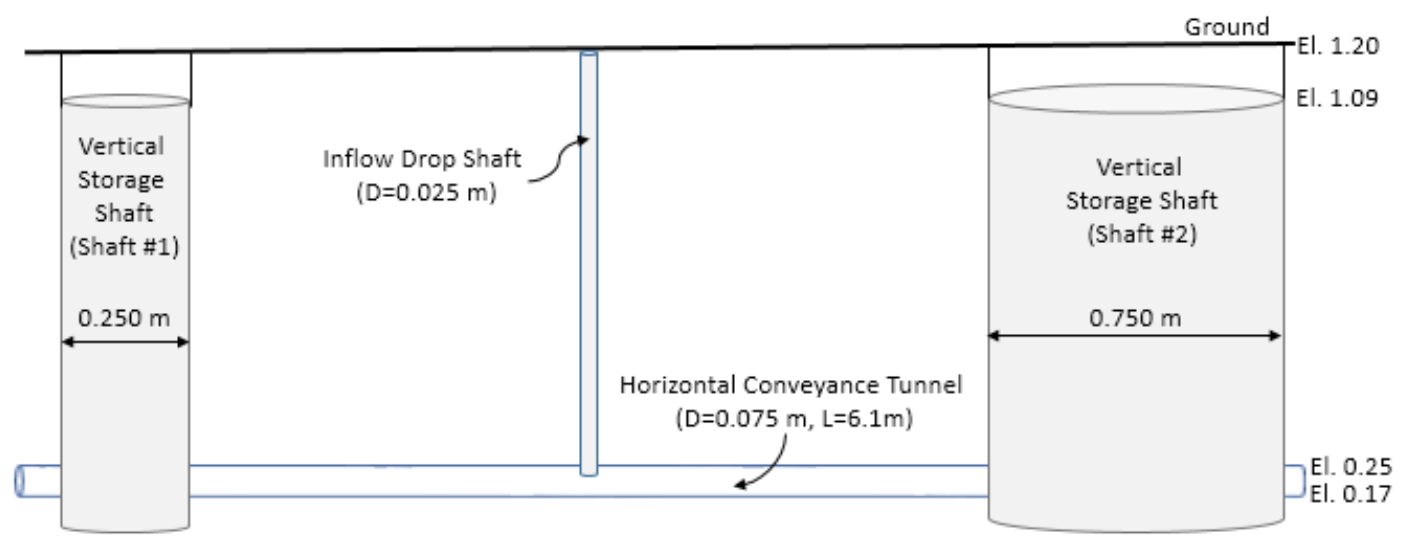

Figure 3-1. Scale Model Design of Simplified Vertical Storage System

The main part of the model consists of a 0.75 m-diameter vertical storage shaft; a 0.25 m-diameter vertical storage shaft; a 0.025 m-diameter inflow drop shaft; and a 0.075 m-diameter horizontal conveyance tunnel. 
The primary storage shaft $\# 2$ has a diameter of $0.75 \mathrm{~m}$, but a smaller diameter storage shaft was added to explore dynamic situations with different sizes of vertical shafts. It can also be considered as a shaft for transporting equipment during the construction stage or for maintenance purposes. The slope of the horizontal tunnel was maintained at $0 \%$ throughout the experiment to simplify the system and to analyze the behaviour of flow oscillating in the system without gravity-driven flows in the tunnel.

The scale factor was determined based on the design of an existing below-grade vertical storage system, the Western Beaches Storage Tunnel built in Toronto, with geometric similarity. Although the tunnel length was horizontally distorted, other design parameters, such as the height and diameters of storage shafts, drop shaft, and tunnel, were compared and the scale factor of 1:40 was determined for the prototype.

The design parameters for the model and prototype were calculated based on Froude law criterion in terms of length scale ratio $\left(L_{R}\right)$, shown in Table 3-1, and the schematic of the prototype is illustrated in Figure 3-2. 
CHAPTER 3. PHYSICAL SCALE MODEL

Table 3-1. Design Setup for Prototype and Physical Scale Model

\begin{tabular}{|c|c|c|c|c|}
\hline Parameters & $\begin{array}{c}\text { Froude } \\
\text { Relationship }\end{array}$ & $\begin{array}{c}\text { Scale Factor } \\
\text { (Prototype } \\
\text { /Model) }\end{array}$ & Model & Prototype \\
\hline Tunnel Diameter (m) & $L_{R}$ & 40 & 0.075 & 3 \\
\hline Tunnel Length (m) & $L_{R}$ & 40 & 6.1 & 224 \\
\hline $\begin{array}{l}\text { Tunnel Cross Sectional Area } \\
\qquad\left(\mathrm{m}^{2}\right)\end{array}$ & $L_{R}{ }^{2}$ & 1600 & 0.0044 & 7.069 \\
\hline Tunnel Storage Volume $\left(\mathrm{m}^{3}\right)$ & $L_{R}{ }^{3}$ & 64000 & 0.0269 & 1725 \\
\hline Storage Shaft \#1 Diameter (m) & $L_{R}$ & 40 & 0.25 & 10 \\
\hline Storage Shaft \#2 Diameter (m) & $L_{R}$ & 40 & 0.75 & 30 \\
\hline $\begin{array}{l}\text { Storage Shafts \#1 \& \#2 Height } \\
(\mathrm{m})\end{array}$ & $L_{R}$ & 40 & 1.2 & 48 \\
\hline $\begin{array}{c}\text { Storage Shafts \#1 \& \#2 Spill } \\
\text { Level }(\mathrm{m})\end{array}$ & $L_{R}$ & 40 & 1.09 & 43 \\
\hline Shaft \# 1 Storage Volume $\left(\mathrm{m}^{3}\right)$ & $L_{R}{ }^{3}$ & 64000 & 0.05 & 3424 \\
\hline Shaft \#2 Storage Volume $\left(\mathrm{m}^{3}\right)$ & $L_{R}{ }^{3}$ & 64000 & 0.48 & 30819 \\
\hline Drop Shaft Diameter (m) & $L_{R}$ & 40 & 0.025 & 1 \\
\hline $\begin{array}{l}\text { Drop Shaft Inlet Hose } \\
\text { Diameter }(\mathrm{m})\end{array}$ & $L_{R}$ & 40 & 0.016 & 0.64 \\
\hline $\begin{array}{c}\text { Drop Shaft Height }(\mathrm{m}) \\
\text { (from the base of the model) }\end{array}$ & $L_{R}$ & 40 & 1.3 & 52 \\
\hline $\begin{array}{l}\text { Drop Shaft Storage Volume } \\
\qquad\left(\mathrm{m}^{3}\right)\end{array}$ & $\mathrm{LR}^{3}$ & 64000 & 0.0005 & 34.2 \\
\hline
\end{tabular}




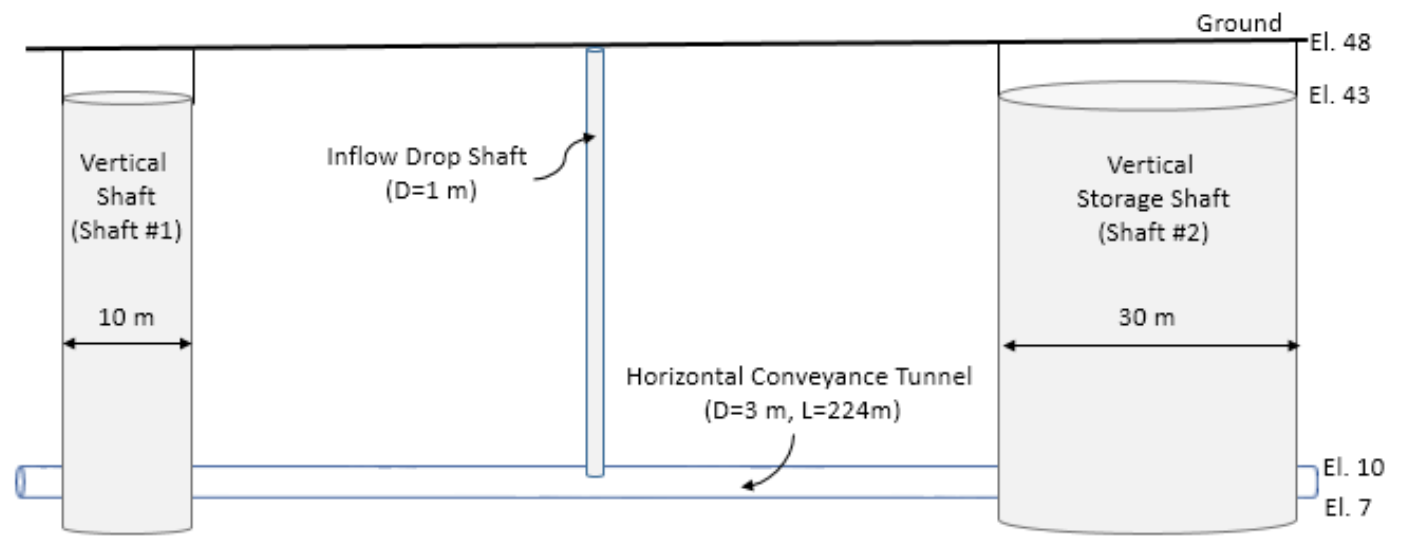

Figure 3-2. Prototype Design of Simplified Vertical Storage System

\subsubsection{Design Inflows and Conditions}

The design inflow were selected based on the flow rates of available supply of water, such as pumps and water tap in the laboratory. In this experiment, the flow is governed by gravity and flow turbulence. The design inflows for the physical scale model and prototype are based on the Froude number scaling for dynamic similarity as shown in Table 3-2.

The definitions of the variables are as follows: $Q_{D}=$ inflow rate to drop shaft; $V_{D(\text { Drop }}$ Shaft $)=$ inflow velocity through the cross section area of drop

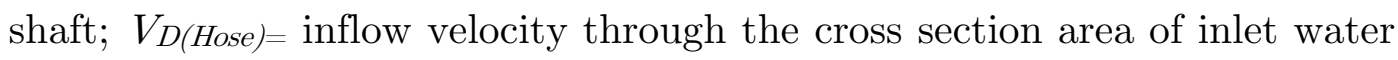
hose; $Q_{1}=$ inflow rate to vertical storage shaft $\# 1$; and $Q_{2}=$ inflow rate to vertical storage shaft $\# 2$. 
CHAPTER 3. PHYSICAL SCALE MODEL

Table 3-2. Design flows for Physical Scale Model and Prototype

\begin{tabular}{|c|c|c|c|c|}
\hline Variables & $\begin{array}{c}\text { Froude } \\
\text { Relationship }\end{array}$ & $\begin{array}{c}\text { Scale factor } \\
\text { (Prototype/Model) }\end{array}$ & Model & Prototype \\
\hline$Q_{D}$ & $\mathrm{~L}^{5 / 2}$ & 10119 & $0.4 \mathrm{~L} / \mathrm{s}$ & $4 \mathrm{~m}^{3} / \mathrm{s}$ \\
\hline$V_{D}$ (Drop Shaft) & $\mathrm{L}^{1 / 2}$ & 6.325 & $0.81 \mathrm{~m} / \mathrm{s}$ & $5.12 \mathrm{~m} / \mathrm{s}$ \\
\hline$V_{D}$ (Inlet Hose) & $\mathrm{L}^{1 / 2}$ & 6.325 & $2 \mathrm{~m} / \mathrm{s}$ & $12.65 \mathrm{~m} / \mathrm{s}$ \\
\hline$Q_{1}$ & $\mathrm{~L}^{5 / 2}$ & 10119 & 1.2 to $2 \mathrm{~L} / \mathrm{s}$ & 10 to $20 \mathrm{~m}^{3} / \mathrm{s}$ \\
\hline$Q_{2}$ & $\mathrm{~L}^{5 / 2}$ & 10119 & 2 to $10 \mathrm{~L} / \mathrm{s}$ & 20 to $101 \mathrm{~m} / \mathrm{s}$ \\
\hline
\end{tabular}

\subsubsection{Scale Effect Issues}

According to HydraTek Associates (1999), one of the drop shafts at the Western Beaches Tunnel, with a diameter of $1.5 \mathrm{~m}$, received an inflow rate of $6.25 \mathrm{~m}^{3} / \mathrm{s}$ during a 5-year storm event. This corresponds to an inflow velocity of $3.5 \mathrm{~m} / \mathrm{s}$, which is equivalent to a velocity of $0.55 \mathrm{~m} / \mathrm{s}$ into a 0.037 m-diameter drop shaft. In this study, the inflow velocity from the water hose was $2 \mathrm{~m} / \mathrm{s}$ into a $0.026 \mathrm{~m}$-diameter drop shaft. An inflow with higher velocity was used to simulate a storm event with a return period greater than 5-year. It also allowed a better simulation of air entrainment in the drop shaft.

For the prototype, the flow $\left(\mathrm{V}_{1}\right)$ from upstream sewer system accelerates to $\mathrm{V}_{2}$ as it approaches the vortex inlet of drop shaft and swirls 
down the shaft $\left(\mathrm{V}_{3}\right)$ until it falls vertically with air like water droplets $\left(\mathrm{V}_{4}\right)$. Then it plunges into the water pool with submerged flow velocity $\left(\mathrm{V}_{0}\right)$ as shown in Figure 3-3.

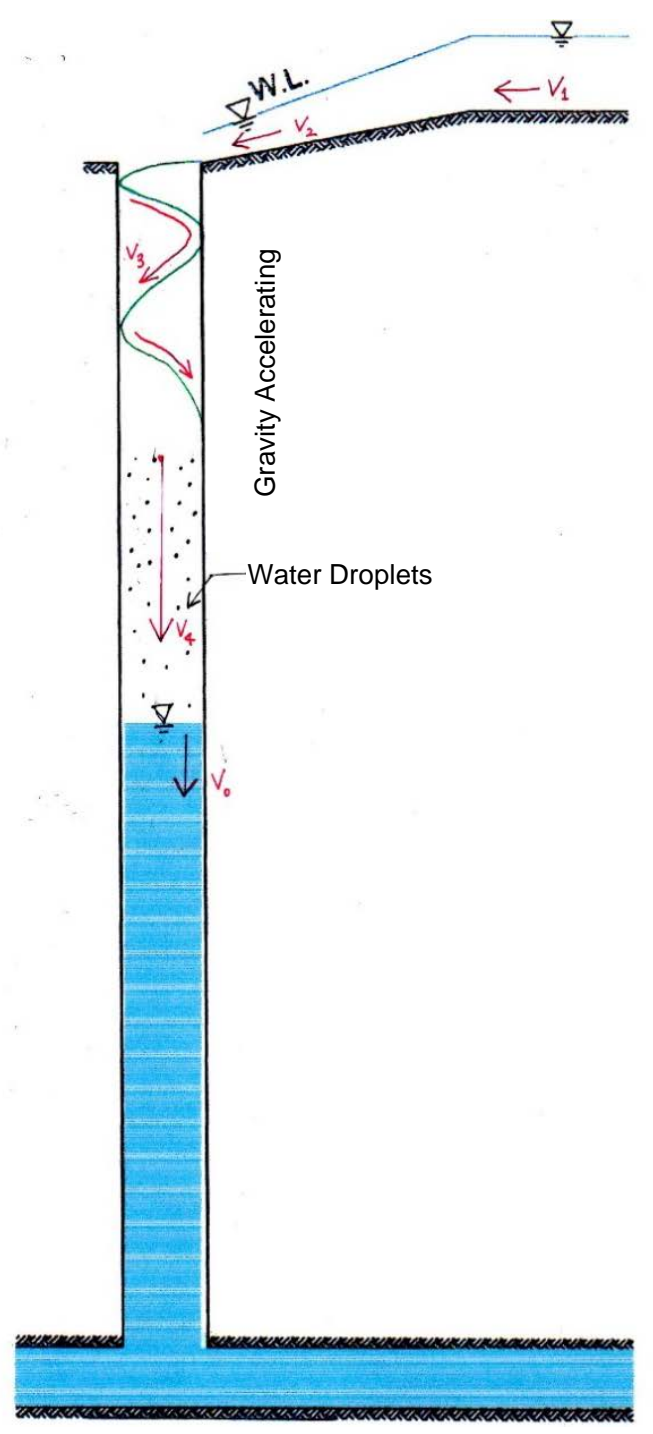

Figure 3-3. Drop Shaft Inlet Hydraulic (Modified from Fok 2015) 
However, a drop height of $1.3 \mathrm{~m}$ in the small-scale model was too short to reproduce the full range of this inlet hydraulic condition. A $0.016 \mathrm{~m}$ diameter water hose was used to supply a jet-like inflow into the drop shaft (QD) with a velocity of $2 \mathrm{~m} / \mathrm{s}$ in order to simulate a significant amount of air entrainment. Although the initial inflow velocity is relatively high, energy losses due to wall friction and the buoyant weight of air bubbles in the flow are expected (Jain 1988).

In the Western Beaches Tunnel, the maximum velocity in the tunnel during a 5-year storm event is estimated to be approximately $6 \mathrm{~m} / \mathrm{s}$ (HydraTek Associates 1999), which is equivalent to $0.95 \mathrm{~m} / \mathrm{s}$ in model. Since only a single drop shaft was modelled, inflows to tunnel from multiple drop shafts were simulated by supplying large inflows into vertical storage shafts. However, most of the inflow was used to fill the storage shaft $\# 2$ during filling, and the tunnel flow from the storage shaft to the drop shaft was significantly less than $0.95 \mathrm{~m} / \mathrm{s}$.

\subsection{Scale Model Construction}

\subsubsection{Model Layout}

Based on the design of the vertical storage system, a physical scale 
model with supporting systems was designed as shown in Figure 3-4. The model was constructed in the hydrology and hydraulic lab located at Ryerson University, as shown in Figure 3-5.

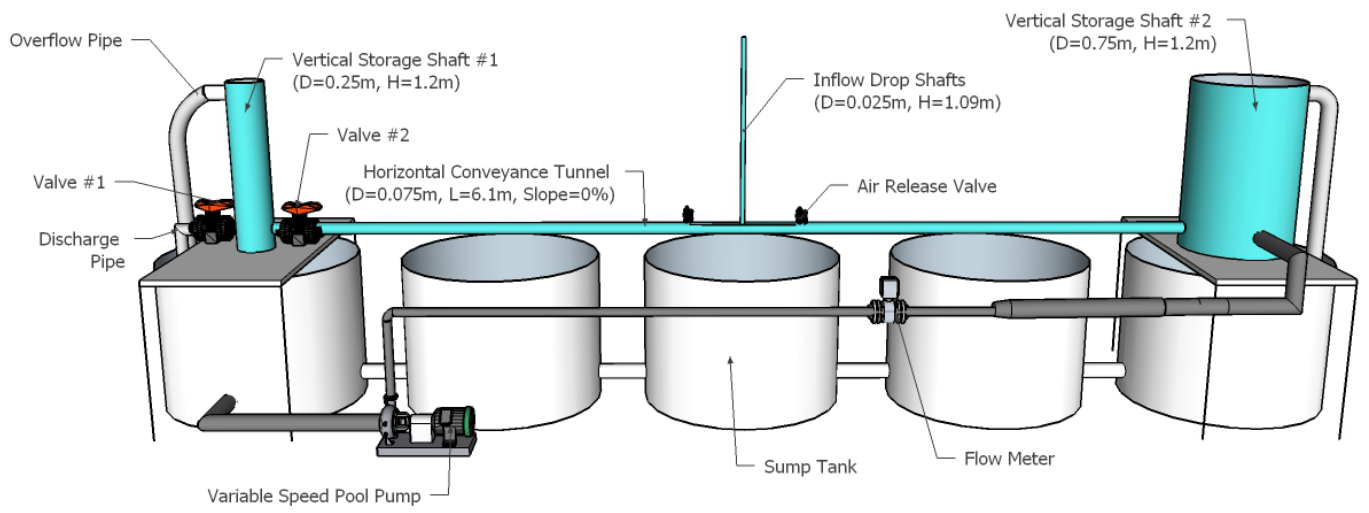

Figure 3-4. Physical Scale Model Design

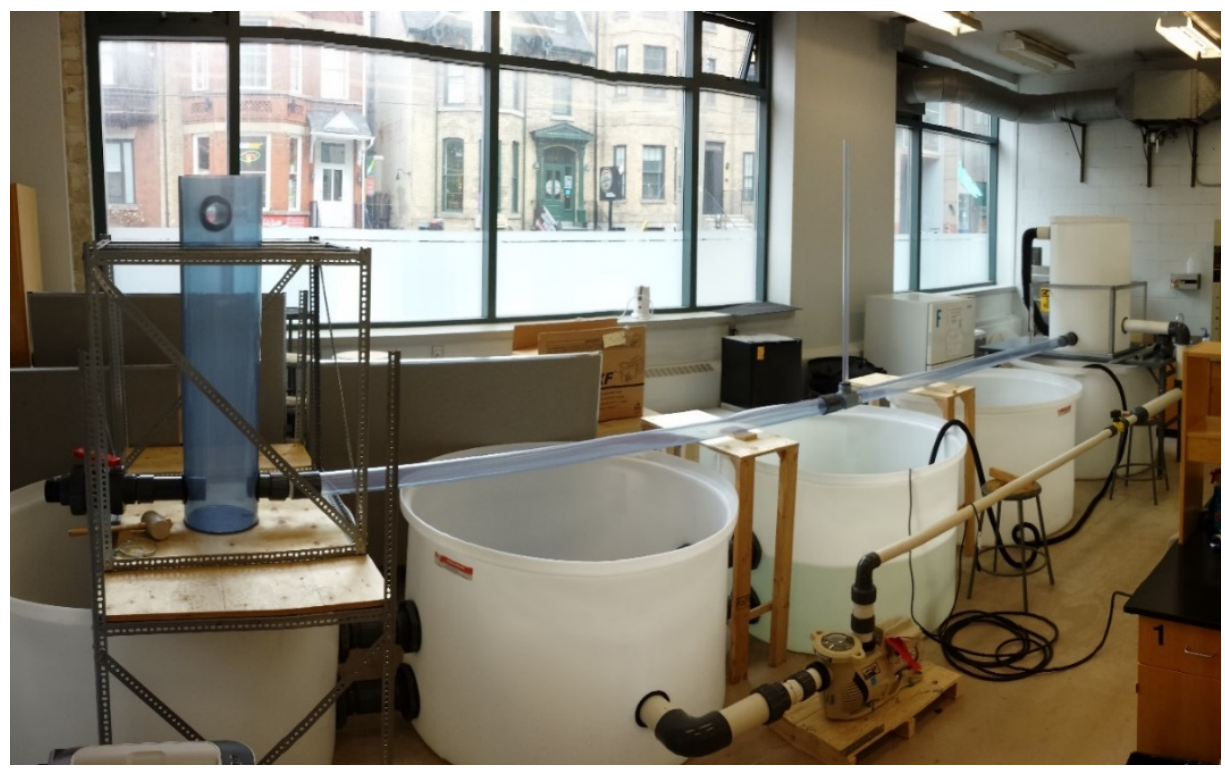

Figure 3-5. Physical Scale Model at Ryerson University 
CHAPTER 3. PHYSICAL SCALE MODEL

The vertical storage system was built using clear Schedule 80 polyvinyl chlorine (PVC) pipes and semi-transparent polyethylene tanks for visual observations. The clear PVC pipes were selected for its visibility, smooth interior walls for minimize friction, resistant to corrosion and chemicals, and a design stress of 2000 psi to prevent physical deformation. The polyethylene tanks were used as an alternative for tanks with a diameter of $0.25 \mathrm{~m}$ or larger due to its availability from the manufacturer.

As discussed previously, the main part of the model consists of small storage shaft (Shaft $\# 1$ ), large storage shaft (Shaft $\# 2$ ), inflow drop shaft, horizontal conveyance tunnel, and air release valves.

For the horizontal conveyance tunnel, two 3.05 m-long section of a clear PVC pipe with a diameter of $0.075 \mathrm{~m}$ were joined together to obtain a 6.1 m-long pipe. It connects the two large vertical shafts on both ends.

Storage shaft \#1 consists of a clear PVC pipe with a diameter of 0.25 m. It is connected to the larger vertical storage shaft $\# 2$ by the tunnel, beginning with a ball valve (Valve $\# 2$ ). This control valve in the tunnel can be closed to isolate Shaft $\# 1$ so that the system only consists of Shaft $\# 2$, the drop shaft and the tunnel. The large vertical storage shaft on the right 
side of the model, Shaft $\# 2$, is 0.75 m-diameter polyethylene circular tank. Both storage shafts are $1.2 \mathrm{~m}$ high with a spill level of approximately 1.09 m.

On the downstream end of Shaft $\# 1$, a discharge pipe with a diameter of $0.075 \mathrm{~m}$ is installed with a ball valve (Valve $\# 1$ ) to drain the model or to divert the outflow from the system into the sump tank for reuse. Flexible PVC pipes were installed near the top of both vertical storage shafts for overflows to be discharged into the sump tanks below if the water level in the shaft reaches the spill level.

A clear PVC pipe with an internal diameter of $0.025 \mathrm{~m}$ was installed as an inflow drop shaft in the middle of the $6.1 \mathrm{~m}$-long horizontal pipe. The height of the drop shaft is $1.3 \mathrm{~m}$, which is approximately $0.2 \mathrm{~m}$ above the spill level of the two vertical storage shafts. This allows for better observation of a geyser event at the drop shaft because the magnitude of the geyser is contained in the shaft above the hypothetical ground level, so that it can be observed and measured.

Two valves with openings of $0.006 \mathrm{~m}$ in diameter are installed $0.38 \mathrm{~m}$ from the drop shaft on both sides. The entrapped air, which is introduced 
into the tunnel through the inflow drop shaft, can be vented by opening these two air release valves during filling.

\subsubsection{Support System for Model}

Besides the proposed vertical storage system with vertical shafts and tunnels, there were other components that were supporting the main part of the physical model, such as sump tanks, tank fittings, pumps, water tap, and flow meter.

Five polyethylene circular tanks with a capacity of 1135 litres each were connected together with 0.1 m-diameter PVC pipes to act as a sump for allowing water to be stored and used by a number of pumps to supply water into the system. The sump was placed under the main part of the physical model in order to save space in the laboratory; to raise the main part of the model at least 1 metres from the floor for easier observation; and to catch overflows from the system to reuse water and prevent excess use of tap water for this research. Water quality in the sump was maintained using chlorine tablets during the research period.

A rubber-like tank fitting, called Uniseal, was used to allow pipes to be attached to curved surface of a circular tank for easy installation. It also 
allows a pipe to be tilted up to 15 degrees in any direction for sloping the tunnel for future studies. For other joint parts, such as tank fittings and adapters, a threaded connection was used for reusability and ease of modification.

Bulkhead tank fittings of appropriate sizes are used where the pipe can be attached to a flat surface or where an angled or sloped connection is not required. The limitation with the use of bulkhead tank fittings or PVC adapters installed in this physical model was that there was an inevitable small gap at the joint where the fitting and the pipe is joined by PVC cement. This gap at the joint may result in inaccuracy in several parameters of the system, such as roughness of the pipe, flow velocity, flow rate, and volume of water.

Rapid filling of the system was achieved by using water supply from the tap located in the laboratory for the drop shaft, and installing several pumps for two larger vertical shafts. For the drop shaft, a water hose with an internal diameter of $0.016 \mathrm{~m}$ was connected to a water tap in the laboratory, and the outlet was fixed at the top of the drop shaft with a clamp. While the maximum flow rate from the water tap was inconsistent, the average flow rate was found to be $0.4 \mathrm{~L} / \mathrm{s}$. Two fixed speed sump pumps with average 
flow rates of $1.2 \mathrm{~L} / \mathrm{s}$ and $2 \mathrm{~L} / \mathrm{s}$ were installed at the bottom of the sump tanks to provide inflow into the storage shaft $\# 2$. In addition, a Pentair Intelliflo XF 3.0 Variable Speed Pool Pump was installed on the floor to pump the water from the sump tank to the larger storage shaft \#1.

To determine the actual flow rate delivered into the tank, a flow meter was installed upstream of the pool pump to monitor pump discharge; and the pump speed was adjusted to achieve the desired average flow rates needed for the experiments in this research. Upon calibration, it was determined that a pump motor speed of 850 RPM can achieve an average flow rate of $2 \mathrm{~L} / \mathrm{s}$ into the system until it is completely filled. An average flow rate of $5 \mathrm{~L} / \mathrm{s}$ was achieved with $1600 \mathrm{RPM}, 7 \mathrm{~L} / \mathrm{s}$ with $2100 \mathrm{RPM}$, and $10 \mathrm{~L} / \mathrm{s}$ with $2850 \mathrm{RPM}$. 


\section{Chapter 4.}

\section{Methodology}

A review of the literature revealed that there is limited guidance and information on designing vertical stormwater storage systems and the critical conditions that can potentially result in hydraulic issues. Based on these findings, it was decided to construct a physical scale model of a simple vertical storage system as described in the previous chapter and to conduct a comparative experimental study to investigate the hydraulic response of the drop shaft during filling under different conditions. Furthermore, this research examined the current hydraulic modelling softwares on analyzing the vertical stormwater storage systems.

\subsection{General Description of the Experiments}

Different inflow conditions and operational problems were simulated to 
gain some insight into the flow mechanisms that can result in hydraulic issues in vertical storage systems; with a particular emphasis on the inflow drop shaft. The first set of experiments were conducted to observe the outcome of air entrapment in the system and its impacts on the drop shaft. The second set of experiments was to study the effects of mass-oscillation due to sudden change of inflow conditions and other operational problems during filling. Operational problems, such as rapid valve closure, tunnel blockage, opening of valves, and pump failure, were also simulated.

As a preliminary test, an empty horizontal tunnel was rapidly filled with a flow of $7 \mathrm{~L} / \mathrm{s}$ until it is completely filled. A geyser-like behaviour was initially observed in the drop shaft near the end of the tunnel filling process, however the geyser was not large enough to reach the spill level and the water level eventually stabilized as the tunnel became completely filled. Therefore, it was decided to simulate only the filling of the vertical shafts in this research. Initially, the tunnel was completely filled and it was allowed to stabilize before initiating the experiments by introducing inflows into the system. For every experimental run, the initial water level in the vertical shafts was at least $0.25 \mathrm{~m}$ or higher so that the tunnel is full at all times.

Once the water level reached the top of two storage shafts at the end of 
filling, excess water was diverted out by the overflow pipes. Then, water was drained from the system through the discharge pipe for the next experiment. Each experiment was repeated at least three times to determine experimental variability and ensure consistency in the results; and to obtain more accurate average measurements.

\subsection{Procedure for Entrapped Air Study}

Twenty-seven different combinations of experimental variables were tested to investigate the effects of entrapped air in a vertical storage system. Figure 4-1 presents a schematic of the physical model used in this study.

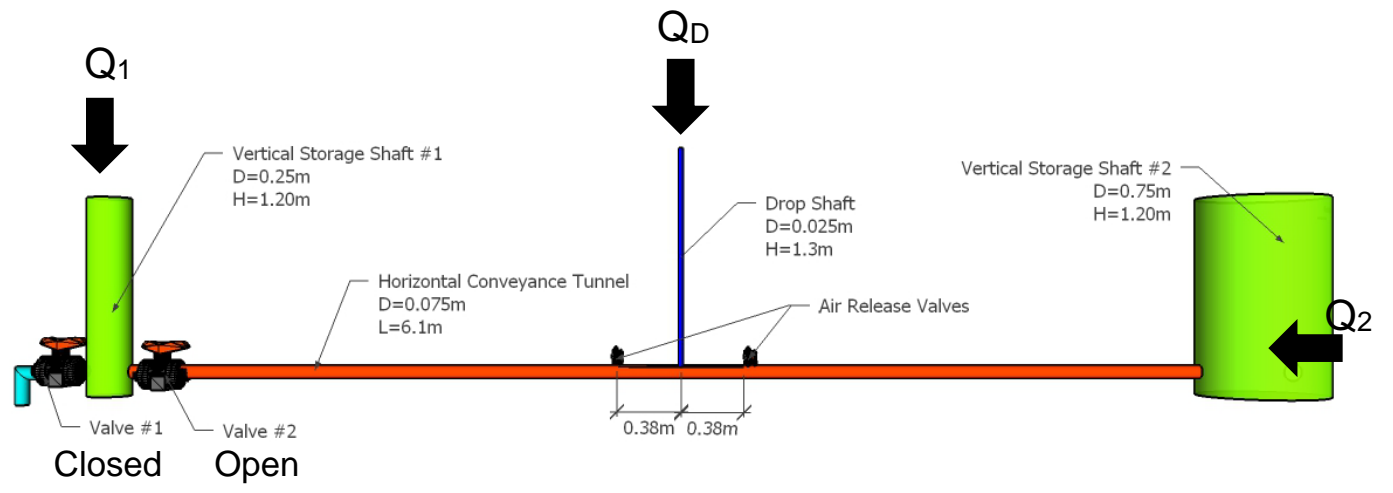

Figure 4-1. Sketch of Model Used in Entrapped Air Study

Valve \#1 was closed and Valve \#2 was opened at all times to allow 
the inflows to fill all three vertical shafts. Two different fixed-speed pumps were installed to supply inflow to Shaft $\# 1$, and a variable speed pool pump was used to supply inflow to Shaft $\# 2$. A water hose attached to the water tap in the laboratory was used to supply an inflow of $0.4 \mathrm{~L} / \mathrm{s}$ to the drop shaft.

Air entrainment was achieved by allowing inflow to plunge into the water pool in the shaft. For different combinations of inflow conditions, the effects of entrapped air in the drop shaft was observed with the air release valves opened and closed. Closing the air release valves near the drop shaft was intended to contain air in the system as much as possible, and to observe its overall impact on the drop shaft.

Table 4-1. Experimental Variables for Entrapped Air Study

\begin{tabular}{|c|c|}
\hline Experimental Variable & Parameters \\
\hline$Q_{1}(\mathrm{~L} / \mathrm{s})$ & $0,1.2,2$ \\
\hline$Q_{2}(\mathrm{~L} / \mathrm{s})$ & $2,5,7,10$ \\
\hline$Q_{D}(\mathrm{~L} / \mathrm{s})$ & $0,0.4$ \\
\hline Air release valves & Open, Closed \\
\hline
\end{tabular}

A summary of the experimental variables used in this study are 
presented in Table 4-1. The definitions of the variables listed in the table are: $Q_{1}=$ inflow rate at storage shaft $\# 1, Q_{2}=$ inflow rate at storage shaft $\# 2$, and $Q_{D}=$ inflow rate at drop shaft.

The experimental procedure can be generalized as follows:

1. Water was introduced into the system until the water level in all three vertical shafts reach approximately $0.25 \mathrm{~m}$, with the tunnel completely filled, then the system was allowed to stabilize to a static condition.

2. Air release valves were adjusted as desired, and the desired inflow rates to selected vertical shafts were prepared by adjusting the pumps and water tap.

3. Inflows were introduced into the system at the selected vertical shafts.

4. With continuous inflows, the water level in the vertical shafts increased.

5. In certain cases, a geyser was observed at the drop shaft during filling. Otherwise, the water level rise in all three shafts was uniform and steady.

\subsection{Procedure for Oscillation Study}

This set of experiments explored potential situations when the water 
CHAPTER 4. METHODOLOGY

level in the drop shaft reaches the spill level due to significant flow oscillation during filling. The flow oscillation was achieved by changing the initial conditions of the system, such as rapid start and stop of inflows at the drop shaft, or opening and closing valves in the horizontal conveyance tunnel.

In order to investigate the effects of flow oscillation without the effects of air entrapment in the system, the air release valves were kept open. Also, the end of the water hose that supplies inflow to the drop shaft was slightly submerged under its surface water level. The water hose was gradually raised during filling with respect to the rising water level in the drop shaft so that the outlet of the hose was maintained at least $1 \mathrm{~cm}$ below the water surface at all times. This procedure ensured that inflow dynamic in the drop shaft can be considered while no air entrainment is introduced at the drop shaft.

\subsubsection{Change of Inflow Conditions}

The change in the inflow condition was achieved by simply turning the drop shaft inflow on and off. For these experimental runs, Valve $\# 2$ at the downstream end of the horizontal conveyance tunnel was kept closed to exclude the storage shaft $\# 1$ from the system. The flow oscillation between a drop shaft and a larger storage shaft can be easily observed, and it also simplifies the analysis of flow behaviour during the oscillation. 
The experimental procedure can be generalized as follows:

1. Water was introduced into the system until the water level in vertical shafts reach approximately $0.25 \mathrm{~m}$, with the tunnel completely filled, then the system was allowed to stabilize to a static condition.

2. Air release valves were opened, and the desired inflow rates to the selected vertical shafts were prepared by adjusting the pumps and water tap.

3. Inflows were introduced into the system at the selected vertical shafts.

4. With continuous inflows, the water level in the vertical shafts increased.

5. The inflow condition at the drop shaft was changed by rapidly stopping or starting the inflow, which resulted in flow oscillation in the drop shaft.

Figure 4-1 presents a sketch of the model used in this study. The experimental variables used in this study are summarized in Table 4-2. 


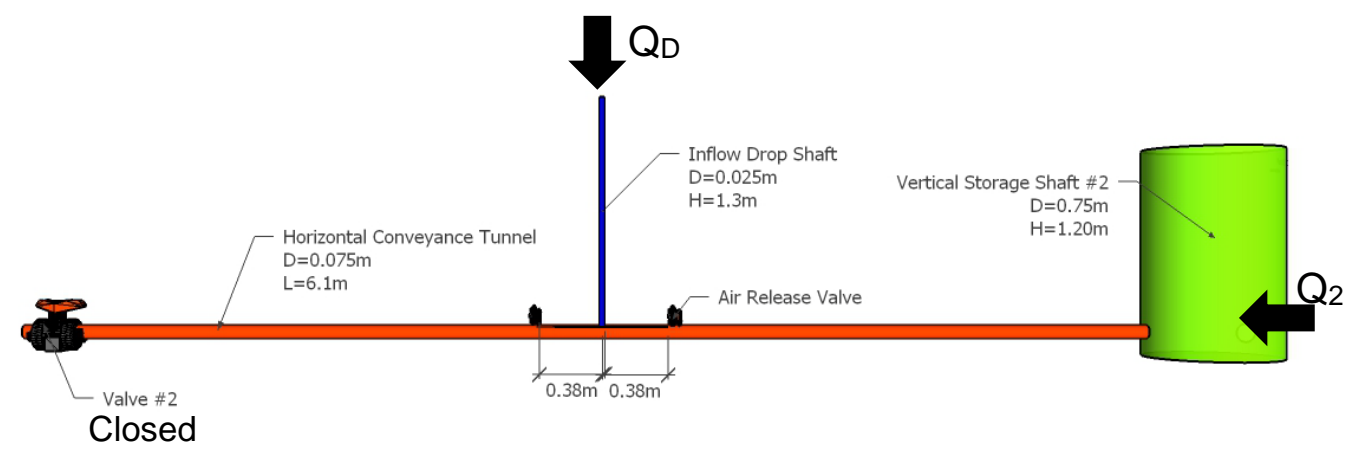

Figure 4-2. Sketch of Model for Flow Oscillation Study with Change in Inflow Conditions

Table 4-2. Experimental Variables for Flow Oscillation Study with Inflow Conditions

\begin{tabular}{|c|c|}
\hline Experimental Variables & Values \\
\hline$Q_{2}(\mathrm{~L} / \mathrm{s})$ & $1,3,5,7$ \\
\hline$Q_{D}(\mathrm{~L} / \mathrm{s})$ & $0,0.4$ \\
\hline
\end{tabular}

\subsubsection{Tunnel Gate Valve Operation}

In these experimental runs, some of the real-world operational problems such as pump failure, blockage, and rapid pumping of the stored stormwater were simulated. The sketch of the experimental model used in this study is presented in Figure 4-3. 


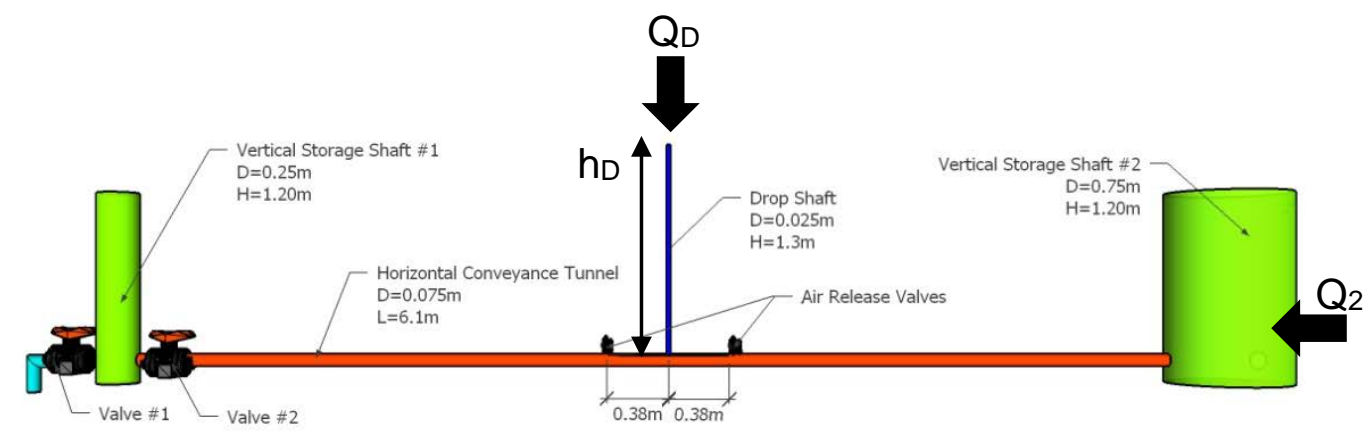

Figure 4-3. Sketch of Model for Flow Oscillation Study with Control Valve Operations

The experimental procedure can be generalized as follows:

1. The system is filled up to the top of the vertical shafts.

2. Desired inflow rates are introduced at selected vertical shafts.

3. Valve $\# 1$ is opened to simulate rapid drainage of the system with high flow velocity in the tunnel.

4. When the water level in the drop shaft reaches a certain water level, hD, Valve $\# 1$ or $\# 2$ was closed at different speeds. Flow oscillation was observed in the drop shaft.

The experimental variables for this study are summarized in Table 4-3. 
Table 4-3. Experimental Variables for Flow Oscillation Study with Control Valve

\begin{tabular}{|c|c|}
\hline Experimental Variables & Parameters \\
\hline$Q_{2}(\mathrm{~L} / \mathrm{s})$ & 0,7 \\
\hline$Q_{D}(\mathrm{~L} / \mathrm{s})$ & $0,0.4$ \\
\hline Valve & $\begin{array}{c}\text { Valve \#1 Open, Valve \#1 Close, } \\
\text { Valve \#2 Open, Valve \#2 Close, }\end{array}$ \\
\hline Valve opening \& closing time (s) & $1,5,10$ \\
\hline
\end{tabular}

\subsection{Experimental Data Analysis}

The experimental runs were recorded with a video camera to aid in collecting data. Measuring tapes were attached to the vertical shafts to track the water level rise during experiments. By watching the video recordings, the water levels in each shaft at the time of first geyser event or at the time when the drop shaft water level reached the spill level were recorded along with comments and remarks based on visual observations. Once the system was filled up to the top of the vertical shafts, final water level measurements at the vertical shafts were also recorded.

For experimental runs that showed most critical behaviours, the video recordings were watched frame-by-frame to record changes in water level 
during filling. The water levels at the shafts over time were plotted for further analysis. In addition, the flows in the system were estimated using mass balance equations.

\subsection{Comparison with Numerical Models}

As discussed in Chapter 2, the behaviour of two-phase flow cannot be described with one-dimensional modelling framework. Furthermore, numerous numerical models were only developed for conveyance tunnels that operate under open channel flow condition. The simple vertical storage system was simulated with two of the commonly used hydraulic modelling software, InfoWorks CS and HAMMER to compare their results to the experimental results and examine the predictions of these numerical models. 


\section{Chapter 5 .}

\section{Experiment Results and Discussion}

Appendix A- 1 and A- 2 provide the results of all experimental runs conducted. Different combinations of experimental variables resulted in geyser events at the drop shaft during filling. The steady water level rise at the vertical storage shafts with large diameters in all experimental runs suggested that the hydraulic response at a drop shaft with a smaller diameter is more sensitive in vertical stormwater storage systems. Experimental results showing the typical behaviours are presented to explain the general phenomenon observed during the studies.

\subsection{Effects of Entrapped Air}

The model set-up schematic and experimental variables used in one of the studies are shown in Figure 5-1. Filling of the shafts was achieved by 
introducing a continuous inflow of $0.4 \mathrm{~L} / \mathrm{s}$ to the drop shaft from the top, and $7 \mathrm{~L} / \mathrm{s}$ to storage shaft $\# 2$. Two air release valves at each side of the drop shaft were controlled to observe the impact of air entrapped in the tunnel. The observation results and discussions for the experiment with opened air release valves are presented in section 5.1.1, and for the experiment with closed air release valves are presented in section 5.1.2.

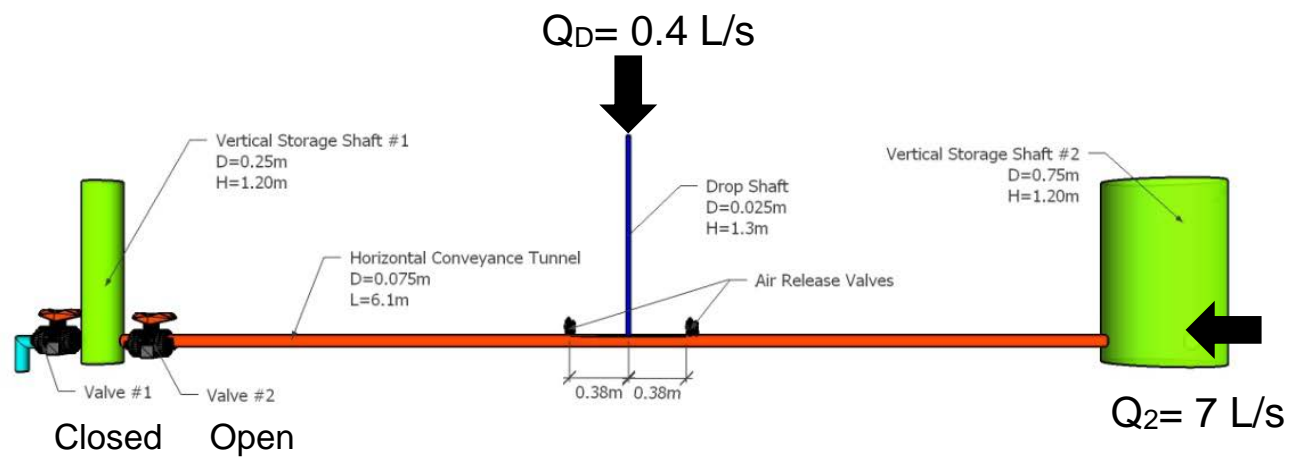

Figure 5-1. Experiment from Entrapped Air Study

\subsection{1. $\quad$ Air in Drop Shaft in Model}

Figure 5-2 presents the observation result from an experiment with opened air release valves, allowing the air in the tunnel to vent out. Overall, the water level rise in the two vertical storage shafts was relatively steady, with both rising at a similar rate. The water level rise in the drop shaft showed 
geyser-like behaviour and reached above the spill level. Based on the behaviour of water in the drop shaft, the filling process of the shaft was divided into three stages: (a) early, (b) intermediate, and (c) final. The numbering in the figure corresponds to different stages of the filling process.

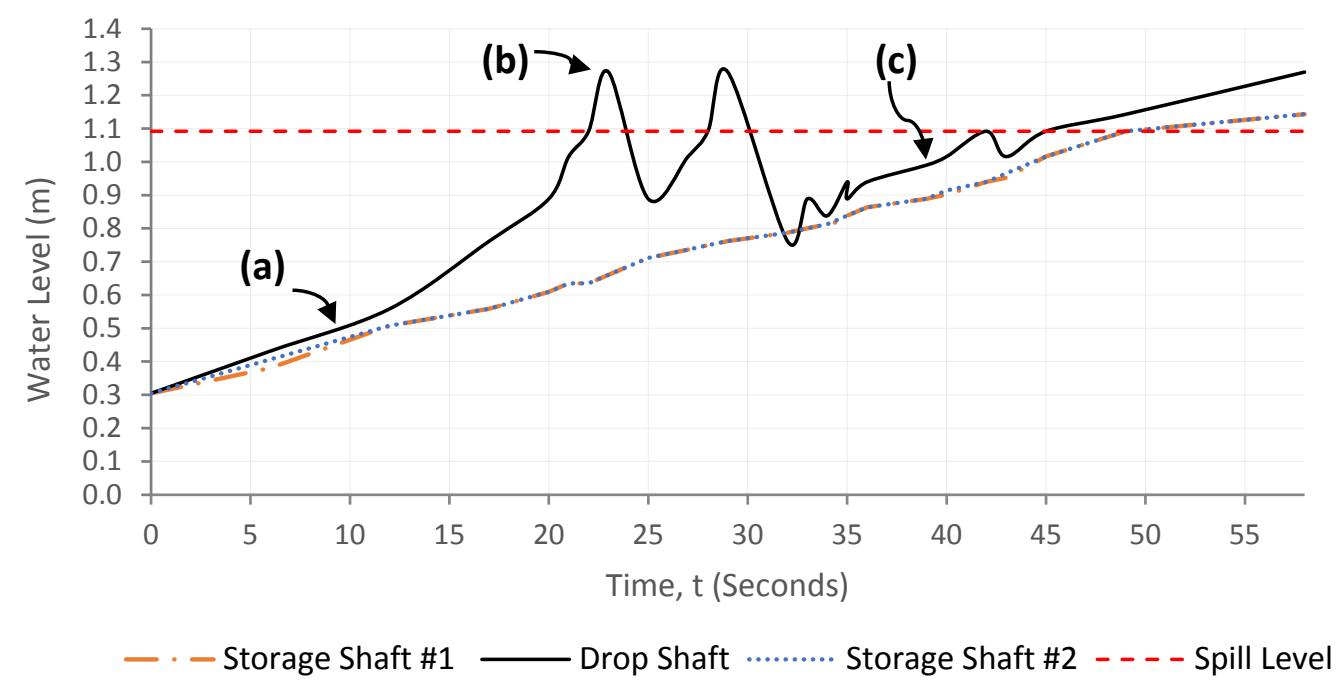

Figure 5-2. Experimental Result with Entrapped in Drop Shaft (Opened Air Release Valves)

(a) In the early stage of vertical shaft filling, a large quantity of air bubbles were entrained when an inflow plunged into the pool in the drop shaft as shown in Figure 5-3. The air entrainment rate was largest during the early stage of filling, and it decreased with the rise of surface water level in the shaft. 
Some of the entrained air travelled upward and was released immediately at the shaft. Most of the air volume continued to travel downward in the drop shaft and was then transported into the tunnel as shown in Figure 5-4 (a).

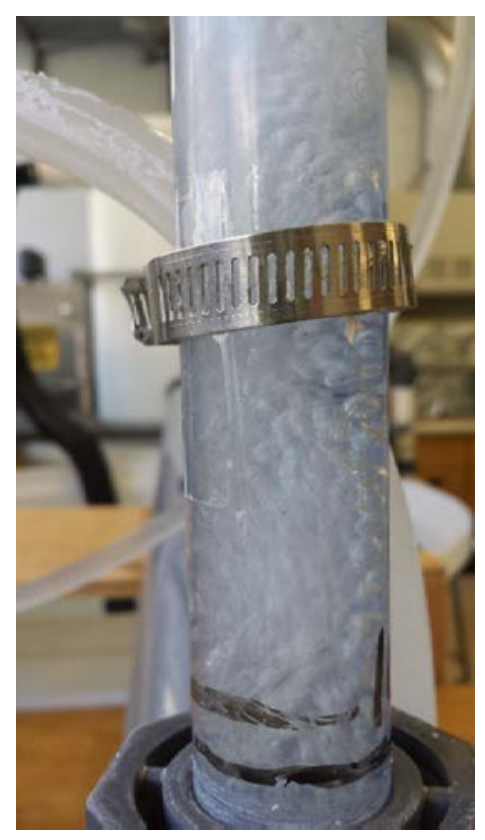

Figure 5-3. Air Entrainment in the Drop Shaft Due to a Free-falling Inflow

(b) During the intermediate stage of filling, the air entrainment was reduced but the inflow still generated a large number of air bubbles. With a longer water column in the drop shaft, only a small amount of entrained air was transported down to the bottom of the drop shaft and escaped into the tunnel. 


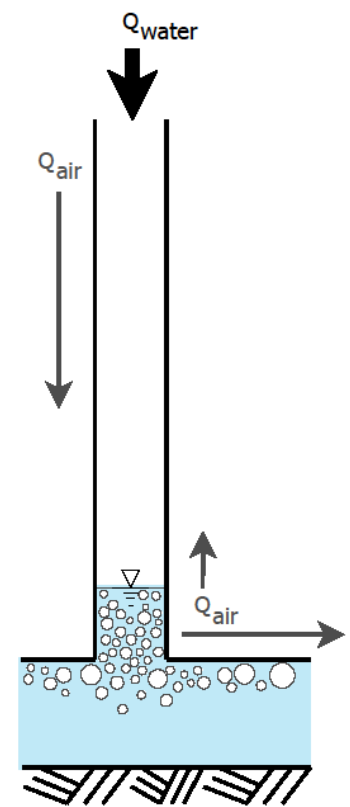

(a) Early Stage

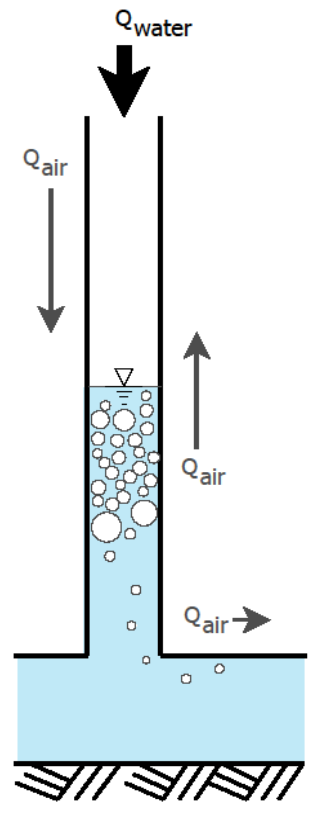

(b) Intermediate Stage

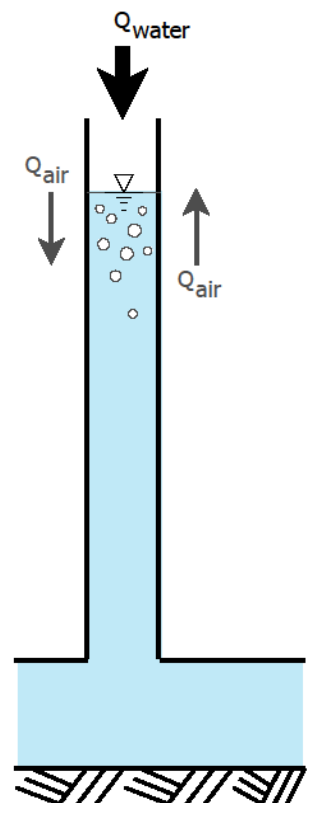

(c) Final Stage

Figure 5-4. Schematic of Air Flow (Qair) in Drop Shaft during Filling

As filling continued, the amount and the size of entrapped air in the drop shaft increased. When a large air pocket rises up the drop shaft due to buoyancy, the water column on top of the air pocket is also lifted up. As the velocity of the rising air pocket and water column accelerates, a geyser-like event reached the spill level of the drop shaft when the equilibrium water level in the storage shafts were almost 0.6 $\mathrm{m}$ below, or about half-full. Figure 5-5 shows a geyser that was observed during the experiment.

After the initial air pocket is released, the water level comes down for 
a brief period of time. Then, another geyser event occurred as the air pockets still remaining in the drop shaft are being released.

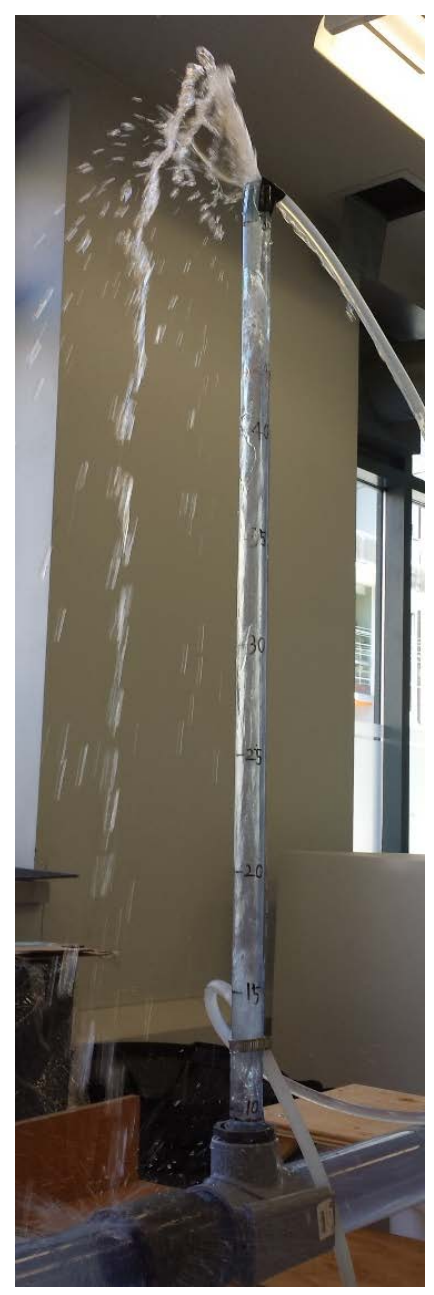

Figure 5-5. Geyser at the Drop Shaft

(c) In the final stage of filling, the flow oscillation was quickly stabilized and a relatively steady rise of water level occurred until it reached the spill level. The amount of air generated was significantly less 
than that of the earlier stages. The air bubbles generated were easily released at the drop shaft. The upward force when the air bubbles are released and the downward force of continuous inflow causes a small fluctuation of water level at the drop shaft.

A schematic diagram in Figure 5-6 shows the directions of the flow and the flow rates in the system when water level at the drop shaft reached the spill level at $\mathrm{t}=27 \mathrm{~s}$. Using the mass balance equation, the tunnel flow rates from Shaft $\# 2$ to the drop shaft was estimated to be approximately $0.38 \mathrm{~L} / \mathrm{s}$, which accounts for only $5 \%$ of the inflow from the upstream of Shaft $\# 2$.

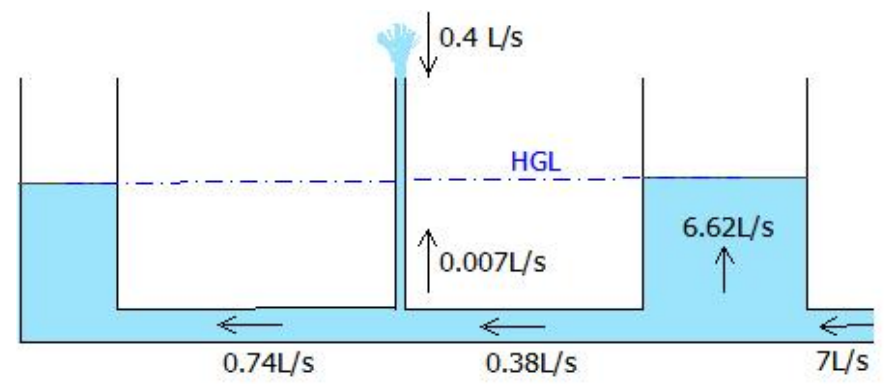

Figure 5-6. Schematic of Flow Behaviour at $\mathrm{t}=27 \mathrm{~s}$

The velocity of the tunnel flow was very low in the physical model due to the constraints discussed in Chapter 3. It is reasonable to predict that this scenario can potentially cause stronger hydraulic response at drop shaft with higher tunnel velocity in prototype and real-life. 
Although the flow velocity in the tunnel was insignificant in this study, a comparison with other experimental runs showed that the magnitude of the geyser events increased as the inflow rate to Shaft $\# 2$ increased. This suggests that the rise speed of water level at the storage shaft was a factor in triggering a geyser event at the drop shaft. The result corresponds with the study conducted by Guo and Song (1991) that showed the maximum amplitude of oscillation in the drop shaft is proportional to the rise speed of the water level in a larger vertical shaft adjacent to the drop shaft.

The geyser strength increased as the equilibrium water level increases, and as the buoyant force of air pocket accelerates longer in the drop shaft, creating more upward momentum until it reaches the free surface. This phenomena was also reported by Lewis, Wright and Vasconcelos (2011).

In the experimental study by Lewis, Wright and Vasconcelos (2011), the air was transported from tunnel whereas in this experimental run, the only source of air was from free falling inflow at the drop shaft due to air entrainment. The air entrainment rate decreased as the filling continues and the drop height of the free falling flow decreases. Thus the largest geyser events generally occurred during the intermediate stage of filling when the air entrainment is enough for the buoyant force to lift water atop the rising 
air; and the rising air pocket has enough distance to gain upward momentum.

Based on the visual observation during this study, the strength of the geyser was dominated by the rise speed of the larger vertical shafts, the amount of air entrainment at the drop shaft and the surface water level in the drop shaft.

The experiments were conducted on a small scale physical model with horizontally distorted conveyance tunnel, thus the experiments only present comparative results for flow behaviours at a drop shaft in a vertical stormwater storage system during filling. Scaling effect is also different for the air entrainment mechanism than for the liquid flows that govern its establishment and dynamics.

\subsection{2. $\quad$ Air in Drop Shaft and Tunnel in Model}

Figure 5-7 presents the result of the same experiment without air release valves. The overall phenomena observed in this experiments was similar to the experimental run without air release valves. No significant difference in tunnel flow was observed.

The main difference was that air in the tunnel could not be vented out by the closed air release valves. Air entrapment occurred in both drop 
shaft and tunnel during the early stage of filling as shown in Figure 5-8.

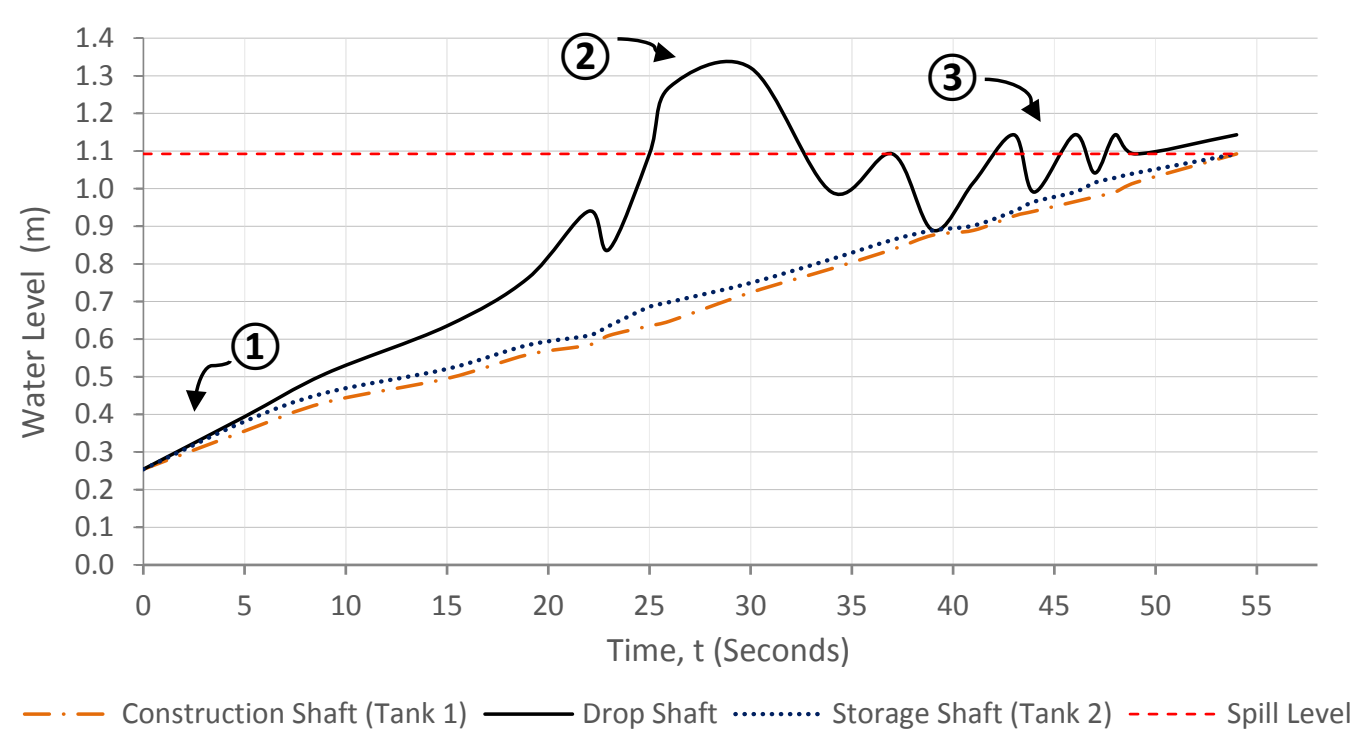

Figure 5-7. Experimental Result with Entrapped Air in Drop Shaft and Tunnel (Closed Air Release Valves)

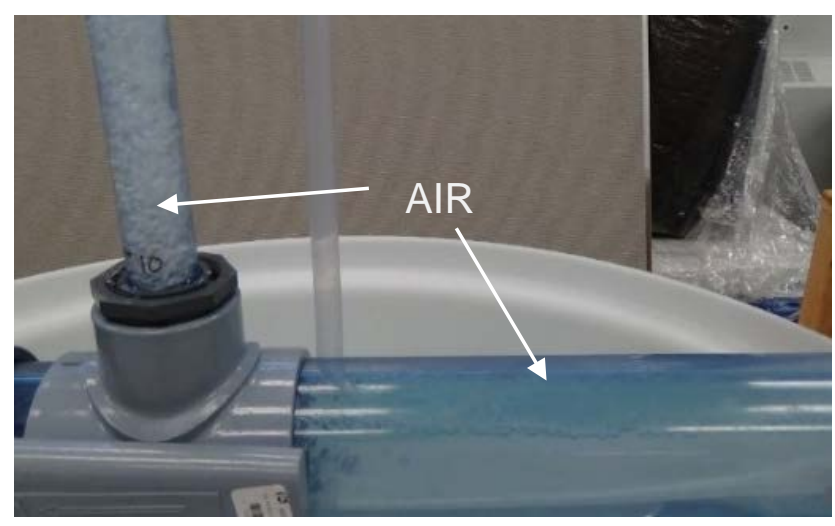

Figure 5-8. Air Pocket in Drop Shaft and Tunnel without Air Release Valves

Oscillation of the flow was observed after a geyser event near the end of the filling process, which was not observed in the experiment 
conducted with air release valves opened. Flow oscillations with irregular pattern continued in smaller amplitude of less than $0.1 \mathrm{~m}$ until the water level reached equilibrium. This oscillation may be due to the cushioning effect of the entrapped air pockets that remained in the tunnel, and the irregular oscillation pattern may be due to the downward force of the continuous inflow and upward buoyant force of the entrained air in the drop shaft.

When the air release valves were opened, the strength of geyser increased by approximately $11 \%$ as shown in Table 5-1. Nevertheless, it should be noted that opening the air release valves also resulted in a geyser event that reached $0.180 \mathrm{~m}$ above the spill level when the hydraulic grade line remained $0.328 \mathrm{~m}$ below the spill level. In summary, the entrapped air in the drop shaft caused a significant hydraulic impact while

Table 5-1. Geyser Height With and Without Air Release Valves

\begin{tabular}{|c|c|c|c|}
\hline $\begin{array}{c}\text { Air release } \\
\text { valves }\end{array}$ & $\begin{array}{c}\text { Geyser height } \\
(\mathrm{m})\end{array}$ & $\begin{array}{c}\text { Equilibrium water level } \\
(\mathrm{m})\end{array}$ & $\begin{array}{c}\text { Geyser above equilibrium } \\
(\mathrm{m})\end{array}$ \\
\hline Open & 1.270 & 0.762 & 0.508 \\
\hline Closed & 1.321 & 0.749 & 0.572 \\
\hline
\end{tabular}




\subsubsection{Air Ventilation Shaft in Prototype}

One of the vertical stormwater storage systems, the Western Beaches Tunnel, is constructed 40 to $50 \mathrm{~m}$ below grade. Unlike the air release valves installed on top of the horizontal conveyance tunnel in this scale model, ventilation shafts in the prototype are extended to ground surface level, and they can also be filled with water during storm events. Figure 5-9 illustrates a schematic of air flow in a system with a ventilation shaft near a drop shaft during filling.

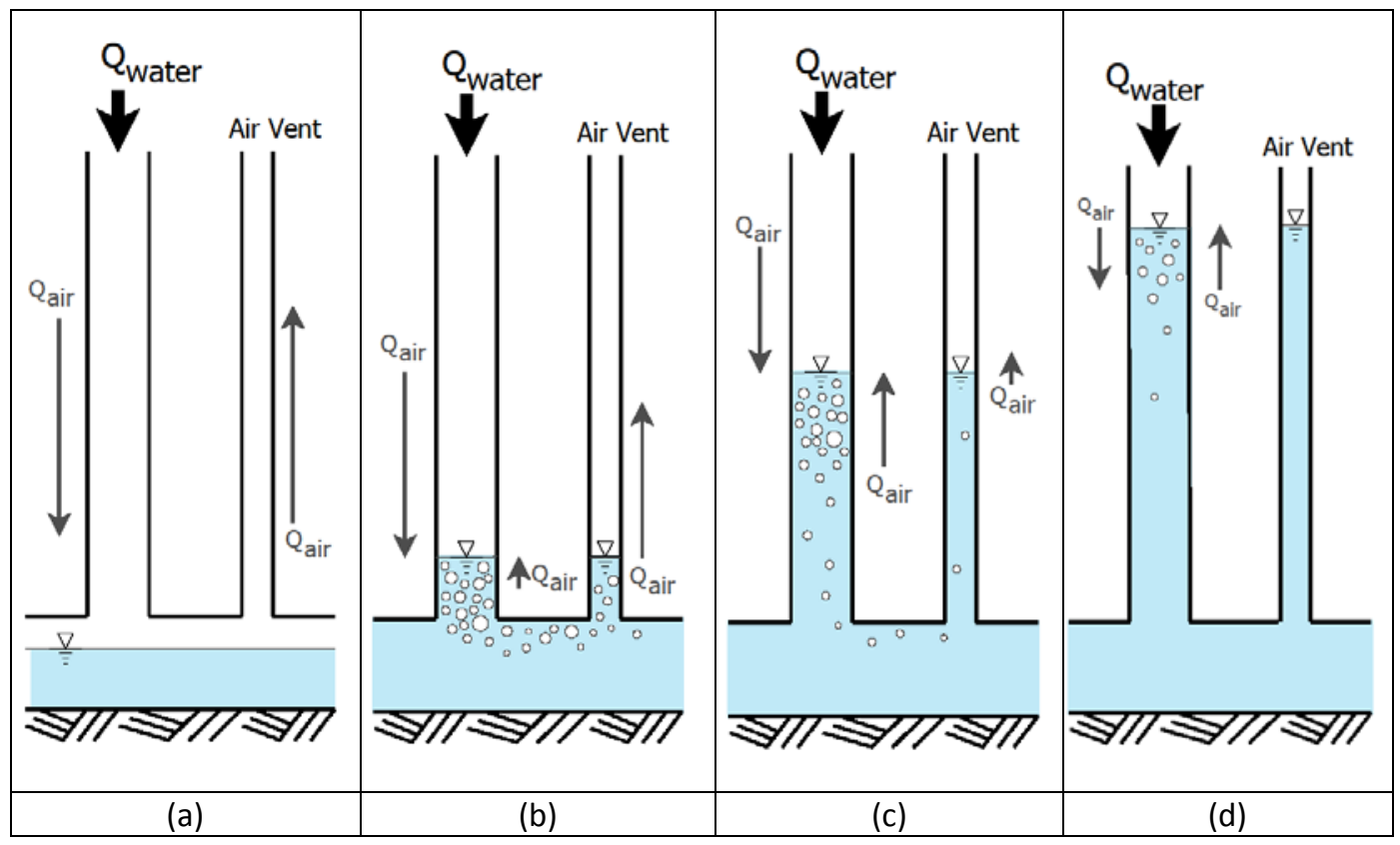

Figure 5-9. Schematic of Air Flow in a Shaft and an Air Ventilation Shaft

(Modified from Fok 2015) 
Ventilation shafts are most effective when the tunnel is partially filled, as shown in Figure 5-9 (a). With continuous filling, the system becomes surcharged, and the amount of air transported from drop shaft to the tunnel is reduced as shown in Figure 5-9 (b). As described in previous sections, air entrainment in drop shaft due to the impact of high velocity inflow have the potential to cause geyser because large entrapped air pockets travel upward and be released at the shaft.

During the intermediate stage of filling, the air release valves installed on top of horizontal tunnel in the physical scale model were ineffective in eliminating entrained air pockets in the drop shaft because the air pockets could not be transported to the bottom of drop shaft and to tunnel where the valves were installed. This implies that air ventilation shafts in the prototype can also be ineffective in eliminating entrained air pockets in the vertical shafts and in preventing the flow instability and pressurization that occurs in drop shaft due to air entrainment during the intermediate stage of filing.

Furthermore, ventilation shafts can also be impacted by entrapped air in the system if the velocity of the tunnel flow is higher and air pockets in the tunnel are travelling towards the ventilation shaft. 
Figure 5-10 shows the observations from an experiment in which a continuous inflow of $1.2 \mathrm{~L} / \mathrm{s}$ was introduced to storage shaft $\# 1$, and a continuous inflow of $0.4 \mathrm{~L} / \mathrm{s}$ was introduced to drop shaft. The inflow was introduced from top of the storage shaft to let it plunge into the water pool. This allowed the flow to generate large air pockets that can be transported by the tunnel and arrive at the drop shaft during the early and intermediate stages of filling.

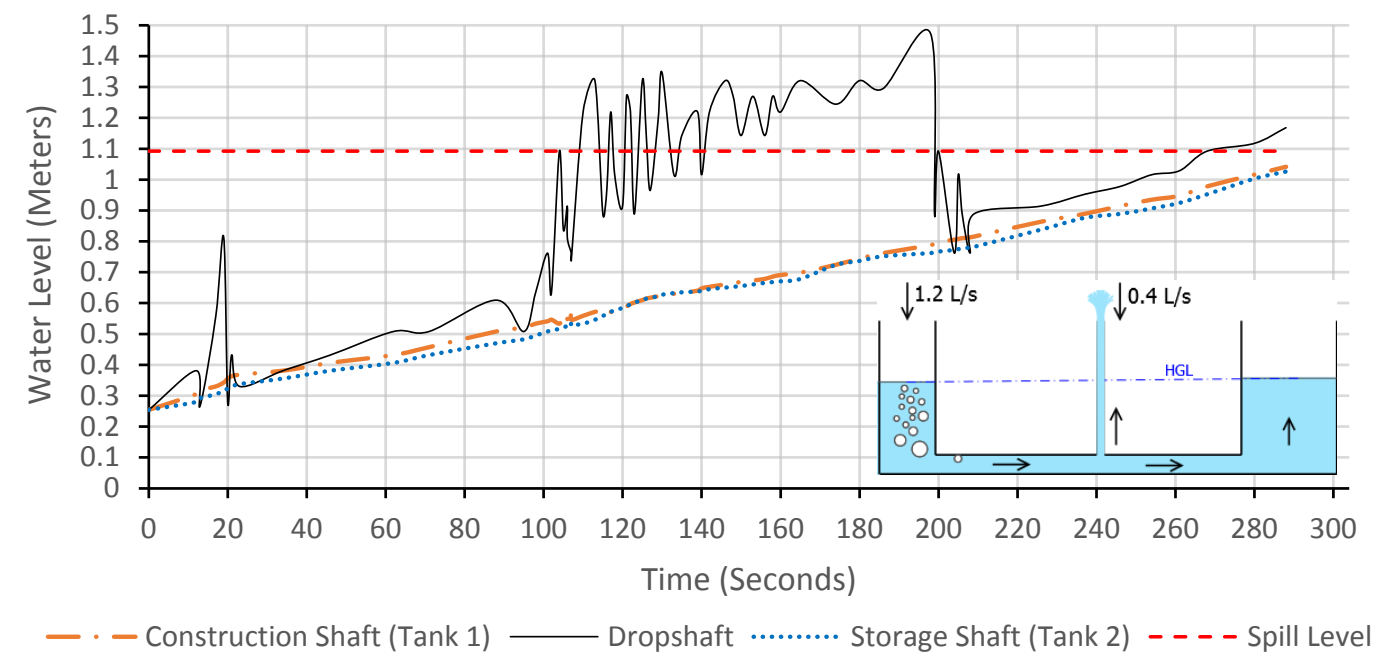

Figure 5-10. Experimental Result with Air Pockets Travelling Towards Drop Shaft

In the early stage, a large air pocket from the tunnel lifted a water column in the drop shaft approximately $0.5 \mathrm{~m}$ above the hydraulic grade line due to buoyant force. As the filling continued, fluctuation in water level 
became more severe, and the release of air pockets resulted in stronger geyser events that reached the spill level.

Since a ventilation shaft near a drop shaft can show similar hydraulic behaviours as a drop shaft near a vertical storage shaft, it was assumed that the storage shaft $\# 1$ is equivalent to drop shaft, and drop shaft is equivalent to ventilation shaft in the prototype. This experiment shows that it may be possible for a geyser to occur at a ventilation shaft in prototype when the air entrained in the drop shaft is released at the ventilation shaft, which is submerged during filling.

\subsection{Effects of Mass Oscillation}

Continuous inflow to vertical shafts without air in the system resulted in a steady and uniform water level rise in all three vertical shafts during filling. This indicated that there is no potential for flow oscillation or a geyser event at a drop shaft in an ideal condition in which experimental variables do not change and air can be completely removed from the system. However, oscillations can occur in vertical storage systems since the initial conditions can always change during filling. The occurrence of geyser at the drop shaft due to flow oscillations showed that hydraulic issues can still occur even 
without entrapped air in the system.

\subsection{1. $\quad$ Rapid Start and Stoppage of Inflow}

The main finding during this study was the effects of flow oscillation due to rapid start and stoppage of inflow at the drop shaft. Figure 5-11 illustrates an experiment that showed the typical behaviours observed during this study. The control valve (Valve $\# 2$ ) at the downstream end of the tunnel was closed to remove Shaft $\# 1$ and simplify the system. A continuous inflow of $7 \mathrm{~L} / \mathrm{s}$ was introduced into Shaft $\# 2$. Rapid start and stoppage of drop shaft inflow $\left(Q_{D}\right)$ were performed during filling to observe how the flow oscillates in this closed system.

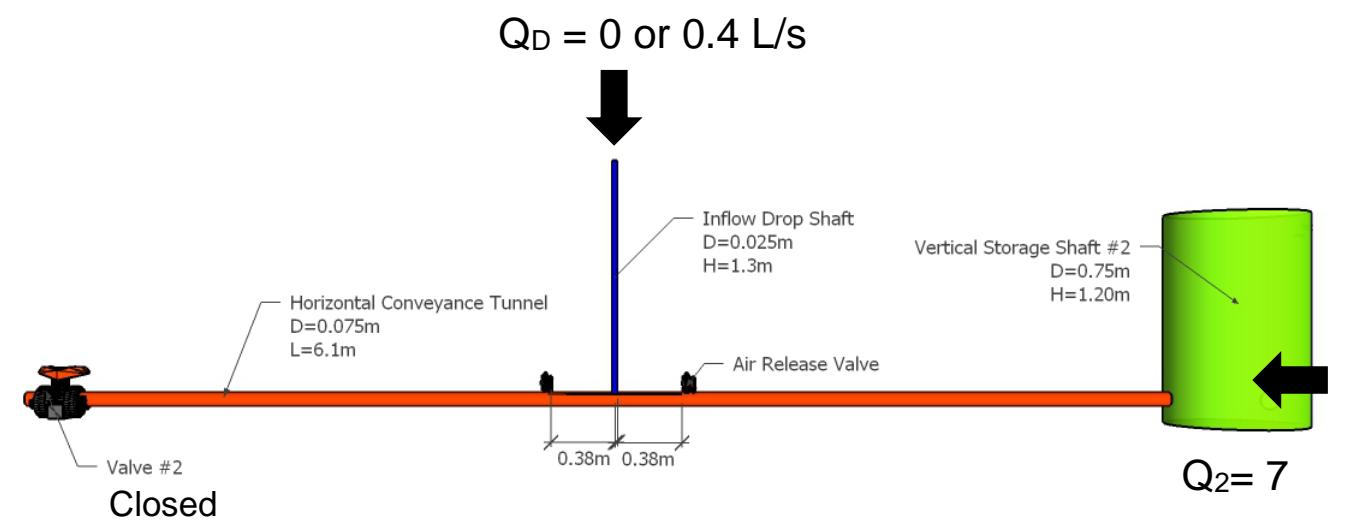

Figure 5-11. Experiment with Rapid Start and Stoppage of Drop Shaft Inflow 
Different flow behaviours occurred at the drop shaft during this experiment, as shown in Figure 5-12, and these are divided into six stages: (a) early stage at $\mathrm{t}=0-15^{-} \mathrm{s}$, (b) rapid start of drop shaft inflow at $\mathrm{t}=15 \mathrm{~s}$, (c) intermediate stage at $\mathrm{t}=15^{+}-37^{-} \mathrm{s}$, (d) rapid stop of drop shaft inflow at $\mathrm{t}=37 \mathrm{~s}$, and (e) final stage at $\mathrm{t}=37^{+}-50 \mathrm{~s}$.

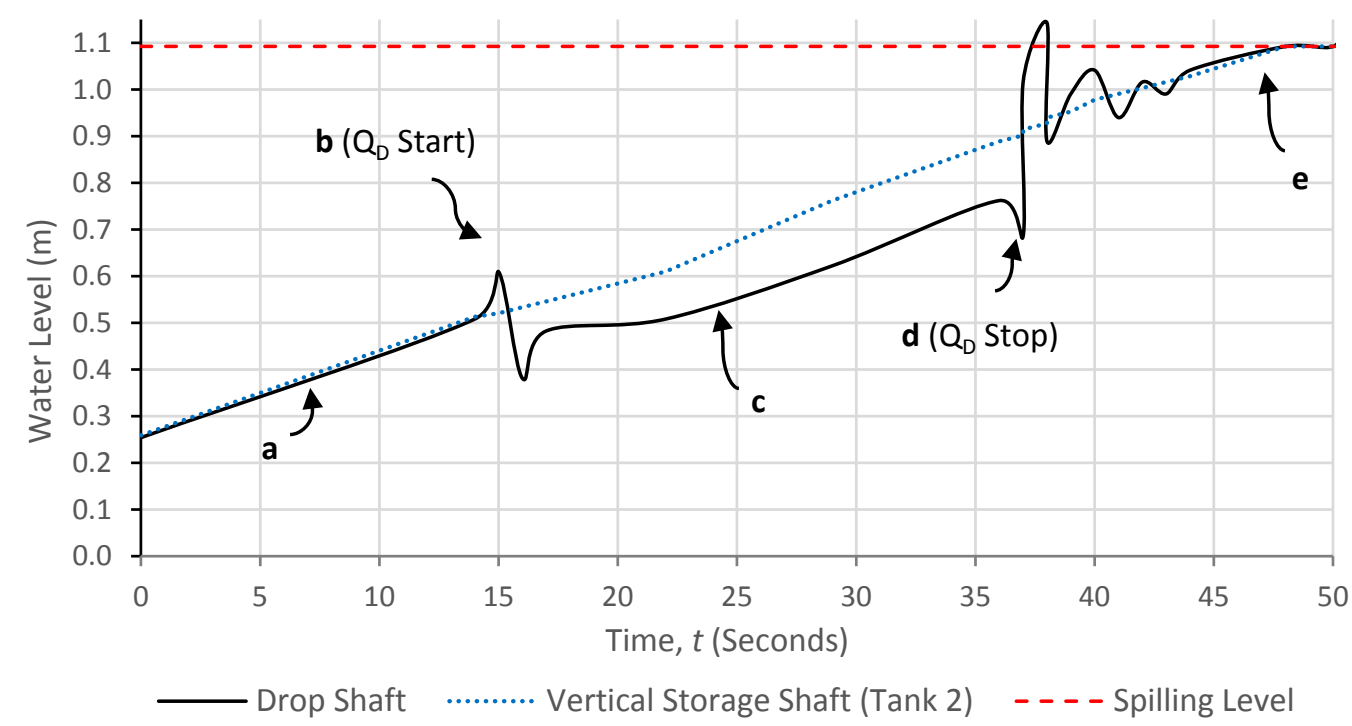

Figure 5-12. Water Level over Time for Flow Oscillation Study

The figures below illustrate the flow behaviours in each stage where: $\mathrm{Q}_{2}=$ pump flow rate at the upstream of the storage shaft \#2; $\mathrm{QSS}_{\mathrm{SS}}=$ filling rate in the storage shaft $\# 2 ; \mathrm{Q}_{\mathrm{T}}=$ tunnel flow rate; $\mathrm{Q}_{\mathrm{D}}=$ inflow rate into the drop shaft; and, QDS=filling rate in the drop shaft. 


\section{(a) Early stage at $\mathrm{t}=0-15^{-} \mathrm{s}$}

Initially, the tunnel was filled up and the system was static with no water movement. At $\mathrm{t}=0$, the filling of the vertical shafts was initiated by introducing an inflow of $7 \mathrm{~L} / \mathrm{s}$ from the pump to Shaft \#2. A steady rise of water level at the shafts was observed while the water level at the drop shaft was maintained $0.005 \mathrm{~m}$ below the water level at the storage shaft $\# 2$ due to friction loss. As shown in Figure 5-13, most of the $7 \mathrm{~L} / \mathrm{s}$ pump flow was used to fill the storage shaft, and the tunnel flow from Shaft $\# 2$ to the drop shaft was only $0.009 \mathrm{~L} / \mathrm{s}$.

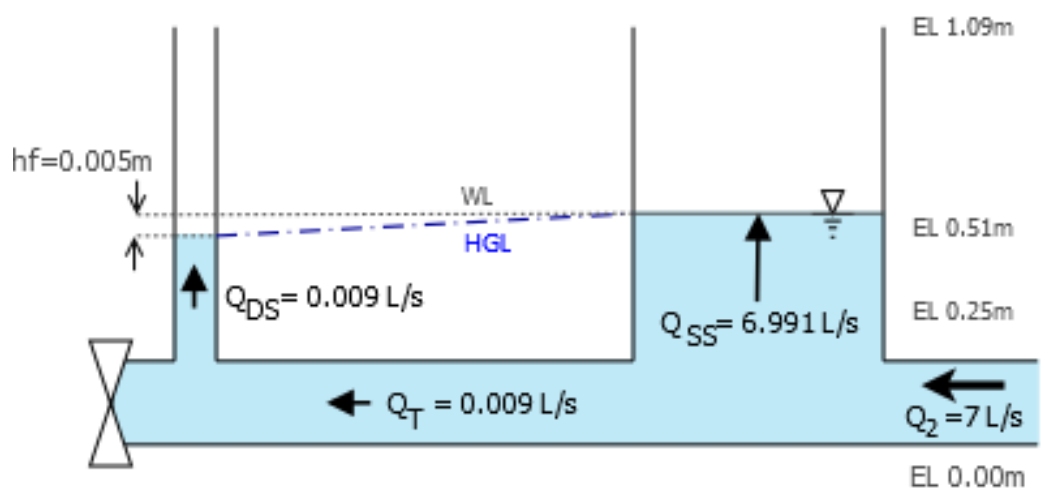

Figure 5-13. Schematic of Flows in Stage (a) 


\section{(b) Rapid start of drop shaft inflow at $t=15 \mathrm{~s}$}

At $\mathrm{t}=15^{-}$, an inflow of $0.4 \mathrm{~L} / \mathrm{s}\left(\mathrm{QD}_{\mathrm{D}}\right)$ was rapidly started at the drop shaft while $Q_{2}$ was still being pumped into the system. Immediately, the water level at the drop shaft jumped approximately $0.095 \mathrm{~m}$ in less than 1 second as the shaft was being filled with $\mathrm{QD}_{\mathrm{D}}$ as well as $\mathrm{Q}_{\mathrm{T}}$ that continued to flow from the storage shaft to the drop shaft.

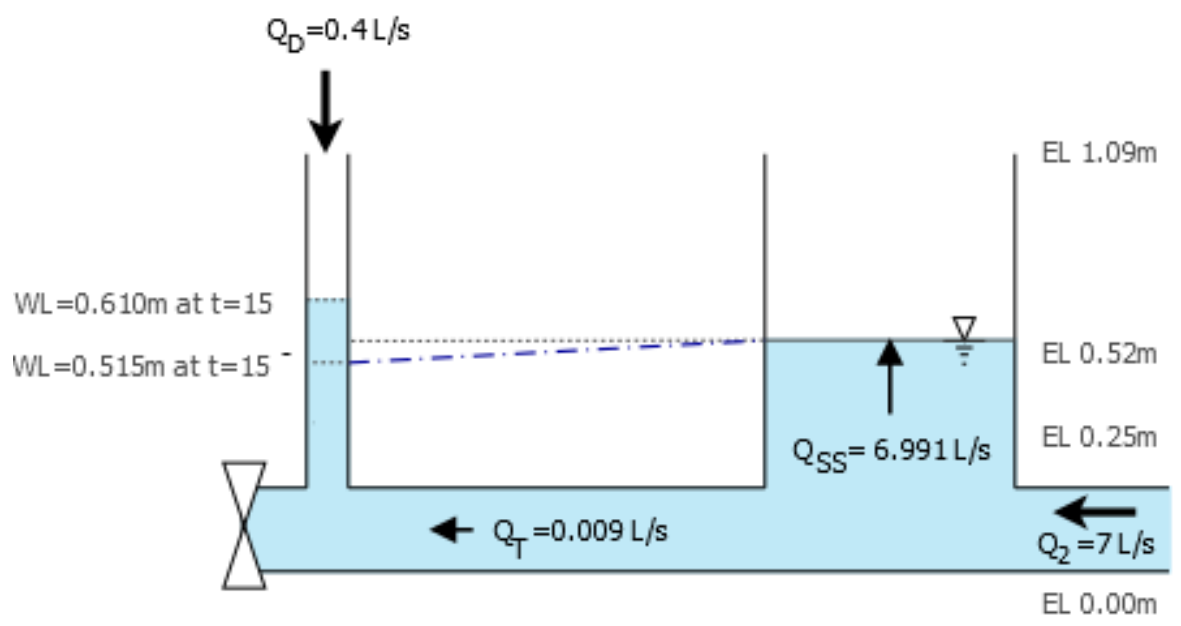

Figure 5-14. Schematic of Flows in Stage (b) at $\mathrm{t}=15^{-} \mathrm{s}$

At $\mathrm{t}=15^{+}$, the direction of $\mathrm{Q}_{\mathrm{D}}$ and $\mathrm{Q}_{\mathrm{T}}$ was reversed due to the rapid water level rise in the drop shaft. The water level rebounded back and dropped more than $0.2 \mathrm{~m}$ as shown in Figure 5-15. 


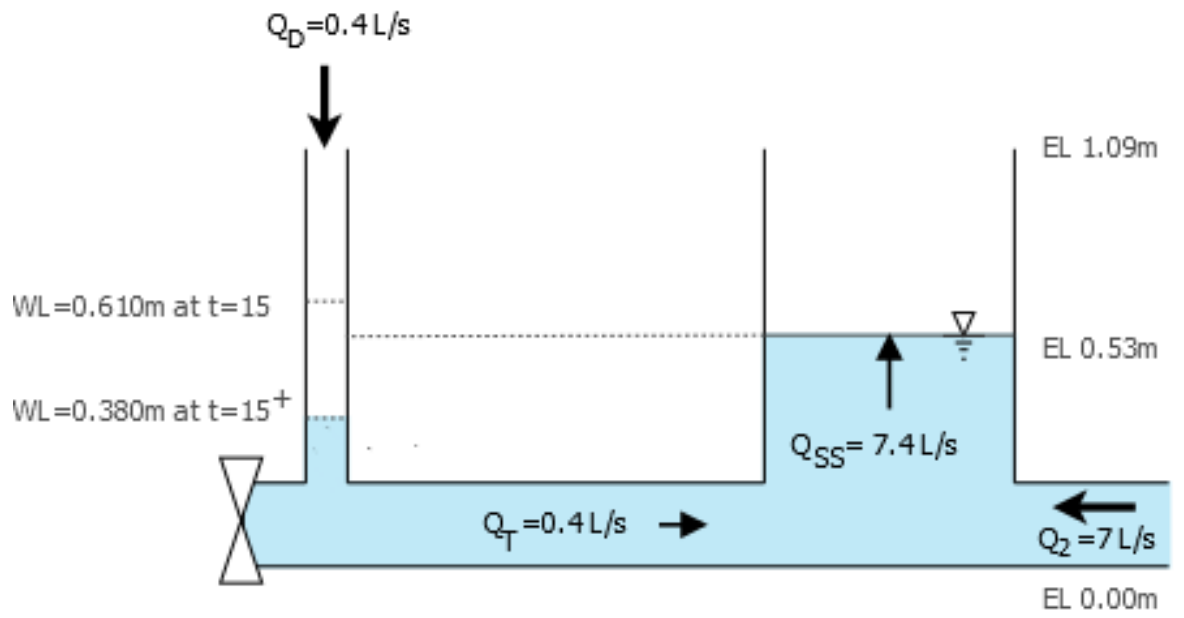

Figure 5-15. Schematic of Flows in Stage (b) at $\mathrm{t}=15^{+} \mathrm{s}$

(c) Intermediate stage at $\mathrm{t}=15^{+}-37^{-} \mathrm{s}$

Shortly after the water level dropped to $0.38 \mathrm{~m}$ at $\mathrm{t}=15^{+}$, it bounced back up about $0.1 \mathrm{~m}$ to $0.48 \mathrm{~m}$, and the water level stabilized. All experimental conditions remained the same. The actual water level in the drop shaft was about $0.1 \mathrm{~m}$ below the equilibrium water level. This is due to the downward force of jet-like inflow with a velocity of $2 \mathrm{~m} / \mathrm{s}$ pushing the water column down in the drop shaft. However, the theoretical hydraulic grade line in the drop shaft was still approximately $0.2 \mathrm{~m}$ above the storage shaft, maintaining a steady tunnel flow of $0.392 \mathrm{~L} / \mathrm{s}$ from the drop shaft to the storage shaft during this stage as shown in Figure 5-16. 


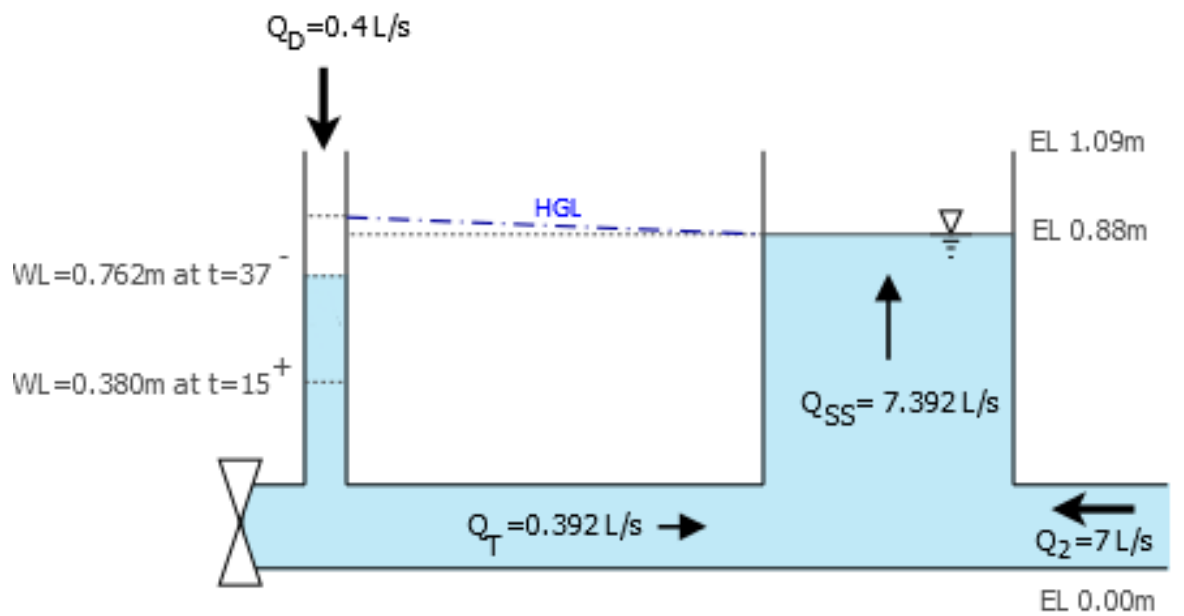

Figure 5-16. Schematic of Flows in Stage (c)

(d) Rapid stop of drop shaft inflow at $t=37 \mathrm{~s}$

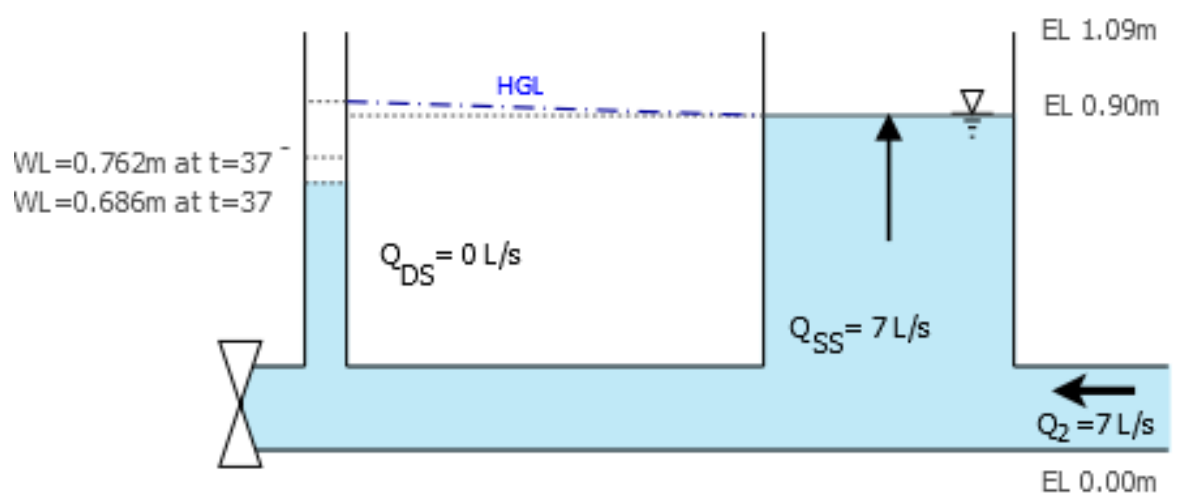

Figure 5-17. Schematic of Flows in Stage (d) at $\mathrm{t}=37 \mathrm{~s}$

At $\mathrm{t}=37^{-}$, the drop shaft inflow was rapidly stopped. The water level was $0.1 \mathrm{~m}$ below the equilibrium water level, but the hydraulic grade line was slightly above the water level at the storage shaft and the tunnel flow 
was still moving from the drop shaft to the storage shaft. This caused a slight sinking in the drop shaft water level that reached approximately 0.22 $\mathrm{m}$ below the equilibrium water level as shown in Figure 5-17. Then, QDS and $\mathrm{Q}_{\mathrm{T}}$ were briefly stopped.

Figure 5-18 shows that the tunnel flow later reversed from the storage shaft to the drop shaft due to the large difference of water level in two vertical shafts. While the change in water level due to this oscillation effect was difficult to observe in the $0.75 \mathrm{~m}$-diameter storage shaft, the momentum had significant impact on the 0.025 m-diameter drop shaft. A rapid water level rise of more than $0.46 \mathrm{~m}$, which resembled a geyser, occurred due to this oscillation effect. The equilibrium water level was at $0.92 \mathrm{~m}$ when the rising water column in the drop shaft reached $1.14 \mathrm{~m}$ above the spill level.

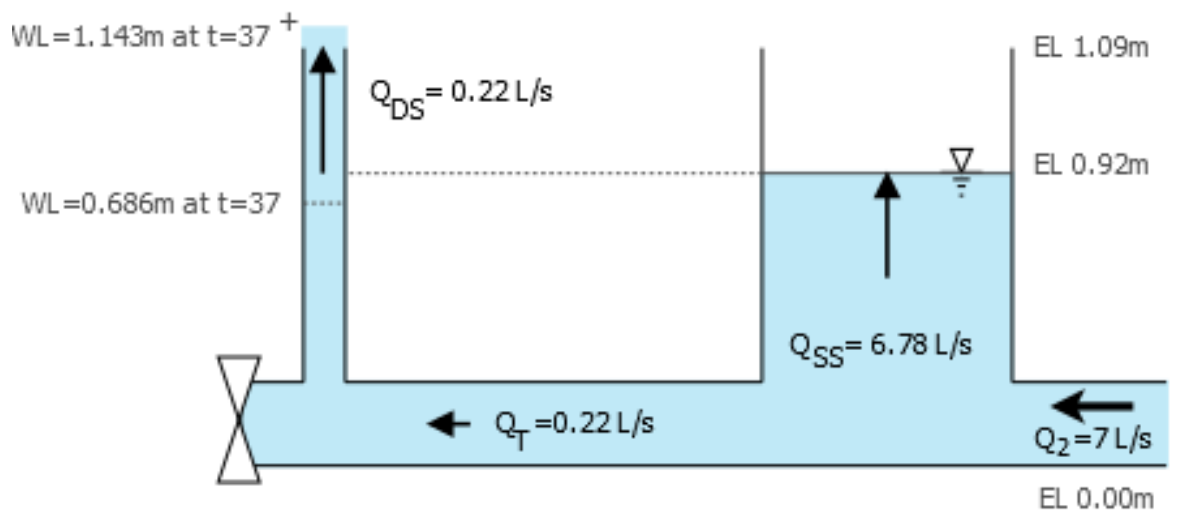

Figure 5-18. Schematic of Flows in Stage (d) at $\mathrm{t}=37^{+}$ 


\section{(e) Final stage at $\mathrm{t}=38-50 \mathrm{~s}$}

After the geyser event that occurred in stage (d), the water level at the drop shaft dropped down to $0.2 \mathrm{~m}$ below the equilibrium water level. Then, the water level in the drop shaft oscillated due to difference in water level until it reached equilibrium, and eventually reached the spill level. The two hydraulic grade line illustrated in the figure represents the water level fluctuation. The storage shaft was filled steadily as shown in the early stage.

Figure 5-19 shows a schematic of the flow during this stage.

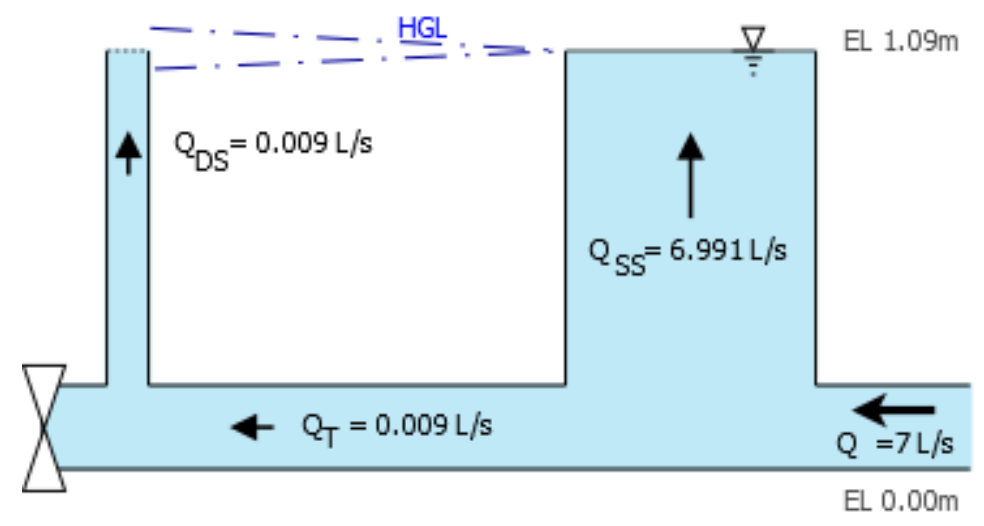

Figure 5-19. Schematic of Flow in Stage (e)

The experiment was repeated several times, and the inflow at drop shaft was stopped at different equilibrium water levels in order to investigate the relationship of rise height of water column and equilibrium water level in vertical shafts. Higher or lower equilibrium water level at the time of rapid 
stoppage of inflow did not show any difference in rise height of the water column, but it was more likely to reach the spill level if the equilibrium water level is higher and the distance for the water column to travel up to the spill level is shorter.

\subsubsection{Tunnel Gate Valve Operation}

Other scenarios that can cause flow oscillations in the system were also explored. While the rapid introduction of drop shaft inflow without air or a rapid opening of the valve at the downstream end of the conveyance tunnel did not result in a significant rise of the water column in the drop shaft, a rapid closure of the valve at the downstream of the tunnel caused a waterhammer-like effect, with a rapid rise of the water column at the drop shaft.

Closing the valves slowly for more than 5 seconds mitigated the effect significantly, but the design should consider rapid stoppage of pump in the line and blockage of the conveyance tunnel, both of which may result in similar behaviours in the prototype. 


\section{Chapter 6.}

\section{Numerical Simulations}

This chapter examined the numerical approaches on analyzing the vertical stormwater storage systems. Chapter 6.1 briefly describes the numerical model simulation of air in the system. Chapter 6.2 presents the results of the two of the most commonly used hydraulic modelling software, InfoWorks CS and HAMMER that simulated the mass oscillation without air in the system. The predictions of the numerical models for the mass oscillation study were compared with the experimental results.

\subsection{Air in Drop Shaft}

The interactions of air and water following air entrainment in drop shaft are 
highly complex, and it is difficult to be modelled numerically. The behaviour of entrapped air and turbulence is difficult to interpret by numerical methods alone. The computational fluid dynamic modelling approach using software, such as FLUENT, are currently used to model these flows with some success (Madhani, Kelson and Brown 2009). This is out of scope of the research in this thesis.

\subsection{Effects of Mass Oscillation}

The numerical models were developed using two of the commonly used hydraulic modelling softwares: InfoWorks CS and HAMMER to simulate the experiment discussed in the previous chapters.

The experiment that was discussed in Chapter 5.2.1 was simulated using InfoWorks CS. In this scenario, an inflow of $0.4 \mathrm{~L} / \mathrm{s}$ was introduced from the top of the inflow drop shaft for a period of time, and then rapidly stopped. A continuous inflow of $7 \mathrm{~L} / \mathrm{s}$ was introduced from upstream of the storage shaft $\# 2$ at all times during filling. The outlet of water hose was kept slightly below the surface level of the water column in the drop shaft, so that inflow dynamics still exist inside the shaft without air entrainment. 


\subsubsection{InfoWorks CS Simulation}

A numerical model developed by Fan and Fok (2014) with a similar physical characteristics of the prototype of the simple vertical stormwater storage system that was designed for this research. Due to the constraints of InfoWorks CS, a drop shaft with 0.025 m-diameter could not be simulated. This model consisted of five inflow drop shafts, instead of one.

The simulation result of the experimental run did not show a similar behaviour as the experimental result shown in Figure 5-12. The comparison of the experimental result and the simulation result is shown in Figure 6-1.

While it was predicted that the mass oscillation will be more dynamic with more drop shafts, the numerical simulation result showed relatively steady and uniform water level rise in the storage shaft and the drop shaft during the filling. This behaviour can be explained with one of the experiments that was conducted, which is shown in Figure 6-2. 


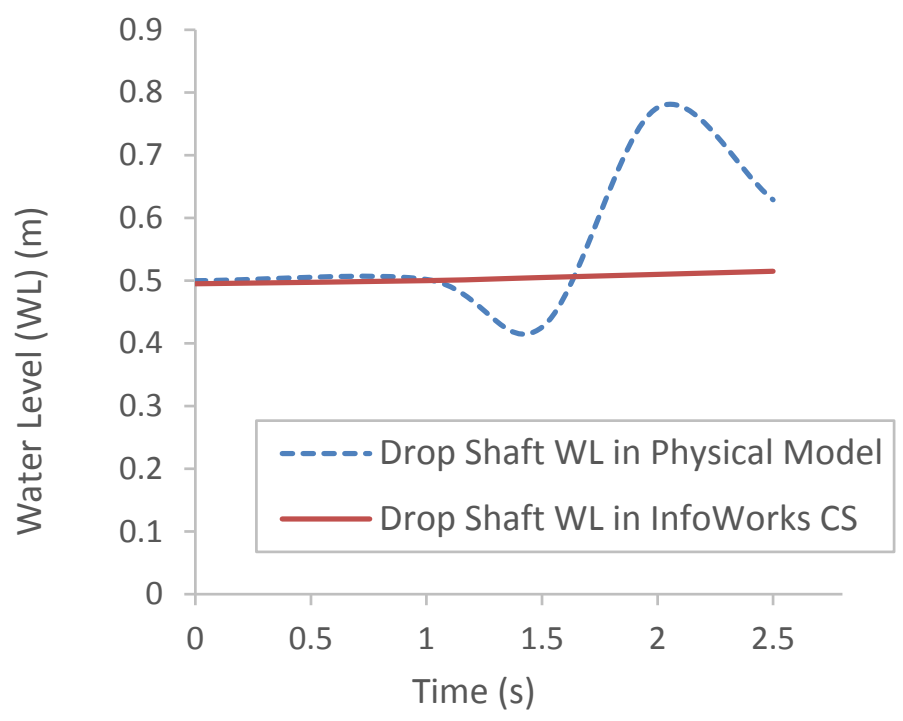

Figure 6-1. Comparison of Experimental and InfoWorks CS Simulation Results

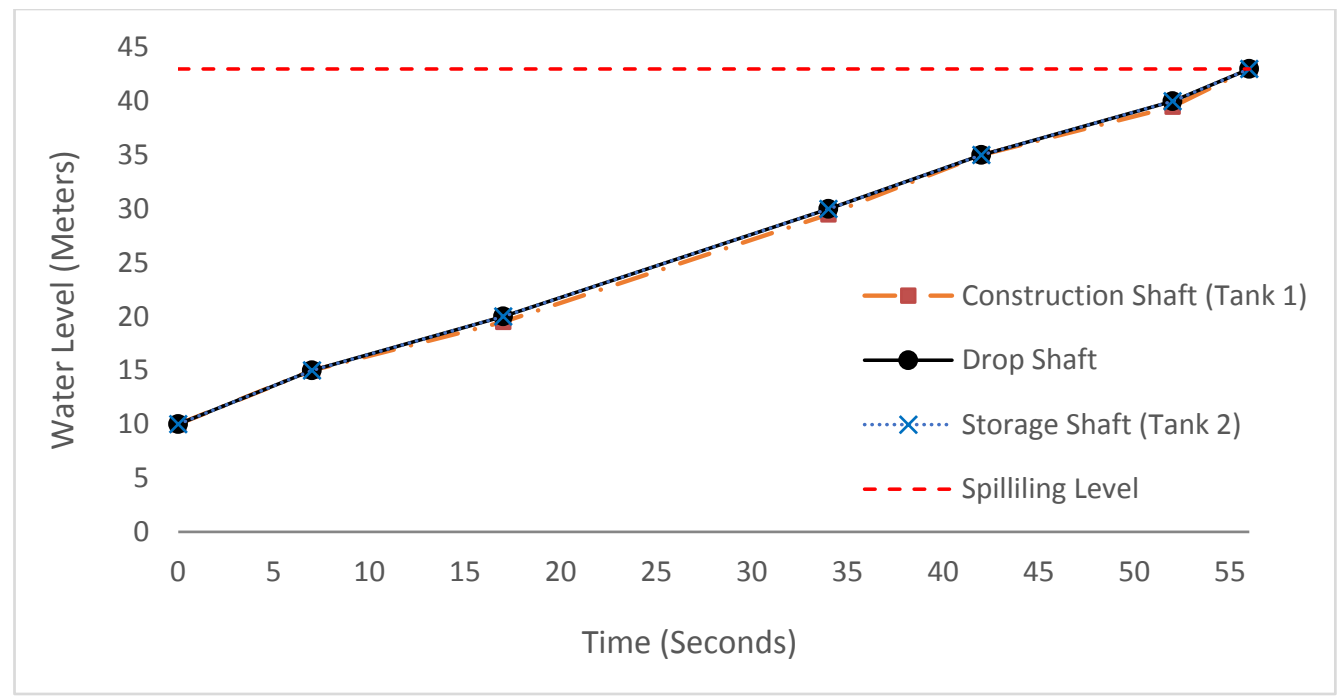

Figure 6-2. Experimental Result with No Inflow Dynamic At Drop Shaft 
The only difference in this experiment was that the outlet of water hose was kept at the bottom of the drop shaft to eliminate inflow dynamic inside the shaft during the entire filling process. The numerical model was used to simulate inflow falling down from the top of the shaft, but the result suggested that this numerical model considers the inflow to be introduced from the bottom of the shaft with no inflow dynamic conditions simulated in the drop shaft. This was also confirmed in writing by Innovyze (Fok 2015).

Although it was unsuccessful in simulating the vertical momentum in the drop shaft and predicting the flow behaviours due to its assumptions, it was able to simulate some of the other scenarios. Fan and Fok (2014) replicated a scenario that filled an empty horizontal tunnel in the system, and it was able predict accelerated filling at the upstream end of the tunnel near the end of the filling process as shown in Appendix B- 2 .

\subsubsection{HAMMER Simulation}

Similar to InfoWorks CS, HAMMER also showed difficulties in simulating inflow dynamics in the drop shaft. An older version of HAMMER from 2002 was modified by the original authors, Zemell and Fok (2015), in order to simulate the dynamics of inflow falling from the top of the shaft, as shown 
in Figure 6-3. The modified HAMMER model uses the MOC to account for the dynamics of full pipe flow in the horizontal tunnel with multiple drop shafts.

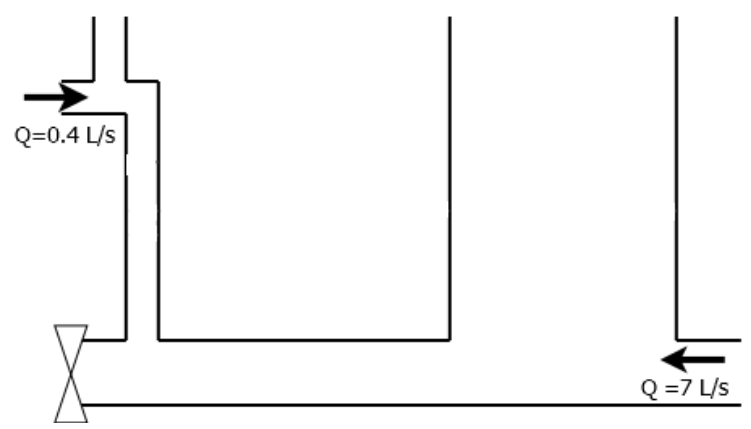

Figure 6-3. Schematic of Modified Numerical Model Using HAMMER

In this numerical model, a continuous inflow of $0.4 \mathrm{~L} / \mathrm{s}$ was introduced into the drop shaft until the water level reached $0.5 \mathrm{~m}$. Rapid stoppage of inflow resulted in a quick dive of water level to approximately $0.4 \mathrm{~m}$ and rebounded to $0.7 \mathrm{~m}$ as shown in Figure 6-4.

The amplitude of the flow oscillation observed in the experiment was more than twice the amplitude predicted in this numerical model. A possible explanation for this difference is the velocity of the drop shaft inflow used in the numerical model. As explained in Chapter 3.1.2, the internal diameter of water hose used to supply inflow into the drop shaft was $0.016 \mathrm{~m}$ and the actual velocity of the inflow was approximately $12 \mathrm{~m} / \mathrm{s}$. The numerical model 
assumes that the inflow is introduced over the cross section area of the drop shaft and applied the theoretical inflow velocity of approximately $5 \mathrm{~m} / \mathrm{s}$, resulting in smaller amplitude of flow oscillation.

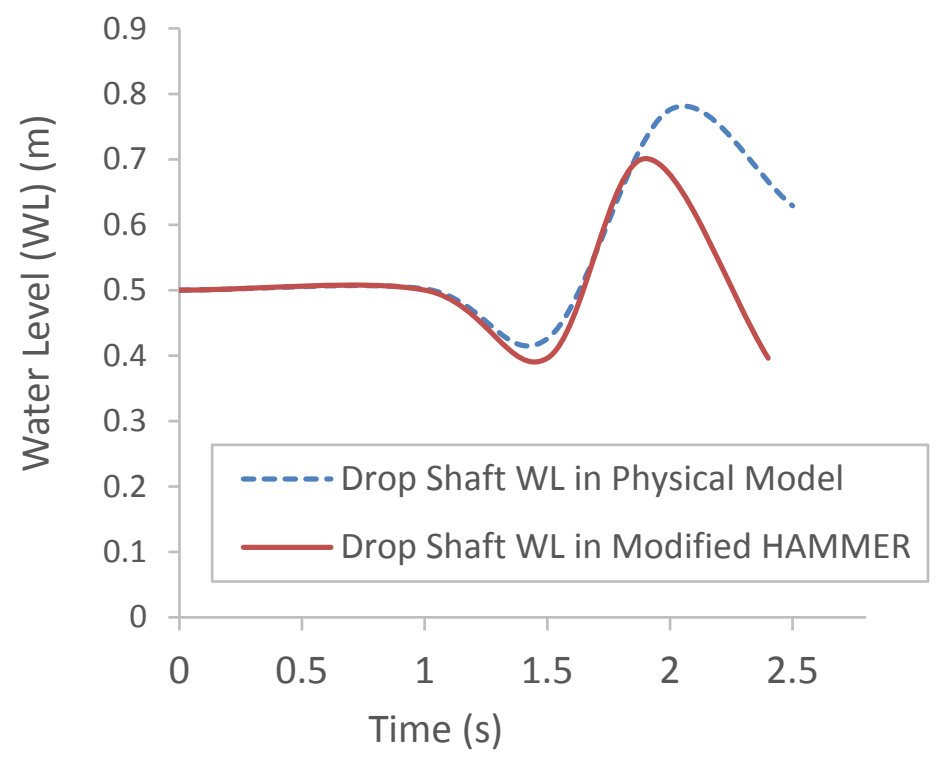

Figure 6-4. Comparison of Experimental and Modified HAMMER Simulation Results

Given the reduction in the high velocity inflow of the HAMMER simulation, the hydraulic grade line extremes at the drop shaft may be comparable to that of the physical scale model. 


\section{Chapter 7.}

\section{Conclusion and Recommendation}

\subsection{Conclusions}

This experimental investigation achieved its general objectives to study the hydrodynamics of drop shaft and to investigate the critical conditions that can potentially cause a rapid rise in the water level, or a geyser, at the inflow drop shaft during filling. The sensitivity of the hydraulic response at the drop shaft was also explored using experimental variables such as inflow rate, inflow locations, amount of air in the system, and opening and closing of valves in horizontal conveyance tunnel.

In a vertical stormwater storage system, the tunnel filling stage does not have a significant hydraulic impact on the system and the hydraulic issues in the tunnel may be terminated at over-sized storage shafts. 
Hydraulic issues such as mass oscillation may still exist in the tunnel segment between two over-sized storage shafts, based on an experimental study with a 1:40 scale model of a simple vertical stormwater storage system.

In this research, the focus was on the hydraulic conditions in the drop shaft and conclusions derived are summarized as follows:

- Geysers in a vertical storm water storage system can result from:

- Release of entrapped air at the drop shaft

- Mass oscillation due to the change of initial conditions

- Air release valves in the tunnel was ineffective in preventing geyser in the physical model of a simple vertical stormwater storage system.

- Some of the current hydraulic modelling software showed difficulties in simulating the flow momentum in the vertical shafts, thus future hydraulic models should consider drop shafts and tunnel as one integrated system

\subsection{Recommendations}

Various hydraulic problems discussed in this research are not only a concern 
for the storage system but also for upper infrastructures that are designed for free surface flow or low pressure and surcharge levels. Since hydraulic issues in the tunnel can potentially lead to major infrastructural damages in the upper sewer system as discussed in Chapter 1, it is recommended to address these problems in future work.

Experimental results and numerical model results presented herein are comparative as it was obtained from a small scale model with horizontal distortion and other constraints. Lewis, Wright and Vasconcelos (2011) noted that the general behaviour observed in a small scale model can be consistent with the behaviour that will occur in a prototype but it is also important to note that small scale models do not reproduce all phenomena that occur in large scale systems. Thus, further studies are recommended to investigate complex hydraulic interaction between the inflow drop shaft and the horizontal conveyance tunnel. A larger scale model can be built to determine whether the results obtained from small scale model is relevant to the prototype.

Further studies can be conducted by modifying the current physical model. Since only a single drop shaft was modelled in this study, it was necessary to pump water directly into the storage shaft to represent tunnel 
flow that was collected from multiple drop shafts. In the modified model, more inflow drop shafts can be added to the vertical storage shaft. This will extend the existing physical scale model to investigate hydraulic issues due to entrapped air and mass flow oscillation in more complex vertical storage systems.

Appendix B- 3 illustrates two examples of extended scale models with different configurations: one with a construction shaft, two storage shaft and five drop shafts, and one with two storage shafts and ten drop shafts. As shown in the second example, longer pipe for conveyance tunnel between vertical storage shafts will eliminate the horizontal distortion seen in this study.

In real-world situations, it is unlikely for inflows to vertical shafts to be continuous with a constant flow rate, or for inflow into a drop shaft to be started or stopped rapidly as simulated in this experiment. Non-uniform spatial distribution and variation in rainfall intensity can be considered in future studies. In order to better simulate the introduction of flow into the drop shafts, alternative drop shaft inlet configurations, such as vortex-type and helicoidal, can be used rather than the plunge-type drop shaft with a jet-like inflow. Different types of drop shaft should be investigated for its 
effectiveness in reducing the air entrainment rate and preventing hydraulic instabilities in the system.

To better simulate the dynamics of the system, the tunnel can be sloped to $0.25 \%$ or higher. In addition, a sedimentation study can be conducted by dropping coloured sediment particles into the drop shafts to estimate the speed of the particles and its movement in the tunnel.

Operational problems with air ventilation shaft can also be considered in the design process to accommodate different filling stages of vertical shafts. It will be helpful to incorporate measures such as the operation of real-time control valves and pumps to avoid mass oscillation in the system that can cause a significant impact on drop shafts.

Furthermore, the experimental results obtained can be used as input and boundary conditions for simulating the vertical stormwater storage system using a 3D simulation model, such as CFD.

Even with the limitations of the present physical scale model, the experimental investigations conducted in this thesis provided some insight that can inform future studies on vertical stormwater storage systems. 


\section{Appendices}


Appendix A

Additional Experimental Results 
Appendix A- 1. Experimental Results for Entrapped Air Study

\begin{tabular}{|c|c|c|c|c|c|c|c|c|c|c|c|c|c|c|}
\hline \multicolumn{6}{|c|}{ INPUT } & \multicolumn{9}{|c|}{ OUTPUT } \\
\hline $\begin{array}{l}\mathbf{Q}_{1} \\
(\mathrm{~L} / \mathrm{s})\end{array}$ & $\begin{array}{l}Q_{D} \\
(L / s)\end{array}$ & $\begin{array}{l}Q_{2} \\
(L / s)\end{array}$ & $\begin{array}{l}\text { Air } \\
\text { Entrain- } \\
\text { ment in } \\
\text { Shaft } 1\end{array}$ & $\begin{array}{c}\text { Air } \\
\text { Entrain- } \\
\text { ment in } \\
\text { Drop } \\
\text { Shaft }\end{array}$ & $\begin{array}{c}\text { Air } \\
\text { Release } \\
\text { Valves }\end{array}$ & $\begin{array}{l}\text { W.L } \\
@ \\
\text { Shaft } \\
1 \text { (m) }\end{array}$ & $\begin{array}{c}\text { W.L } \\
@ \\
\text { Drop } \\
\text { Shaft } \\
\text { (m) }\end{array}$ & $\begin{array}{c}\text { W.L. } \\
@ \\
\text { Shaft } \\
2(\mathrm{~m})\end{array}$ & $\begin{array}{c}Q_{T(D-1)} \\
(\mathrm{L} / \mathrm{s})\end{array}$ & $\begin{array}{c}\mathbf{Q}_{T(2-D)} \\
(\mathrm{L} / \mathrm{s})\end{array}$ & $\begin{array}{c}\mathrm{V}_{\mathrm{T}(\mathrm{D}-1)} \\
(\mathrm{m} / \mathrm{s})\end{array}$ & $\begin{array}{c}\mathrm{V}_{\mathrm{T}(2-\mathrm{D})} \\
(\mathrm{m} / \mathrm{s})\end{array}$ & Geyser & Comments \\
\hline \multirow{8}{*}{0} & \multirow{8}{*}{0.4} & 2 & No & Yes & Close & 1.02 & 1.02 & 1.02 & 0.22 & 0.03 & 0.05 & 0.01 & No & $\begin{array}{l}\text { Low tunnel flow velocity. The rise } \\
\text { speed W.L in the vertical shafts was } \\
\text { very slow. }\end{array}$ \\
\hline & & 5 & No & Yes & Close & 1.02 & 1.04 & 0.99 & 0.53 & 0.223 & 0.12 & 0.05 & No & $\begin{array}{c}\text { Drop shaft water level was oscillating } \\
\text { during filling. }\end{array}$ \\
\hline & & \multirow{3}{*}{7} & No & Yes & Close & 0.64 & 1.09 & 0.66 & \multirow{3}{*}{0.74} & \multirow{3}{*}{0.38} & \multirow{3}{*}{0.17} & \multirow{3}{*}{0.09} & Yes & $\begin{array}{l}\text { Significant amount of entrapped air } \\
\text { in the drop shaft. }\end{array}$ \\
\hline & & & No & Yes & Open & 0.64 & 1.09 & 0.66 & & & & & Yes & $\begin{array}{l}\text { Significant amount of entrapped air } \\
\text { in the drop shaft. }\end{array}$ \\
\hline & & & No & No & Open & 1.02 & 1.00 & 0.99 & & & & & No & $\begin{array}{l}\text { Steady and uniform W.L rise in all } \\
\text { three vertical shafts. }\end{array}$ \\
\hline & & \multirow{3}{*}{10} & No & Yes & Close & 0.69 & 1.09 & 0.72 & \multirow{3}{*}{1.02} & \multirow{3}{*}{0.8} & \multirow{3}{*}{0.23} & \multirow{3}{*}{0.18} & Yes & $\begin{array}{l}\text { Significant amount of entrapped air } \\
\text { in the drop shaft. }\end{array}$ \\
\hline & & & No & Yes & Open & 0.71 & 1.09 & 0.71 & & & & & Yes & $\begin{array}{l}\text { Significant amount of entrapped air } \\
\text { in the drop shaft. }\end{array}$ \\
\hline & & & No & No & Open & 1.02 & 1.03 & 1.04 & & & & & No & $\begin{array}{l}\text { Steady and uniform W.L rise in all } \\
\text { three vertical shafts. }\end{array}$ \\
\hline
\end{tabular}




\begin{tabular}{|c|c|c|c|c|c|c|c|c|c|c|c|c|c|c|}
\hline \multirow{4}{*}{1.2} & 0 & & Yes & Yes & Close & 1.02 & 1.02 & 1.02 & -1.08 & -1.07 & -0.24 & -0.24 & Yes & $\begin{array}{l}\text { Air from the storage shaft \#1 entered } \\
\text { the tunnel and was released at drop } \\
\text { shaft, lifting the water column } \\
\text { approximately } 0.2 \text { to } 0.5 \mathrm{~m} \text { in height } \\
\text { several times during the early stage } \\
\text { of filling. It did not reach the spill } \\
\text { level. }\end{array}$ \\
\hline & \multirow{3}{*}{0.4} & & Yes & Yes & Close & 0.51 & 1.09 & 0.51 & \multirow{3}{*}{-1.06} & \multirow{3}{*}{-1.22} & \multirow{3}{*}{-0.24} & \multirow{3}{*}{-0.28} & Yes & $\begin{array}{c}\text { Air entrained in both the storage } \\
\text { shaft \#1 and the drop shaft caused a } \\
\text { larger geyser event. }\end{array}$ \\
\hline & & & Yes & Yes & Open & 0.51 & 1.09 & 0.51 & & & & & Yes & $\begin{array}{l}\text { Air entrained in both the storage } \\
\text { shaft \#1 and the drop shaft caused a } \\
\text { larger geyser event. }\end{array}$ \\
\hline & & & No & No & Open & 1.02 & 1.02 & 1.02 & & & & & No & $\begin{array}{c}\text { Steady and uniform W.L rise in all } \\
\text { three vertical shafts. }\end{array}$ \\
\hline \multirow{6}{*}{2} & \multirow{3}{*}{0} & 0 & Yes & Yes & Close & 0.41 & 1.09 & 0.36 & \multirow{3}{*}{-1.85} & \multirow{3}{*}{-1.37} & \multirow{3}{*}{-0.42} & \multirow{3}{*}{-0.31} & Yes & $\begin{array}{l}\text { Air from the storage shaft } \# 1 \\
\text { resulted in geysers when it is } \\
\text { released at the drop shaft. W.L @ the } \\
\text { drop shaft stabilized at around } 0.6 \mathrm{~m}\end{array}$ \\
\hline & & & Yes & Yes & Open & 0.41 & 1.09 & 0.37 & & & & & Yes & $\begin{array}{c}\text { W.L @ the drop shaft stabilized @ } \\
\text { around } 0.5 \mathrm{~m}\end{array}$ \\
\hline & & & No & No & Open & 1.02 & 1.02 & 1.02 & & & & & No & $\begin{array}{l}\text { Steady and uniform W.L rise in all } \\
\text { three vertical shafts. }\end{array}$ \\
\hline & \multirow[t]{3}{*}{0.4} & & Yes & Yes & Close & 0.89 & 1.02 & 0.88 & \multirow[t]{3}{*}{-1.82} & \multirow[t]{3}{*}{-1.6} & \multirow[t]{3}{*}{-0.41} & \multirow[t]{3}{*}{-0.36} & Yes & $\begin{array}{l}\text { Air entrainment occurred both in the } \\
\text { storage shaft \#1 and the drop shaft, } \\
\text { resulting in more and larger geysers } \\
\text { when entrapped air is released. }\end{array}$ \\
\hline & & & Yes & Yes & Open & 0.89 & 1.02 & 0.88 & & & & & No & Same as above. \\
\hline & & & No & No & Open & 1.02 & 1.02 & 1.02 & & & & & No & $\begin{array}{c}\text { Steady and uniform W.L rise in all } \\
\text { three vertical shafts. }\end{array}$ \\
\hline
\end{tabular}




\begin{tabular}{|c|c|c|c|c|c|c|c|c|c|c|c|c|c|c|}
\hline \multirow{5}{*}{1.2} & \multirow{5}{*}{0.4} & \multirow{2}{*}{5} & Yes & Yes & Open & 1.02 & 1.02 & 0.00 & \multirow{2}{*}{-0.59} & \multirow{2}{*}{-5.47} & \multirow{2}{*}{-0.13} & \multirow{2}{*}{-1.24} & No & \multirow{2}{*}{$\begin{array}{c}\text { The velocity of the tunnel flow } \\
\text { towards the drop shaft was very low } \\
\begin{array}{c}\text { Steady and uniform W.L rise in all } \\
\text { three vertical shafts. }\end{array}\end{array}$} \\
\hline & & & No & No & Open & 1.02 & 1.02 & 1.02 & & & & & No & \\
\hline & & & Yes & Yes & Close & 0.79 & 1.09 & 0.77 & \multirow{3}{*}{-0.37} & \multirow{3}{*}{-7.48} & \multirow{3}{*}{-0.08} & \multirow{3}{*}{-1.69} & Yes & $\begin{array}{c}\text { A relatively slower geyser was } \\
\text { observed due to buoyant force of } \\
\text { entrapped air in the drop shaft. No } \\
\text { jet-like behaviour. }\end{array}$ \\
\hline & & I & Yes & Yes & Open & 0.79 & 1.09 & 0.77 & & & & & Yes & $\begin{array}{l}\text { Same as above experiment. No jet- } \\
\text { like behaviour. }\end{array}$ \\
\hline & & & No & No & Open & 1.02 & 1.02 & 1.02 & & & & & No & $\begin{array}{l}\text { Steady and uniform W.L rise in all } \\
\text { three vertical shafts. }\end{array}$ \\
\hline \multirow{7}{*}{2} & \multirow{7}{*}{0.4} & \multirow{2}{*}{2} & Yes & Yes & Close & 1.02 & 1.02 & 1.02 & \multirow{2}{*}{-1.59} & \multirow{2}{*}{-3.71} & \multirow{2}{*}{-0.36} & \multirow{2}{*}{-0.84} & Yes & \multirow{2}{*}{$\begin{array}{l}\text { Air from the storage shaft \#1 caused } \\
\text { small geysers at the drop shaft } \\
\text { during the early stage of filling. But it } \\
\text { did not reach the spill level. }\end{array}$} \\
\hline & & & Yes & Yes & Open & 1.02 & 1.02 & 1.02 & & & & & Yes & \\
\hline & & 5 & Yes & Yes & Close & 1.02 & 1.02 & 1.02 & \multirow[t]{2}{*}{-1.27} & \multirow[t]{2}{*}{-6.6} & \multirow[t]{2}{*}{-0.29} & \multirow[t]{2}{*}{-1.49} & Yes & $\begin{array}{l}\text { A relatively slower geyser was } \\
\text { observed due to buoyant force of } \\
\text { entrapped air in the drop shaft. No } \\
\text { jet-like behaviour. }\end{array}$ \\
\hline & & & No & No & Open & 1.02 & 1.02 & 1.02 & & & & & No & $\begin{array}{l}\text { Steady and uniform W.L rise in all } \\
\text { three vertical shafts. }\end{array}$ \\
\hline & & \multirow{3}{*}{7} & Yes & Yes & Close & 0.79 & 1.09 & 0.76 & \multirow{3}{*}{-0.94} & \multirow{3}{*}{-8.44} & \multirow{3}{*}{-0.21} & \multirow{3}{*}{-1.91} & Yes & No jet-like behaviour. \\
\hline & & & Yes & Yes & Open & 0.8 & 1.09 & 0.77 & & & & & Yes & $\begin{array}{l}\text { Same as above. Slightly smaller } \\
\text { geyser with air release valves open. }\end{array}$ \\
\hline & & & No & No & Open & 1.02 & 1.02 & 1.02 & & & & & No & $\begin{array}{c}\text { Steady and uniform W.L rise in all } \\
\text { three vertical shafts. }\end{array}$ \\
\hline
\end{tabular}

Note: $Q_{T(D-1)}=$ Tunnel Flow Rate from the Drop Shaft to the Storage Shaft \#1; $V_{T(D-1)}=$ Tunnel Flow Velocity from the Drop Shaft to the Storage Shaft \#1. 
Appendix A- 2. Experimental Results for Flow Oscillation Study

a) Rapid start and stoppage of drop shaft inflow

\begin{tabular}{|c|c|c|c|c|c|c|}
\hline \multicolumn{5}{|c|}{ INPUT } & \multicolumn{2}{|r|}{ OUTPUT } \\
\hline & $\begin{array}{c}Q_{D \_ \text {_nitial }} \\
(L / s)\end{array}$ & $\begin{array}{c}Q_{D_{\text {ffinal }}} \\
(\mathrm{L} / \mathrm{s})\end{array}$ & $\mathbf{Q}_{2(L / s)}$ & $\begin{array}{l}\text { W.L. when } \\
Q_{D} \\
\text { Changes }\end{array}$ & Geyser & Remark \\
\hline $\begin{array}{l}\text { Rapid Start of } \\
\text { Drop Shaft } \\
\text { Inflow }\end{array}$ & 0 & 0.4 & 7 & 0.5 & No & W.L jumped $0.095 \mathrm{~m}$ to $0.61 \mathrm{~m}$, then rebounded down to $0.38 \mathrm{~m}$. \\
\hline \multirow{4}{*}{$\begin{array}{l}\text { Rapid } \\
\text { Stoppage of } \\
\text { Drop Shaft } \\
\text { Inflow }\end{array}$} & \multirow{4}{*}{0.4} & \multirow{4}{*}{0} & 1 & 0.9 & No & $\begin{array}{l}\text { Initially, the water level at the drop shaft slightly sank. The magnitude of } \\
\text { oscillation was very small, because the filling rate at the storage shaft \#2 was } \\
\text { slow and there was not enough momentum. }\end{array}$ \\
\hline & & & 3 & 0.9 & Yes & $\begin{array}{l}\text { Initially, the water level at the drop shaft slightly sank. The magnitude of } \\
\text { oscillation was small between } 0.05 \mathrm{~m} \text { to } 0.1 \mathrm{~m} \text {, because the filling rate at the } \\
\text { storage shaft \#2 was slow and there was not enough momentum. }\end{array}$ \\
\hline & & & 5 & 0.9 & Yes & Same as above. The magnitude of geyser was $0.2 \mathrm{~m}$ to $0.3 \mathrm{~m}$. \\
\hline & & & 7 & 0.25 & No & $\begin{array}{l}\text { Initially, the water level at the drop shaft slightly sank. The magnitude of } \\
\text { oscillation was very small, because there was not enough momentum built in } \\
\text { the early stage of filling. }\end{array}$ \\
\hline
\end{tabular}


APPENDIX A

\begin{tabular}{|l|l|l|c|c|c|}
\hline & & & 0.5 & Yes & $\begin{array}{c}\text { Initially, the water level at the drop shaft slightly sank. The magnitude of } \\
\text { geyser was 0.3 } \mathrm{m} \text { to } 0.4 \mathrm{~m} .\end{array}$ \\
\cline { 3 - 5 } & & 0.9 & Yes & Same as above. The magnitude of geyser was $0.4 \mathrm{~m}$ to $0.5 \mathrm{~m}$. \\
\hline
\end{tabular}


b) Rapid closure of a tunnel gate valve

\begin{tabular}{|c|c|c|c|c|c|c|c|c|c|}
\hline \multicolumn{7}{|c|}{ INPUT } & \multirow[b]{2}{*}{$\begin{array}{l}\text { W.L } \\
\text { when a } \\
\text { valve is } \\
\text { closing }\end{array}$} & \multicolumn{2}{|r|}{ OUTPUT } \\
\hline $\begin{array}{l}Q_{D} \\
(L / s)\end{array}$ & $\begin{array}{l}Q_{2} \\
(L / s)\end{array}$ & $\begin{array}{c}\text { Valve } \\
\quad \# 1 \\
\text { (Initial) }\end{array}$ & $\begin{array}{l}\text { Valve } \\
\# 1 \\
\text { (Final) }\end{array}$ & $\begin{array}{c}\text { Valve } \\
\quad \# 2 \\
\text { (Initial) }\end{array}$ & $\begin{array}{c}\text { Valve } \\
\quad \# 2 \\
\text { (Final) }\end{array}$ & $\begin{array}{c}\text { Valve } \\
\text { Closing } \\
\text { Time }\end{array}$ & & $\begin{array}{c}\text { W.L @Drop Shaft } \\
\text { Reached the Spill } \\
\text { Level? }\end{array}$ & Remark \\
\hline \multirow{5}{*}{0} & \multirow{5}{*}{7} & \multirow{5}{*}{ Close } & \multirow{5}{*}{ Close } & \multirow{5}{*}{ Open } & \multirow{5}{*}{ Close } & \multirow{2}{*}{1} & 0.5 & Yes & $\begin{array}{l}\text { The rapid valve closure resulted in a rapid rise of } \\
\text { water level at the drop shaft. }\end{array}$ \\
\hline & & & & & & & 1 & Yes & " \\
\hline & & & & & & \multirow{2}{*}{5} & 0.5 & No & Slow valve closure was able to prevent geyser. \\
\hline & & & & & & & 1 & Yes & " \\
\hline & & & & & & 10 & 1 & No & " \\
\hline \multirow[t]{2}{*}{0.4} & \multirow[t]{2}{*}{7} & \multirow[t]{2}{*}{ Close } & \multirow[t]{2}{*}{ Close } & \multirow[t]{2}{*}{ Open } & \multirow[t]{2}{*}{ Close } & \multirow[t]{2}{*}{1} & 0.5 & Yes & $\begin{array}{c}\text { Similar to the experiments shown above. With } \\
\text { an inflow to the drop shaft, the magnitude of } \\
\text { oscillation due to rapid closure of valve is slightly } \\
\text { increased. }\end{array}$ \\
\hline & & & & & & & 1 & Yes & " \\
\hline
\end{tabular}


APPENDIX A

\begin{tabular}{|c|c|c|c|c|c|c|c|c|c|}
\hline & & & & & & 5 & 0.5 & No & $\begin{array}{l}\text { The water level at the drop shaft rose } \\
\text { approximately } 0.2 \mathrm{~m} \text {, and it could not reach the } \\
\text { spill level. }\end{array}$ \\
\hline & & & & & & & 1 & Yes & " \\
\hline & & & & & & 10 & 1 & No & Slow valve closure was able to prevent geyser. \\
\hline \multirow{5}{*}{0} & \multirow{5}{*}{7} & \multirow{5}{*}{ Open } & \multirow{5}{*}{ Close } & \multirow{5}{*}{ Open } & \multirow{5}{*}{ Open } & \multirow[t]{2}{*}{1} & 0.5 & Yes & $\begin{array}{l}\text { With the discharge valve (Valve \#1) open, the } \\
\text { velocity of the tunnel flow is very high compared } \\
\text { to the tunnel flows in other experiments. This } \\
\text { caused stronger water-hammer-like behaviour. }\end{array}$ \\
\hline & & & & & & & 1 & Yes & " \\
\hline & & & & & & \multirow{2}{*}{5} & 0.5 & Yes & " \\
\hline & & & & & & & 1 & Yes & " \\
\hline & & & & & & 10 & 1 & No & Slow valve closure was able to prevent geyser. \\
\hline
\end{tabular}


Appendix B

Additional Figures 
Appendix B- 1. An Example of Localized Rain Events in Toronto

a) July 8th, $2013 @ 3: 50$ PM

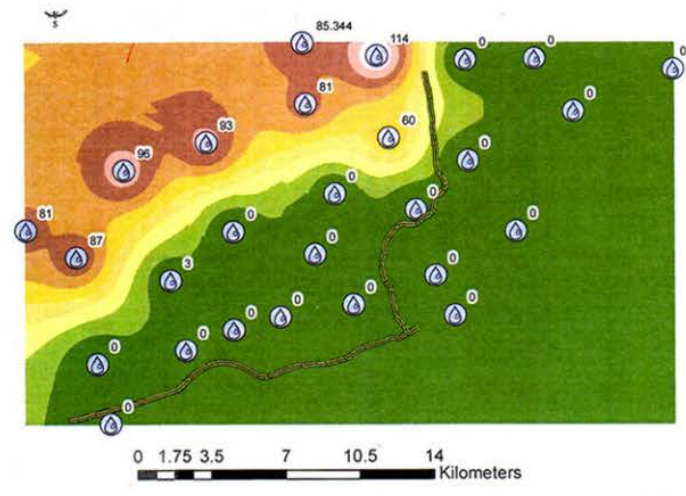

b) July 8th, $2013 @$ 4:00 PM

$$
\text { 为。 }
$$

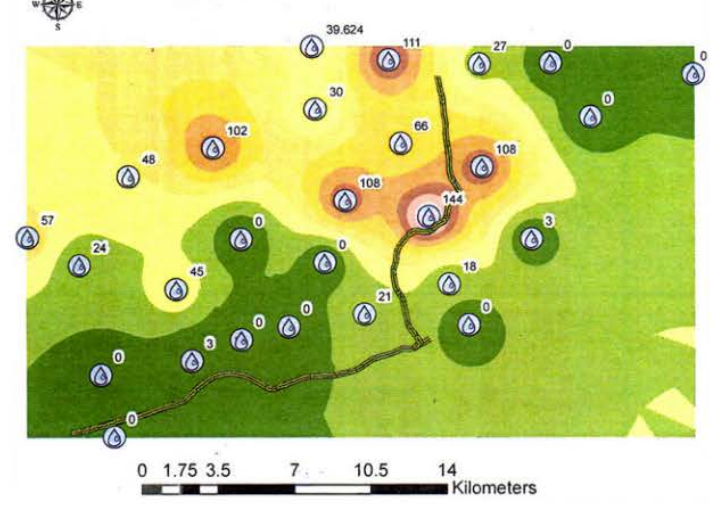

c) July 8th, $2013 @ 4: 10$ PM

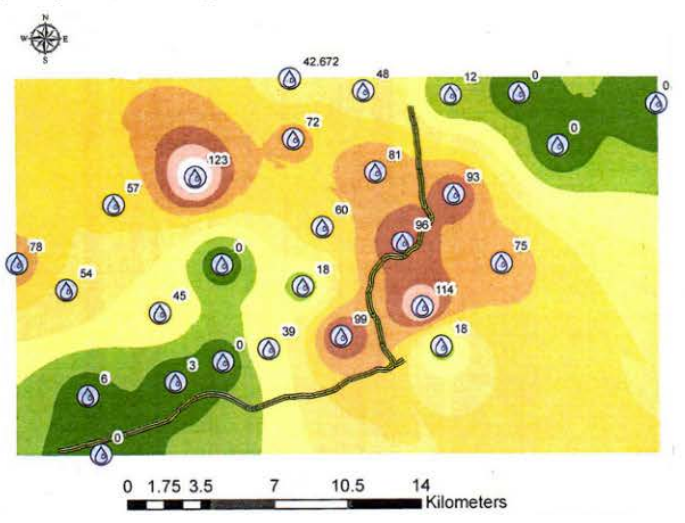

\section{Legend}

ב Gardiner_and_Don_Valley_Parkway

(C) Rainfall Intensity measured in $\mathrm{mm} / \mathrm{hr}$

$0.001267552-13.33437358$

$13.33437359-26.66747961$ $26.66747962-40.00058564$ $40.00058565-53.33369166$

$53.33369167-66.66679769$ $66.6667977-79.99990372$ $79.99990373-93.33300975$ $93.33300976-106.6661158$ 106.6661159 - 119.9992218 
Appendix B- 2. Schematic of Storage Tunnel Filling (Fok 2015)

a) Early Filling

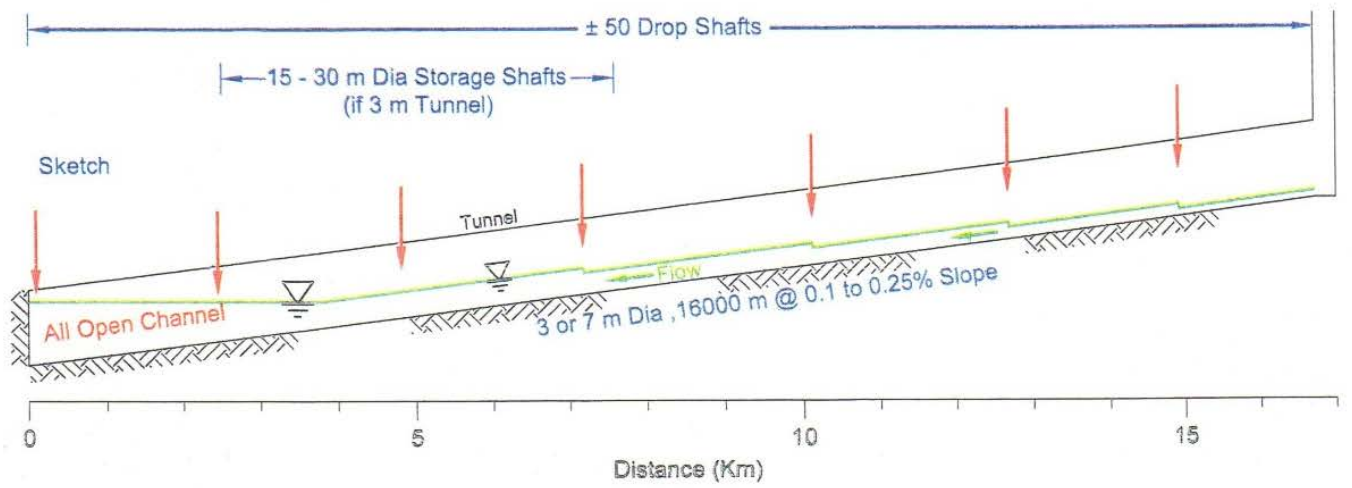

b) Late Filling

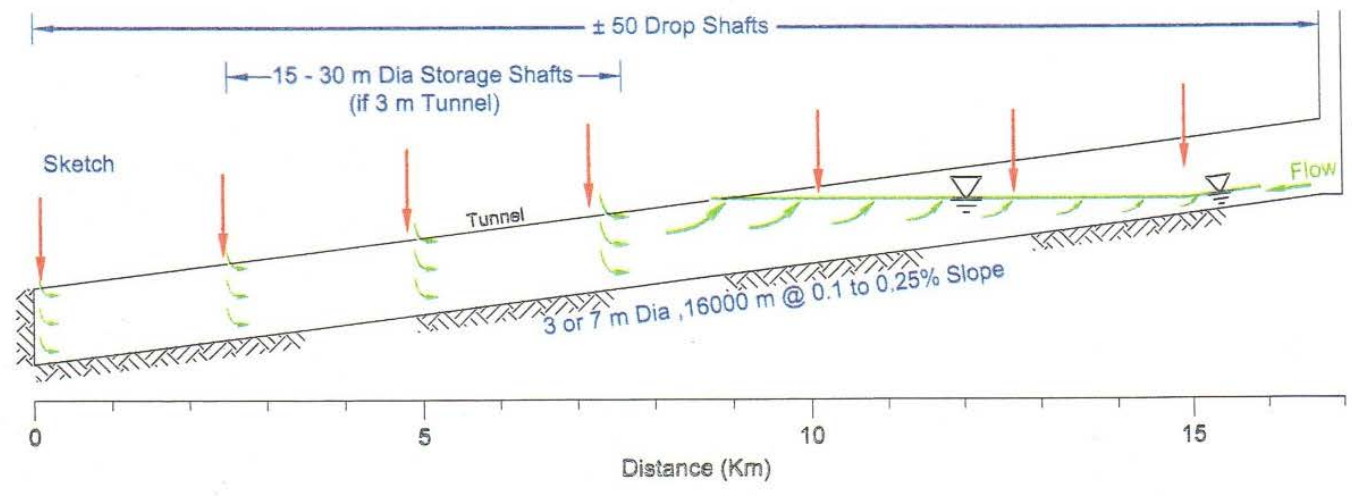

c) End Filling

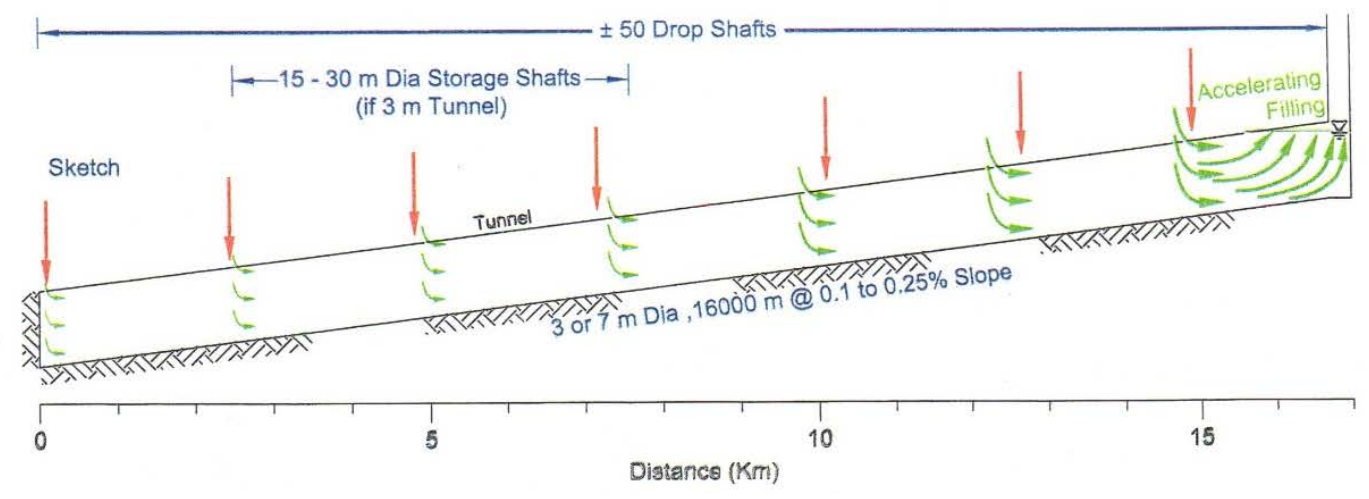


Appendix B- 3. Examples of Extended Physical Scale Model

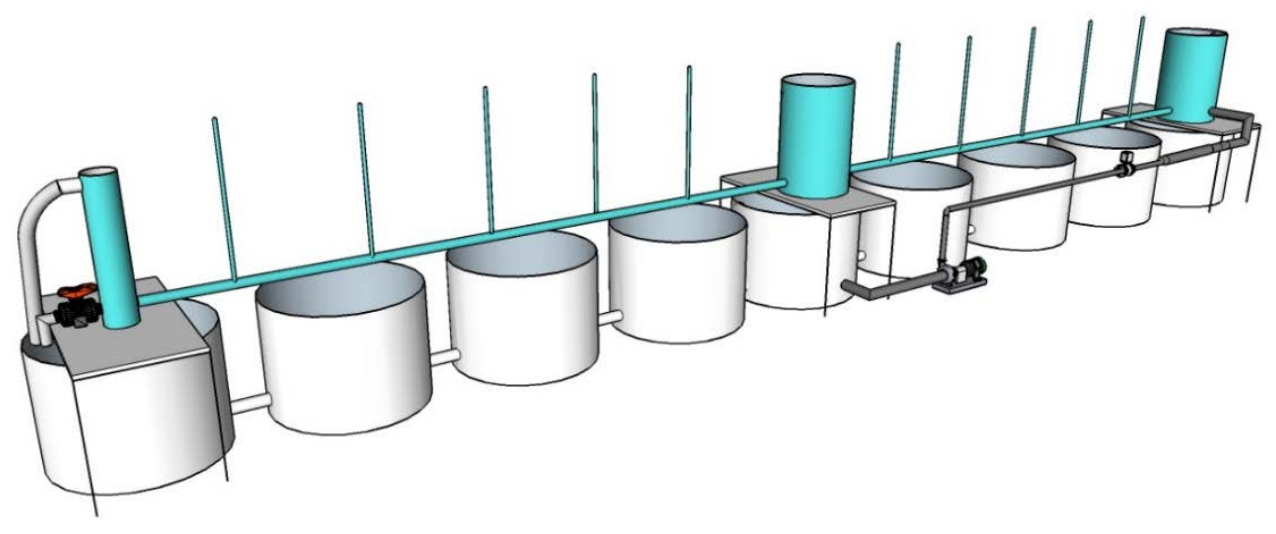

(a) Two sections

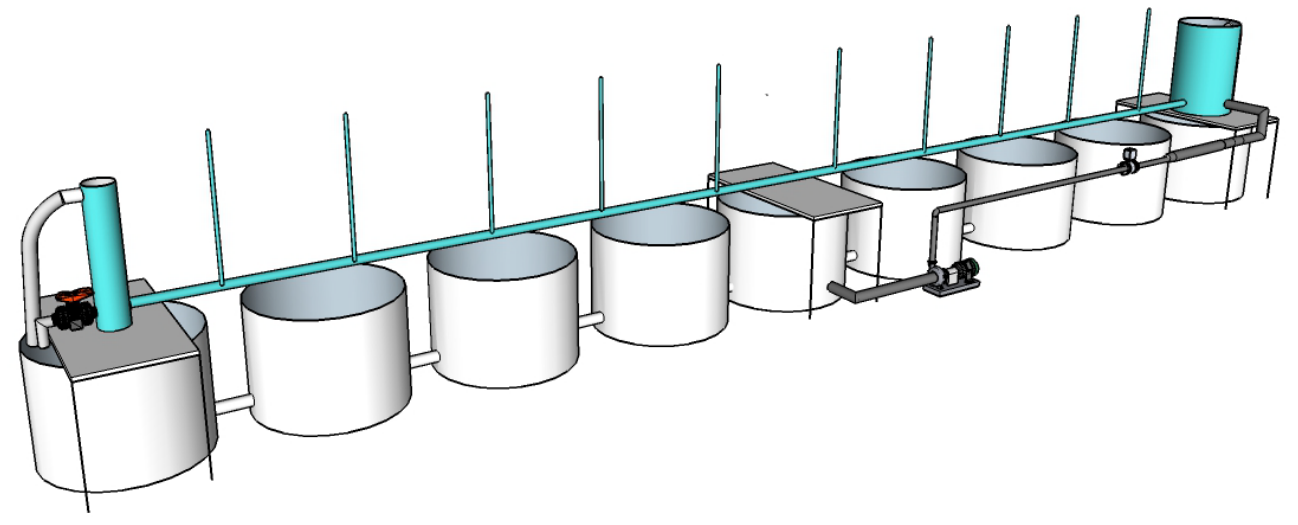

(b) One section 


\section{References}

American Society of Civil Engineers (ASCE). 2000. "Sewage storage tunnel to reduce Toronto beach closures." Civil Engineering (American Society of Civil Engineers) 70 (1): 14.

Bentley Systems Inc. 2015. "Bentley." Bentley Hammer V8i. Accessed June 17, 2015. http://www.bentley.com/enUS/Products/HAMMER/.

Bousso, S., M. Daynou, and M. Fuamba. 2013. "Numerical Modeling of Mixed Flows in Storm Water Systems: Critical Review of Literature." Journal of Hydraulic Engineering 139: 385-396.

Ervine, D. A. 1998. "Air entrainment in hydraulic structures: A review." Proceedings of the ICE - Water Maritime and Energy 130 (3): 142153.

Fan, Celia, and Alan Fok. 2014. "InfoWorks CS Modelling of Vertical Stormwater Storage Systems." Not Published.

Fok, Alan. 2015. Myth of Hydraulics. Toronto: In Press.

Fuamba, Musandji. 2002. "Contribution on transient flow modelling in storm sewers." Journal of Hydraulic Research 40 (6): 685-693.

Guo, Qizhong, and Charles C. S. Song. 1991. "Dropshaft Hydrodynamics Under Transient Conditions." Journal of Hydraulic Engieering 117: 1042-1055.

Guo, Qizhong, and Charles C. S. Song. 1988. "Hydraulic Transient 
Analysis of Tarp Phase II System." St. Anthony Falls Hydraulic Laboratory.

Hamam, M. A., and J. A. McCorquodale. 1982. "Transient conditions in the transition from gravity to surcharged sewer flow." Canadian Journal of Civil Engineering 9 (2): 189-196.

HydraTek Associates. 1999. Hydraulic Transient Analysis. Toronto: City of Toronto.

Innovyze. 2015. "InfoWorks ICM Overview." Innovyze. Accessed June 17, 2015. http://www.innovyze.com/products/infoworks_icm/.

Jain, Subhash C. 1988. "Air Transport in Vortex-flow Drop Shafts." Journal of Hydraulic Engineering 114 (12): 1485-1497.

Jain, Subhash C. 1984. "Tangential Vortex-Inlet." Journal of Hydraulic Engineering 110 (12): 1693-1699.

Klaver, P. 2010. "Modeling helps tame surges in rapidly filling storage tunnels." Mining Engineering 62 (3): 36-42.

Lewis, James W., Steven J. Wright, and Jose G. Vasconcelos. 2011. "Mechanisms for Surges in Vertical Shafts in Stormwater Tunnels." Cognitive Modeling of Urban Water Systems, Monograph 19. CHI. 41-54.

Li, J., and A. McCorquodale. 1999. "Modeling Mixed Flow In Storm Sewers." Journal of Hydraulic Engineering 125: 1170-1180.

Lingireddy, S., J. Wood, and N. Zloczower. 2004. "Pressure surges in pipeline systems resulting from air releases." American Water Works Association. Journal 96 (7): 88-94.

Madhani, Jehangir T, Neil A. Kelson, and Richard J Brown. 2009. "An experimental and theoretical investigation of flow in a gross pollutant trap." Water Science and Technology 59 (6): 1117-1127.

Politano, M., A. J. Odgaard, and W. Klecan. 2007. "Case Study: Numerical Evaluation of Hydraulic Transients." Journal of 
Hydraulic Engineering 133: 1103-1110.

Ridgway, K., and G. Kumpula. 2007. "Surge modelling in Sewers using the Transient Analysis Program (TAP)." Edited by William James. Contemporary Modeling of Urban Water Systems, Monograph 15. Toronto, Ontario, Canada: CHI. 133-146.

Song, C., J. Cardie, and K. Leung. 1983. "Transient Mixed-Flow Models for Storm Sewers." Journal of Hydraulic Engineering 109 (11): 14871504 .

Song, C.S., Q. Guo, Y. Zheng, and St. Anthony Falls Hydraulic Laboratory. 1988. Hydraulic Transient Modeling of TARP Systems.

Vasconcelos, J., and G. Leite. 2012. "Pressure Surges Following Sudden Air Pocket Entrapment in Storm-Water Tunnels." Journal of Hydraulic Engineering 138 (12): 1081-1089.

Vasconcelos, J., and S Wright. 2011. "Geysering Generated by Large Air Pockets Released through Water-Filled Ventilation Shafts." Journal of Hydraulic Engineering 137 (5): 543-555.

Vasconcelos, Jose G., and Steven J. Wright. 2007. "Comparison between the two-component pressure approach and current transient flow solvers." Journal of Hydraulic Research 45 (2): 178-187.

Vasconcelos, Jose, and Steven Wright. 2005. "Experimental Investigation of Surges in a Stormwater Storage Tunnel." Journal of Hydraulic Engineering 131 (10): 853-861.

Vitullo, Jessica. 2013. "Toronto beaches experience 'record levels of E. coli' after storm pumps up to one billion litres of sewage into lake." National Post. http://news.nationalpost.com/toronto/torontobeaches-experience-record-levels-of-e-coli-after-storm-pumps-up-toone-billion-litres-of-sewage-into-lake.

Wiggert, David C. 1972. "Transient flow in free-surface, pressurized systems." Journal of the Hydraulics division (ASCE) 98 (1): 11-27.

Williamson, S. 2001. Drop Structure Design for Wastewater and 
Stormwater Collection Systems. Parsons Brinckerhoff.

Wright, S., J. Lewis, and J. Vasconcelos. 2011. "Geysering in Rapidly Filling Storm-Water Tunnels." Journal of Hydraulic Engineering 137 (1): 112-115.

Wright, Steven J, Jose G Vasconcelos, Calvin T Creech, and James W Lewis. 2008. "Flow regime transition mechanisms in rapidly filling stormwater storage tunnels." Environmental Fluid Mechanics (Springer Netherlands) 8 (5-6): 605-616.

Yen, B.C. 1978. "Hydraulic instabilities of storm sewer flows." Proc., Int. Conf. on Urban Storm Drainage. London, U.K.: P.R. Helliwel, Pentech Press. 282-293.

Yen, B.C. 1986. "Hydraulic of sewers." Advanced in Hydroscience 14: 1122.

Zemell, Sheldon, and Alan Fok. 2014. "Dynamic Tunnel Model." In Press.

Zemell, Sheldon, and Alan Fok. 2015. "Modified HAMMER Simulation for Vertical Stormwater Storage Systems." Not Published.

Zhao, C., D. Zhu, S. Sun, and Z. Liu. 2006. "Experimental Study of Flow in a Vortex Drop Shaft." Journal of Hydraulic Engineering 132 (1): 61-68.

Zhou, F., F. Hicks, and P. Steffler. 2002. "Transient Flow in a Rapidly Filling Horizontal Pipe Containing Trapped Air." Journal of Hydraulic Engineering 128 (6): 625-634. 